


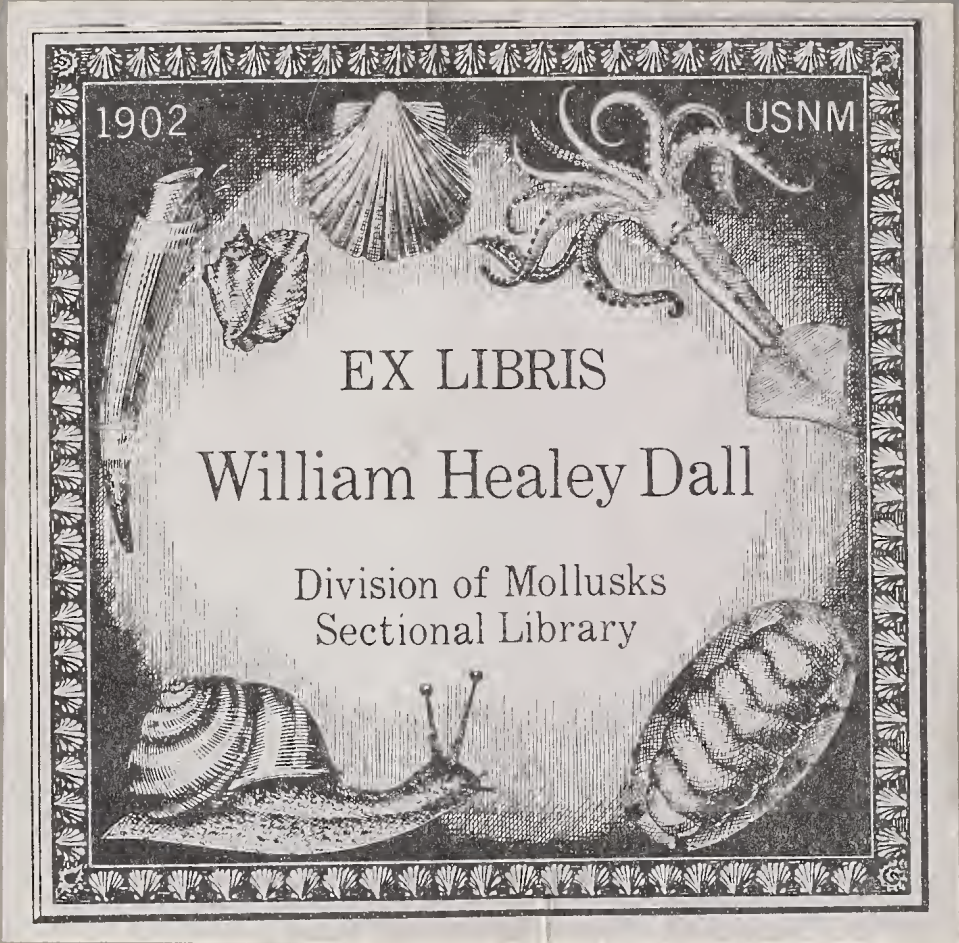





B

H Duclos

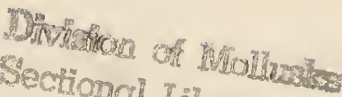

Sectional Librocry

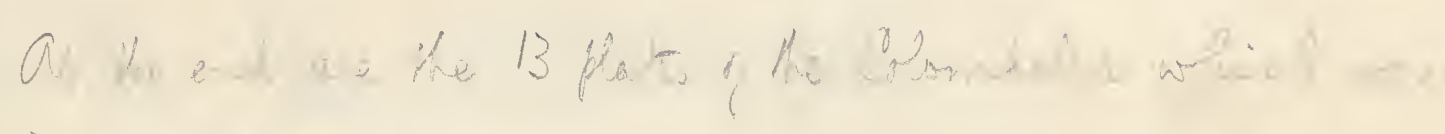

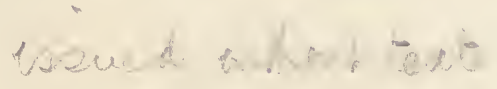

Pout 1-2 - two wheld text 12 plated inded

nou, 1835

Plater 13-33. insued Mar, 1840.

Colomballe - pait $1-2,13$ pl, apiel, $1540-$

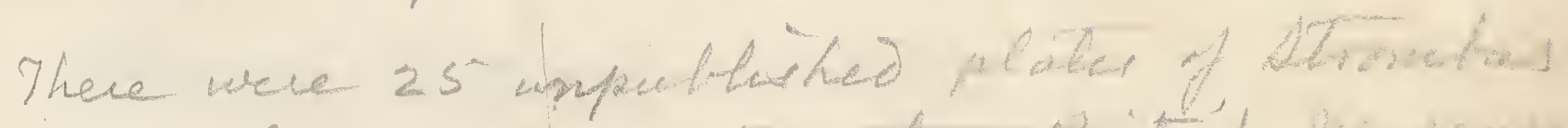
of which pworg awa the the 13 itith humbuses See Proc. Mak, foc, Luendm, ix, p, 26. 



\section{AISTOIMS NATURELLA}

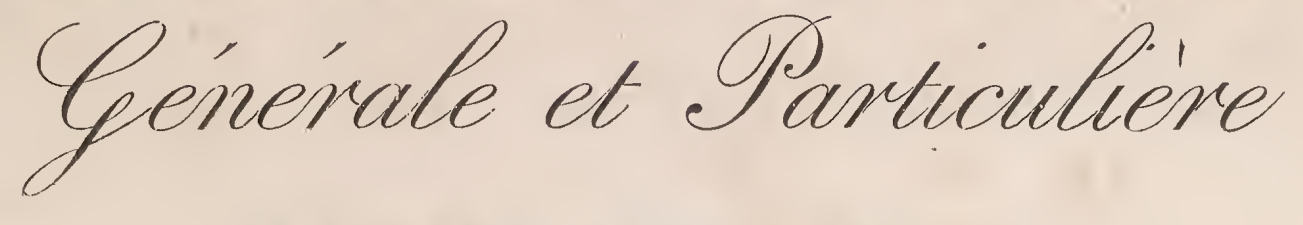

DE TOUS LFS GFNRES

DE

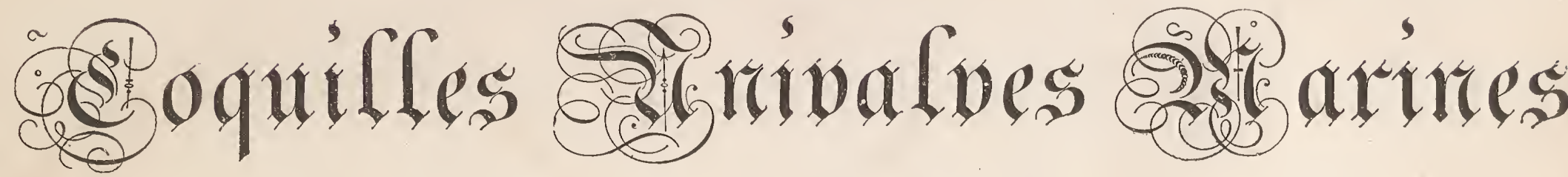

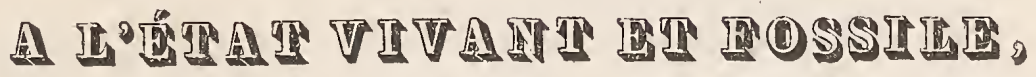

\section{PUBLIÉE PAR MONOGRAPHIES;}

OU

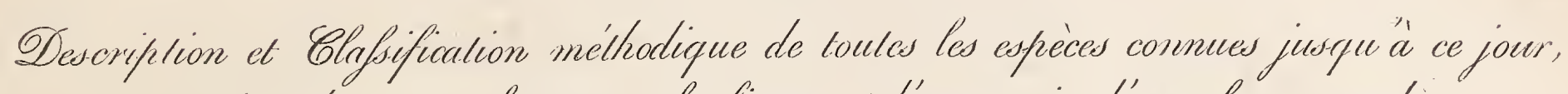
reforésentées en couleur avec la figure et l'anatomie d'un afses grand

nombre de Abollusques nouvellement découverts,

PAD P. IDUCHOS?

ÉLEVEE DE LAMARGK,

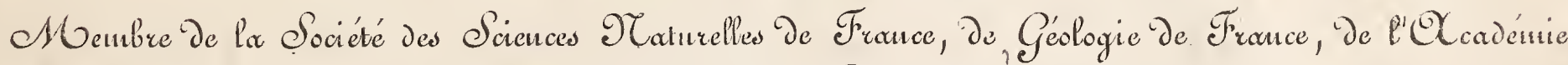
Des Sciences STaturelles de SBbiladelpbie, etc., etc.

\section{Gente Oline. 1835640 in 6 leirs}

\section{Colombella 1840, 2 liom.}

PARIS.

TYPOGRAPHIE DE FIRMIN DIDOT FRERES,

IMPRIMEURS DE L'INSTITUT DE FRANCE,

RUE JACOB, N ${ }^{\circ} 24$. 
(ininititis 
A LA MÉMOIRE

\section{DE LAMARCK,}

CRÉATEUR

DE LA SCIENGE CONCHYLIOLOGIQUE.

\section{HOMMAGE}

DE VÉNÉRATION ET DE PROFOND RESPECT

DE SON ÉLÈVE

P. L. Duclos. 



\section{CLASSEMENT MÉTHODIQUE}

DE TOUTES LES ESPĖGES D'OLIVES DÉCRITES ET FIGURÉES DANS GET OUVRAGE.

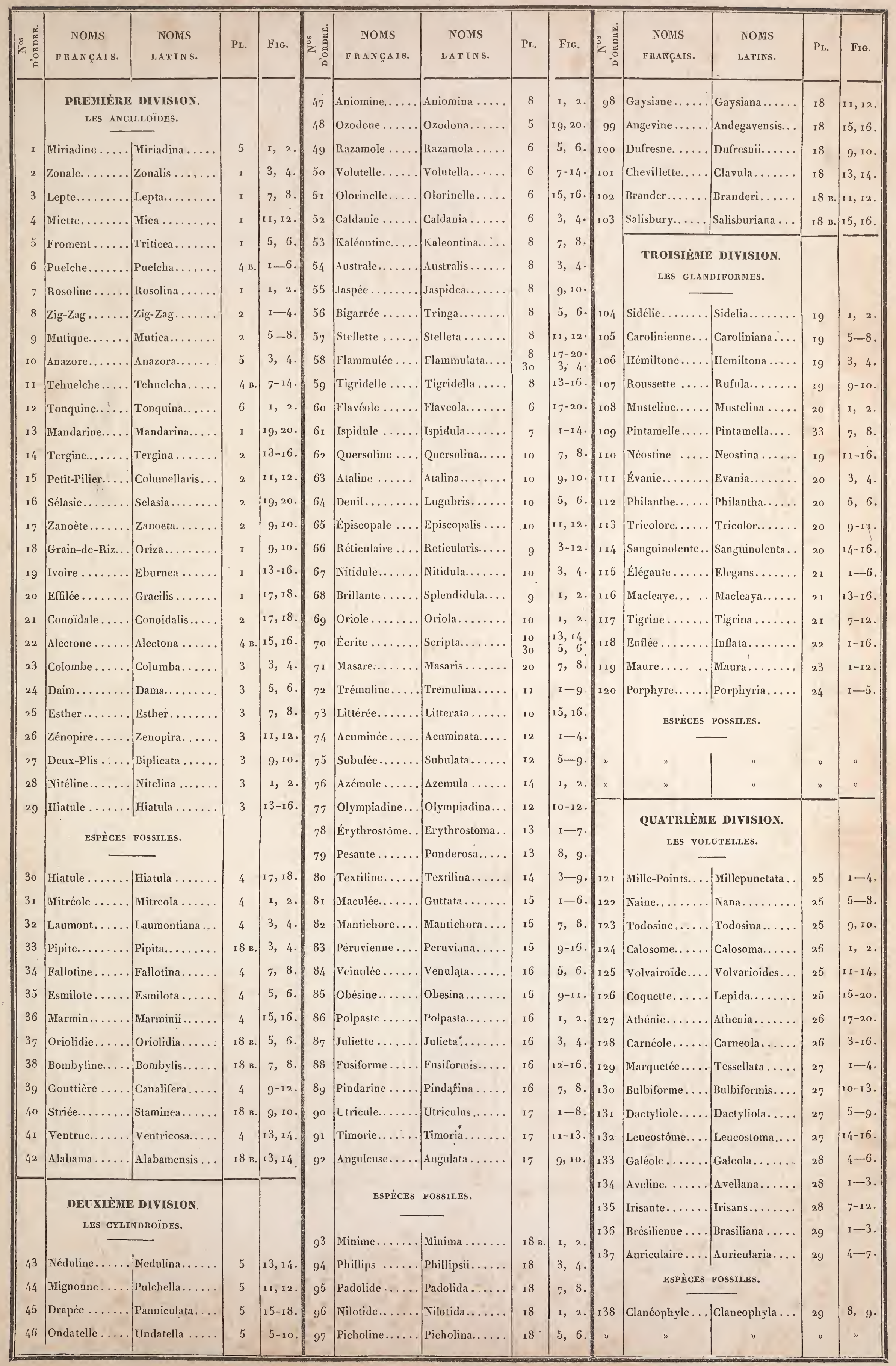


TABLE ALPHABÉTIQUE FRANGGASE

DES ESPËGES DÉGRITES ET FIGURÉES DANS CET OUVRAGE.

\begin{tabular}{|c|c|c|c|c|c|c|c|c|c|c|c|c|c|c|}
\hline $\begin{array}{c}\text { NOMS } \\
\text { FRANÇA I S. }\end{array}$ & $\begin{array}{c}\text { NOMS } \\
\text { L A T I N S. }\end{array}$ & 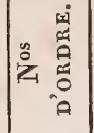 & PL. & EIG. & $\begin{array}{c}\text { NOMS } \\
\text { FRANGAIS. }\end{array}$ & $\begin{array}{c}\text { NOMS } \\
\text { LATrNS. }\end{array}$ & 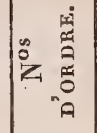 & PL. & FIG. & $\begin{array}{c}\text { NOMS } \\
\text { FRA N ÇA I S. }\end{array}$ & $\begin{array}{l}\text { NOMS } \\
\text { LATINS. }\end{array}$ & 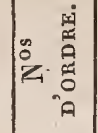 & PL. & FIG. \\
\hline cuminée & Acuminata. & 74 & I 2 & $I-4$. & Froment. & Triticea. & 5 & I & 5,6 & Oriolidie... fos. & Oriolidia... & 37 & І 8 в. & 5,6 . \\
\hline Alabaina... fos. & Alabainensis... & 42 & I 8 в. & 13,14 & Fusiforme. . & Fusiformis. & 88 & I 6 & $12-16$ & Ozodone.. & Ozodona..... & 48 & 5 & I9, 20. \\
\hline Alectone & Alectona.. & 22 & 4 в. & I5-16 & Galéole... & Galeola. & I 33 & 28 & $4-6$ & Padolide... fos. & Padolida . & $9^{5}$ & 18 & $7,8$. \\
\hline Anazore . & Anazora.. & Io & 5 & 3,4 . & Gaysiane... fos. & Gaysiana.. & 98 & I 8 & II-I 2 & Péruvienne & Peruviana. & 83 & $x 5$ & $9^{-16}$. \\
\hline Angevine.. fos. & Andegavensis.. & 99 & 18 & 15,16 & Gouttière... fos. & Canalifera . & 39 & 4 & $9^{-12}$ & Pesante. & Pouderosa & 79 & 13 & 8,9 . \\
\hline Anguleuse. & Angulata. & $9^{2}$ & 17 & 9, го. & Grain-de-riz.. & Oriza.... & 18 & I & 9,10 & Petit-Pilier . & Columellaris.. & I5 & 2 & I I-I 2 . \\
\hline Aniomine. & Aniomina.. & 47 & 8 & I, 2. & Hémiltone. . & Hemiltona & Io6 6 & I 9 & $3,4 \cdot$ & Philan the.. & Philantha. & I I 2 & 20 & 5,6 . \\
\hline Ataline... & Atalina....... & 63 & 10 & 9,10 & Hiatule. . & Hiatula.... & 29 & 4 & $\mid \begin{array}{l}13-16 \\
19-20 \\
17-10\end{array}$ & Phillips.... fos. & Phillipsii ... & 94 & I 8 & 3,4 . \\
\hline Athénie. & Athenia. . & 127 & 26 & $17-20$ & Hiatule.... . fos. & Hiatula... & 30 & $4^{4}$ & $17,18$. & Picholine.. fos. & Picholina..... & 97 & 18 & 5,6 . \\
\hline Auriculaire & Auricularia... & 137 & $\begin{array}{l}29 \\
33\end{array}$ & $\begin{array}{l}4-7 \cdot \\
1,2 \cdot\end{array}$ & Irisante. & Irisans. . & 135 & 28 & $7-12$ & Pindarine. & Pindarina . & 89 & I 6 & $7,8$. \\
\hline Australe.. & Aisstralis. & 54 & 8 & 3,4 . & Ispidule.. & Ispidula. . & $6 \mathrm{I}$ & 7 & $\mathrm{I}-\mathrm{I} 4$. & Pintamelle. & Pintamella.... & 109 & 33 & $7,8$. \\
\hline Aveline. & Avellaua.. & 134 & 28 & $\mathrm{I}-3$ & Ivoire. . & Eburnea & 19 & I & I $3-16$. & Pipire.... fos. & Pipita.. & 33 & 18 в. & 3,4 . \\
\hline Azémule & Azemula .... & 76 & 14 & $1,2$. & Jaspée. & Jaspidea.. & 55 & 8 & 9 , го. & Polpaste... & Polpasta.. & 86 & I 6 & I, 2 . \\
\hline Bigarrée. & Tringa.... & 56 & 8 & 5,6 & Juliette . & Julieta. . & 87 & I 6 & $3,4$. & Porphyre. & Porphyria... & 120 & 24 & $I-5$. \\
\hline Bombyline. fos. & Bombylis.... & 38 & I $8 \mathrm{~B}$ & $7,8$. & Kaléoutine . & Kaleontina. . & 53 & 8 & $7,8$. & Puelche.. & Puelcha.... & 6 & $4 \mathrm{~B}$. & $I-6$. \\
\hline Brander... fos. & Branderi . & 102 & I 8 в. & II, I 2 & Laumont. . . fos. & Laumontiana.. & 32 & 4 & 3,4 & Quersoline... & Quersolina.... & 62 & 10 & $7,8$. \\
\hline Brésilienne & Brasiliana & I 36 & $\begin{array}{l}29 \\
33\end{array}$ & $\begin{array}{l}\mathrm{I}-3 \\
5,6\end{array}$ & Lepte. . & Lepta. . & 3 & I & 7,8 & Razamole & Razamola..... & 49 & 6 & 5,6 . \\
\hline Brillante & Splendidula... & 68 & 9 & $\mathrm{I}, 2$. & Leucostôme. & Leucostoma. . & 132 & 27 & I 4-I 6 & Réticulair & Reticulari & 66 & 9 & $3-12$. \\
\hline Bullbiformı & Bulbiformis... & 130 & 27 & 10-13. & Littéréc & Litterata . & 73 & Io & I5, I 6 & Rosolin & Rosolina & 7 & I & I, 2 . \\
\hline Caldanie... & Caldania...... & 52 & 6 & 3,4 & Macleay & Macleaya. & 116 & 2 I & I3-I 6 & Rous & Rufula. & 107 & I9 & 9 , то. \\
\hline Calosome... & Calosoma..... & 124 & 26 & I, 2. & Maculée. & Guttala. & $8 I$ & I5 & $\mathrm{I}-6$ & Salisbury .. fos. & Salisburiana .. & 103 & І 8 в. & I5, I 6 . \\
\hline Carnéole... & Carneola . & 128 & 26 & $3-16$ & Mandarine. & Maudarin & 13 & I & I 9,20 & Sanguinoleute. & Sanguinolenta. & II 4 & $\begin{array}{l}20 \\
33\end{array}$ & $\begin{array}{r}14-16 \\
3,4 .\end{array}$ \\
\hline Carolinienne.... & Caroliniana... & 105 & I9 & $5-8$ & Mantichore. & Mantichora.... & 82 & I 5 & $7,8$. & Sélasie.. & Selasia.. & I 6 & 2 & $19,20$. \\
\hline Chevillette. fos. & Clavula .. & IOI & 18 & I3, I 4 . & Marquetée.. & Tessellata..... & 129 & 27 & $I-4$ & Sidélie... & Sidelia.. & 104 & I 9 & I, 2. \\
\hline Clanéopiyle fos. & Claneophila & I38 & 29 & 8,9 & Marmin.... fos. & Marminii. & 36 & 4 & $\mathrm{x} 5, \mathrm{x} 6$ & Stellette . & Stelleta.. & 57 & 8 & II I I 2 . \\
\hline Colombe. & Columba..... & 23 & 3 & $3,4 \cdot$ & Masare... & Masaris . . & $7 \mathbf{x}$ & 20 & 7,8 & Striée.... fos. & Stamine & 40 & I 8 в. & 9, го. \\
\hline Conoïdale & Conoidali & $2 \mathrm{I}$ & 2 & I $7, \mathbf{1} 8$. & $M$ & Mau & I I 9 & $\begin{array}{l}23 \\
32\end{array}$ & $\begin{array}{l}\mathbf{I}-\mathbf{1} 2 \\
3,4\end{array}$ & Subu & Subul & $7^{5}$ & $\begin{array}{l}\text { I } 2 \\
30\end{array}$ & $\begin{array}{l}5-9 . \\
1,2 .\end{array}$ \\
\hline Coquette... & Lepida....... & 126 & 25 & 15,20 & Mielte..... & Mica. . & 4 & I & II, I 2 & Tehuelche..... & Tehnelcha... & I I & $4 \mathrm{~B}$. & $7-14$ \\
\hline Dactyliole... & Dactyliola.... & I 3 I & 27 & $5-9$. & Mignonne... & Pulchella. & 44 & 5 & II, I 2. & Tergine...... & Tergina. & 14 & 2 & I3-ז6. \\
\hline Daim.... & Dama....... & 24 & 3 & $5,6$. & Mille-points.. & Millepunctata . & I2I & 25 & $1-4$ & Textiline..... & Textilina... & 80 & $\begin{array}{l}74 \\
32\end{array}$ & $\begin{array}{l}3-9 \cdot \\
5,6 .\end{array}$ \\
\hline Deuil.. & Lugubris. & $6 / 4$ & Io & $5,6$. & Minime.... fos. & Minima . . & $9^{3}$ & I 8 в. & I, 2. & Tigridelle. & Tigridella.... & 59 & 8 & I3-16. \\
\hline Deux-Plis... & Biplicata. & 27 & 3 & 9, го. & Miriadine . & Miriadina.... & I & 5 & $\mathrm{I}, 2$. & Tigrine ... & Tigrina... & II 7 & $2 I$ & $7-12$ \\
\hline Drapée . & Panniculata... & 45 & 5 & I5-I8. & Mitréole... . fos. & Mitreola.. & 3 I & 4 & $\mathrm{I}, 2$. & Timorie... & Timoria..... & $9^{\text {I }}$ & $\mathbf{I} 7$ & II I-I3. \\
\hline Dufresne... fos. & Dufresnii..... & 100 & I 8 & 9 -го. & Musteline ... & Mustelina..... & 108 & 20 & I, 2. & Todosine... & Todosina..... & 123 & 25 & 9 , то. \\
\hline Écrite. & Script & 70 & $\begin{array}{l}\text { 10 } \\
30\end{array}$ & $\begin{array}{r}13, \text { 工 } 4 . \\
5,6 .\end{array}$ & Mutique.. & Mutica .. & 9 & 2 & $5-8$ & Tonquine & Tonquina..... & 12 & 6 & $\mathrm{I}, 2$. \\
\hline Effilée. & Gracilis.. & 20 & $\mathbf{I}$ & I $7, \mathbf{1} 8$ & Naine & Nana & 122 & 25 & $5-8$ & Trémuline & Tremulina.... & 72 & I I & $x-9$. \\
\hline Élégante.. & Elegans...... & 115 & $\begin{array}{l}21 \\
32\end{array}$ & $\begin{array}{l}\mathrm{I}-6 . \\
\mathrm{I}, 2 .\end{array}$ & Néduline. & Nedulina... & 43 & 5 & 13,14 & Tricolore.. & Tricolor...... & I 3 & 20 & $9^{-\mathrm{I} 3}$ \\
\hline Enflée.... & Inflata . & II 8 & 22 & $I-I 6$ & Néostine... & Neostina... & I IO & I9 & I $1-16$ & Utricule. & Utriculus.. & 90 & I 7 & $\mathrm{I}-8$ \\
\hline Épiscopale.. & Episcopalis... & 65 & 10 & II, 12 & Nilotide... . fos. & Nilotida ...... & 96 & I 8 & $\mathbf{I}, 2$. & Veinulée... & Venulata ..... & 84 & 16 & 5,6 \\
\hline Érythrostôn & Erythrostoma. & 78 & $\begin{array}{l}\text { I3 } \\
3 \text { I }\end{array}$ & $\begin{array}{l}\mathrm{I}-7 . \\
\mathrm{I}-8 .\end{array}$ & Niteline. . . & Nitelina & 28 & 3 & $\mathrm{I}, 2$ & Ventrue ... fos. & Ventricosa... & $4 \mathrm{I}$ & 4 & I3, I4. \\
\hline Esmilote... fos. & Esmilota. & 35 & 4 & $5,6$. & Nitidule... & Nitidula. . & 67 & Io & $3,4$. & Volutelle... & Volutella.... & 50 & 6 & $7-14$ \\
\hline Esther.. & Esther...... & 25 & 3 & $7,8$. & Obésine...... & Obesina....... & 85 & $x 6$ & 9 -II & Volvairoïde..... & Volvarioides.. & 125 & 25 & II I I 4 \\
\hline Évarie... & Evania...... & III & 20 & $3,4$. & Olorinelle...... & Olorinella .... & 51 & 6 & I5, I 6 . & Zanoète........ & Zanoeta..... & $x_{7}$ & 2 & 9, то. \\
\hline Fallotine... fos. & Fallotina . & 34 & 4 & $7,8$. & Olympiadine. . & Olympiadiana. & 77 & 12 & $10-12$. & Zénopire.. & Zenopira... & 26 & 3 & II 12 \\
\hline Flamnulé & Flam & 58 & $\begin{array}{r}8 \\
30\end{array}$ & $\begin{array}{r}17-20 \\
3,4\end{array}$ & Ondatelle. & Undatella.... & 46 & 5 & 5 - 10. & Zig-Zag. & Zig-Zag . & 8 & 2 & $x-4$ \\
\hline Flavéole & Flaveola. & 60 & 6 & $17-20$ & Oriole. & Oriola. & 69 & ro & I, 2 . & Zonale & Zonalis. & 2 & I & 3,4 . \\
\hline
\end{tabular}


TABLE ALPHABÉTIQUE LATINE

DES ESPECES DÉCRITES ET FIGUREES DANS CET OUVRAGE.

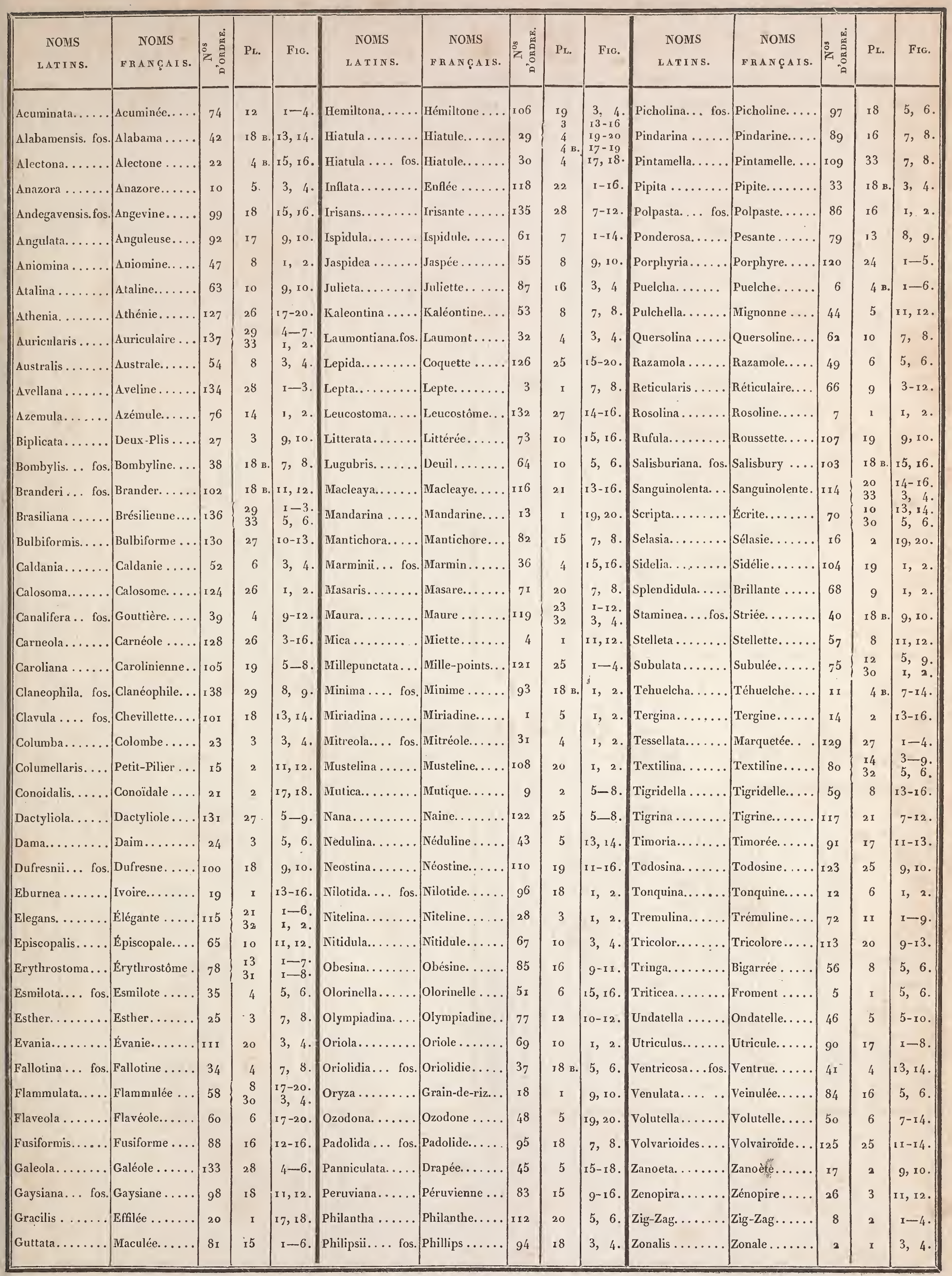


TABLE AIPHABÉTIQUE

DES ESPEEGS D'OLIVES DÉCRITES PAR LAMARGK ET CONSERVÉES DANS CET OUVRAGE.

\begin{tabular}{|c|c|c|c|c|c|c|c|}
\hline NOMS FRANÇAIS. & NOMS LATINS. & 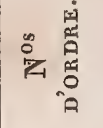 & 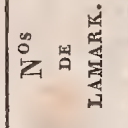 & NOIMS FRANCAAIS. & NOMS LATINS. & 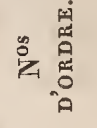 & 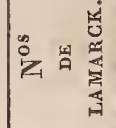 \\
\hline A cuminée... & Acuminata. . & $\mathbf{I}$ & 48 & Littérée. & Litterata... . & .23 & 20 \\
\hline Anguleuse . & Angulata. . & 2 & 6 & Maculée.:. & Guttata........ & 24 & $x 4$ \\
\hline Auriculaire.. & Auricularis.. & 3 & 47 & Marquetée. . & Tessellata . & 25 & 38 \\
\hline Aveline . & Avellana .... & 4 & 37 & Maure... & Maura........ & 26 & 7 \\
\hline Brésilienne.. & Brasiliana .... & 5 & 45 & Mitréole............ foss. & Mitreola .. & 27 & 4 \\
\hline Carnéole. & Carneola .... & 6 & 39 & Musteline... & Mustelina...... & 28 & 24 \\
\hline Chevillette.......... fos.. & Clavula .... & 7 & 3 & Naine. .. & 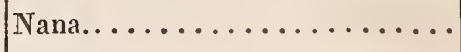 & 29 & 60 \\
\hline Conoïdale & Conoidalis. . & 8 & 55 & Ondatelle. . & Undatelia. . & 30 & 58 \\
\hline Deuil. . & Lugubris .... & 9 & 25 & Oriole.. & Oriola.... & $3 x$ & $4 x$ \\
\hline Écrite ... & Scripta... & xo & $2 x$ & Péruvienne... & Peruviana..... & 32 & 28 \\
\hline Élégante.. & Elegans .... & II & II & Porphyre... & Porphyria..... & 33 & I \\
\hline Enflée & Inflata ....... & $x_{2}$ & 32 & Réticulaire... & Reticularis...... & 34 & $x 6$ \\
\hline Épiscopale. & Episcopalis.... & I3 & $x_{2}$ & Sanguinolente... & Sanguinolenta........ & 35 & 23 \\
\hline Érythrostôme. & Erythrostoma . & $x_{4}$ & 3 & Subulée. . & 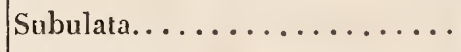 & 36 & 49 \\
\hline Flammulée & Flammulata. . & 15 & $x 7$ & Textiline. & Textilina ..... & 37 & 2 \\
\hline Fusiforme . & Fusiformis... & $x 6$ & 30 & Tigrine.. & Tigrina......... & 38 & 44 \\
\hline Gouttière........... foss. & Canalifera .. & $x_{7}$ & I & Trémuline. & Tremulina . & 39 & 5 \\
\hline Hiatule. . & Hiatula . & 18 & 52 & Tricolore... & Tricolor... & 40 & 22 \\
\hline Irisante. & Irisans ... & 5 & Io & Utricule... & Utriculus... & $4 \mathrm{I}$ & 46 \\
\hline Ispidule. . & Ispidula.... & 20 & 40 & Veinulée ... & Venulata....... & 42 & ז 3 \\
\hline Ivoire . & Eburnea............... & $2 \mathrm{I}$ & 59 & Volutelle... & Volutella... & 43 & 43 \\
\hline Laumont.............. fos. & Laumontiana..... & 22 & 5 & Zonale. & Zonalis . & 44 & $6 \mathrm{I}$ \\
\hline
\end{tabular}

TABLE ALPHABÉTIQUE

DES ESPÈCES D'OLIVES DÉCRITES PAR LAMARCK ET SUPPRIMÉES COMME N'ÉTANT QUE DES VARIÉTÉS.

\begin{tabular}{|c|c|c|c|c|c|c|c|}
\hline 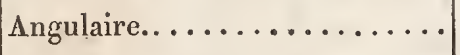 & Var. de l'o. Maculée....... & I & I5 & Hépatique.............. & Var. de l'o. Trémulinue...... & x 3 & 35 \\
\hline Aranéeuse.. & Var. de l'o. Réticulaire...... & 2 & $x 9$ & Lutéole.............. & Var. de 10. Subulée ... & 14 & 50 \\
\hline Blanche. & Id. $\quad$ Id. $\ldots \ldots \ldots$ & 3 & 42 & Nébuleuse... & Jeune âge de l'Utricule...... & 15 & 55 \\
\hline Ceylan. & Var. de l'O. Trémuline........ & 4 & 54 & Obtusaire.. & Var de l'O. Trémuline....... & $x 6$ & 53 \\
\hline Deux-bandes. & Var. de l'O. Enflée... & 5 & 33 & 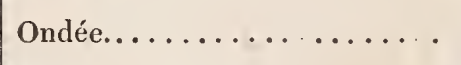 & Var. de l'O. Enflée.... & I 7 & $3 x$ \\
\hline Féverolle... & Id. $\quad$ Id. ... & 6 & 56 & Pic ..... & Var. de l'O. Textiline... & 18 & 4 \\
\hline Foudroyante. & Var. de l'O. Maure... & 7 & 9 & Plicaire ........... foss. & Var. de l'o. Hiatule.... & I9 & 2 \\
\hline Funébrale . & Id. . . . . & 8 & 26 & Rôtie.... & Var. de l'O: Réliculaire... & 20 & 36 \\
\hline Glandiforme.. & Var. de l'o. Tigrine ......... & 9 & 27 & Sénégal..... & Var. de l’o. du Pérou... & $2 I$ & 29 \\
\hline Grain-de-Riz. & Jeune âge de l'o. Ivoire ....... & Io & 62 & Sépulturale .. & Var. de l'o. Maure... & 22 & 8 \\
\hline Granitelle . & Var. de l'o. Textiline. ........ & II & 18 & Testacée.... & Var. de l'o. Hiatule.... & 23 & $5 x$ \\
\hline Harpulaire. . & Var. de l'o. Réticulaire ...... & 12 & 34 & $\nu$ & $"$ & ” & ” \\
\hline
\end{tabular}




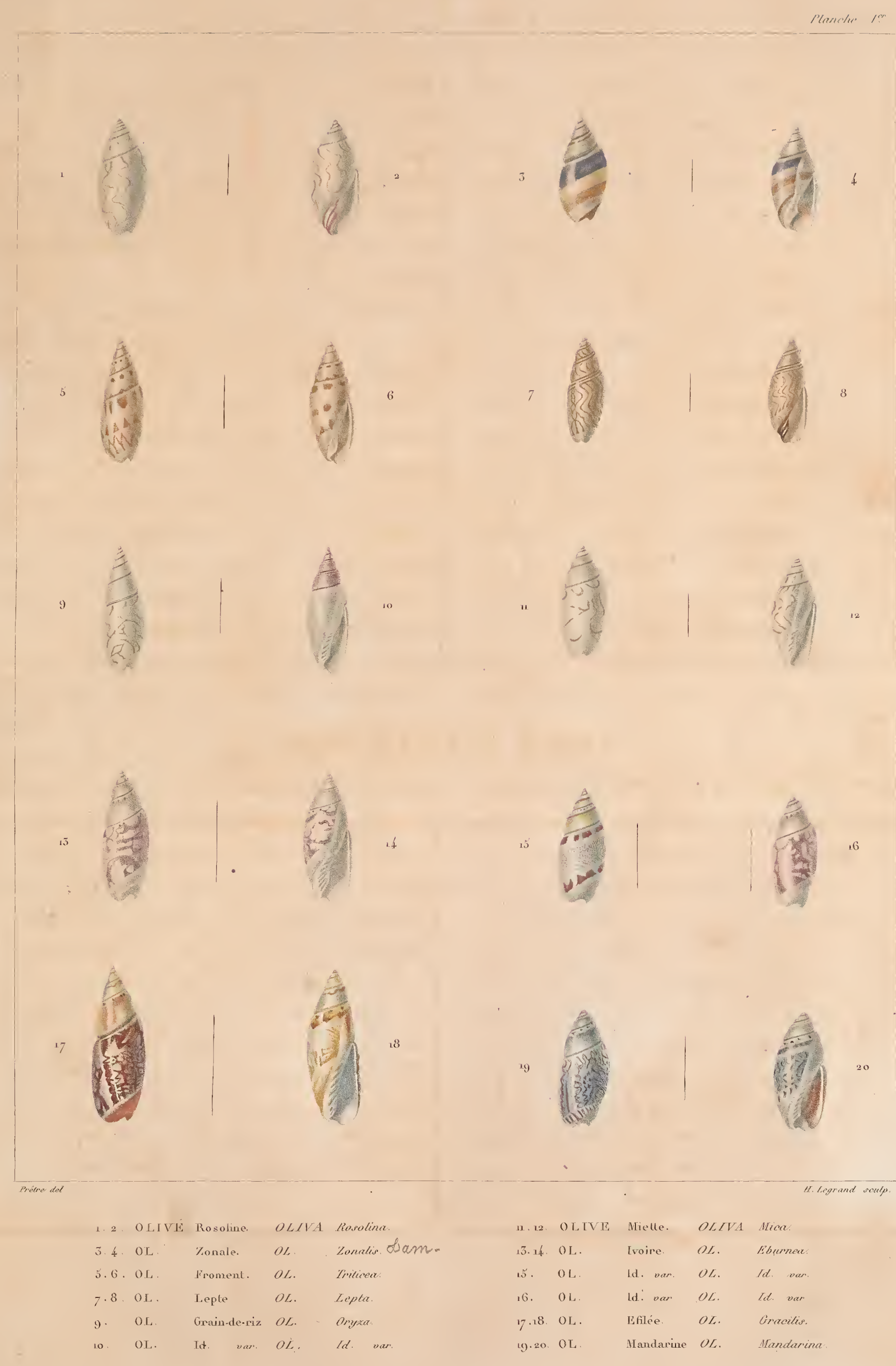




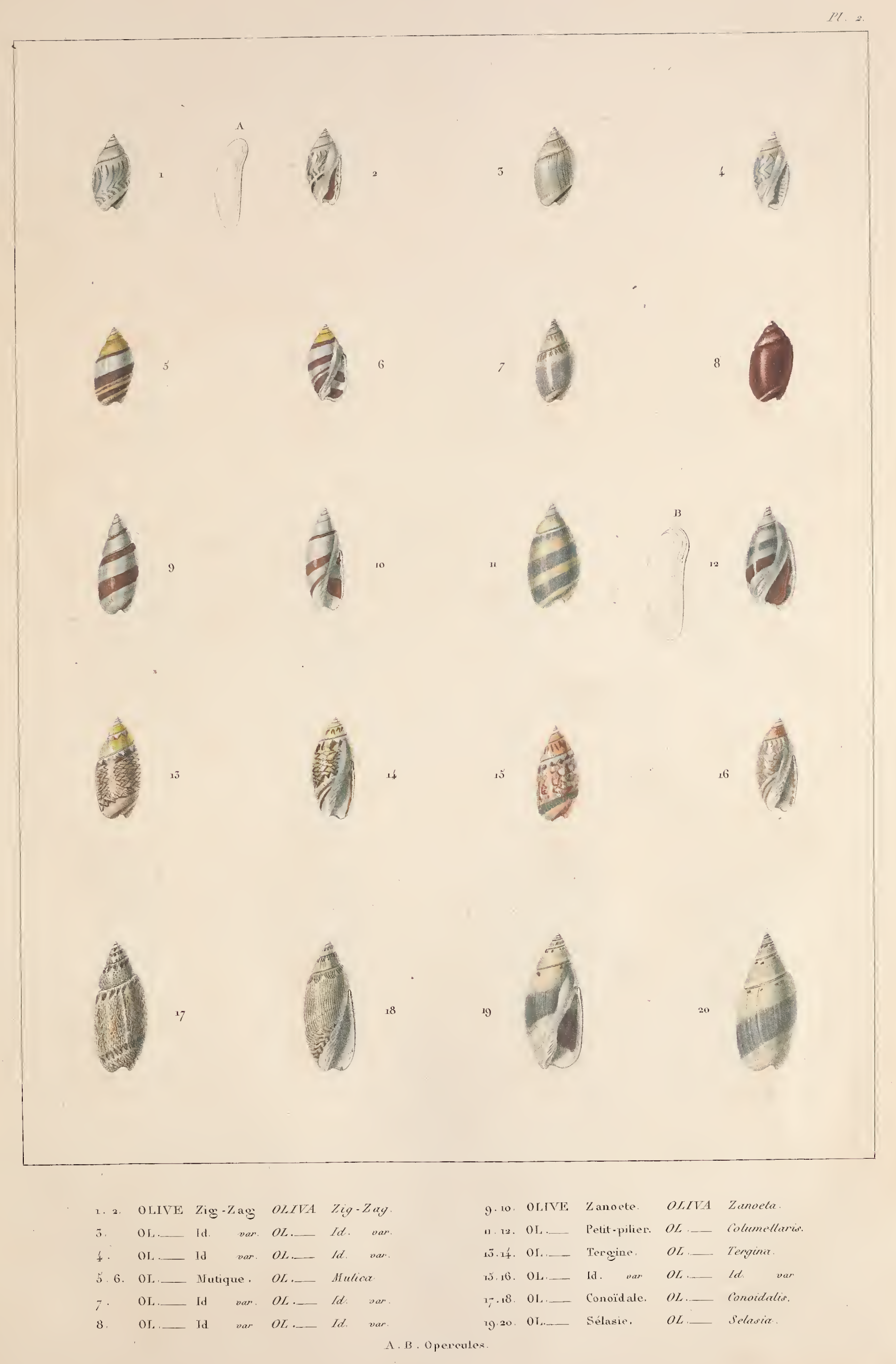





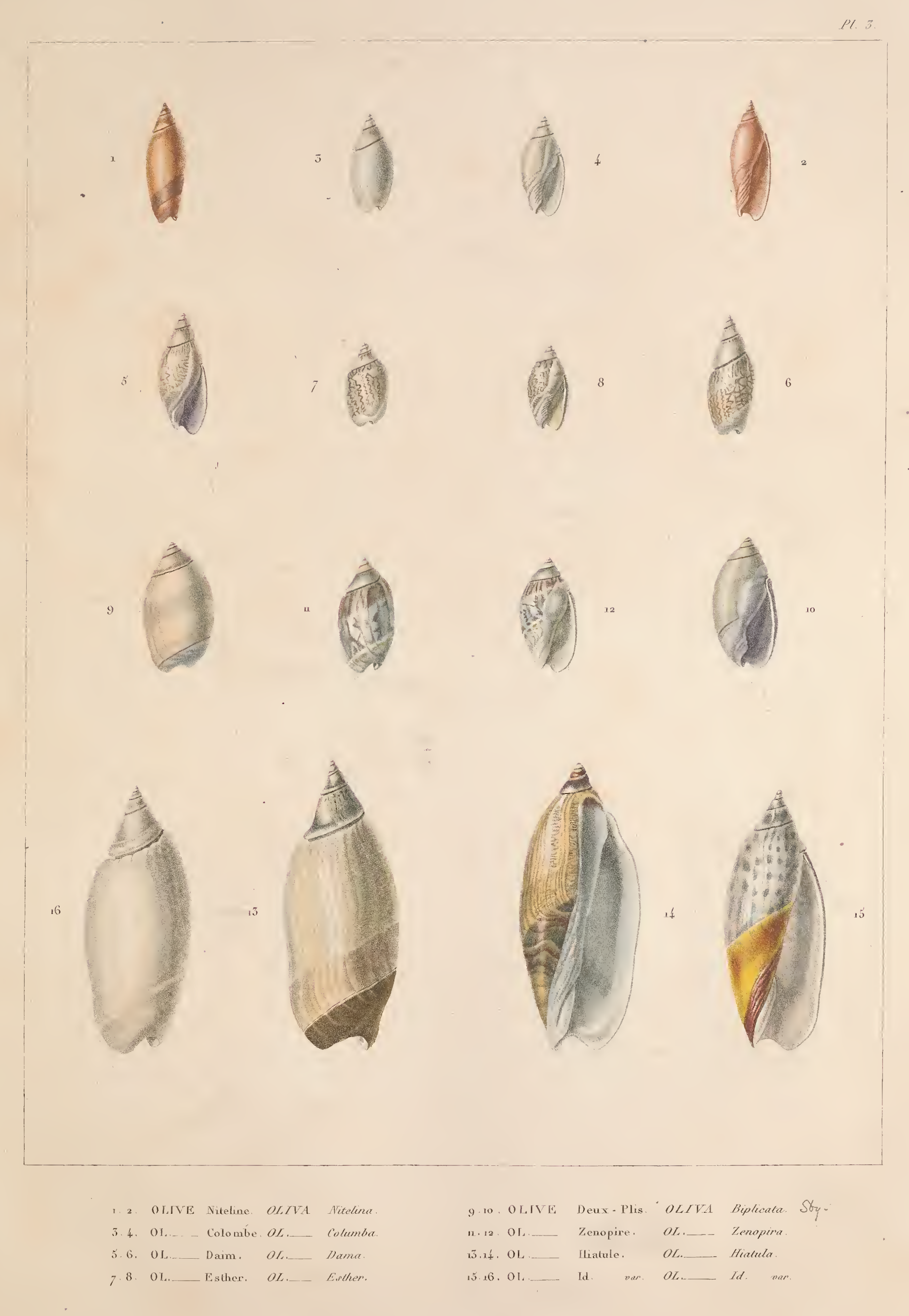





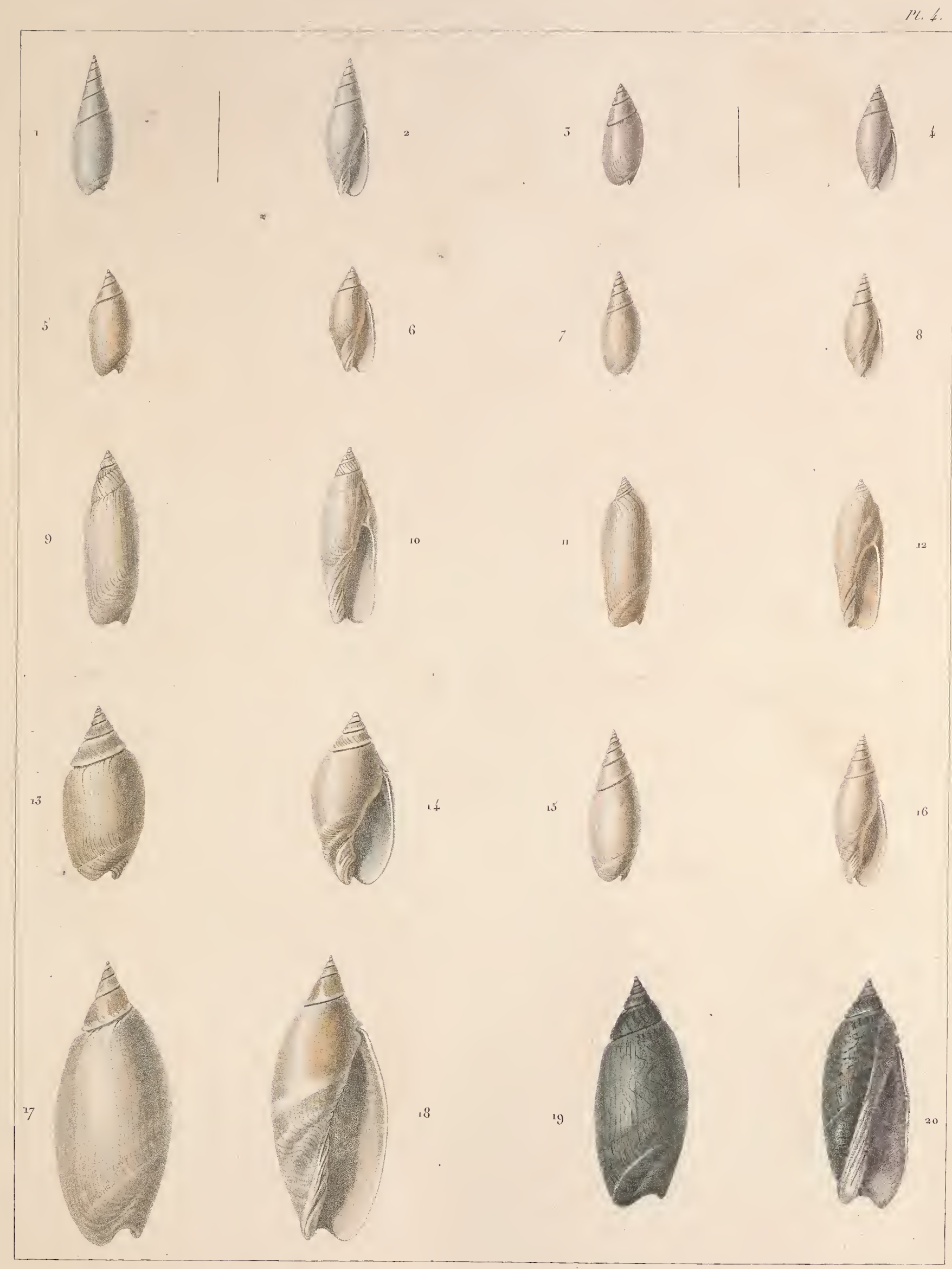
1.2. OLIVE Mitréole OLIVA Mitrenta
4. 12. OLIVE Gouttiere wan OLTVA Canaliferce
3.4. OL._L Laumont. OL._L Lamontiana
5.6. OL _ Esmilote. OL..._E Esrmilota.
13.4. OL._ Ventrue OL. - Ventricose
7.8. OL._. Fallotine. OL._._Fallotina.
L5.16. OL. Marmin. OL._Marminii
9.10. OL.__ Gouttiere. OL ___ Canalifera.
17.18 OI.___ Ifiatule. OL.__ Hiatula.
19.20 OI. _ Id. nan OL__ ld. war 



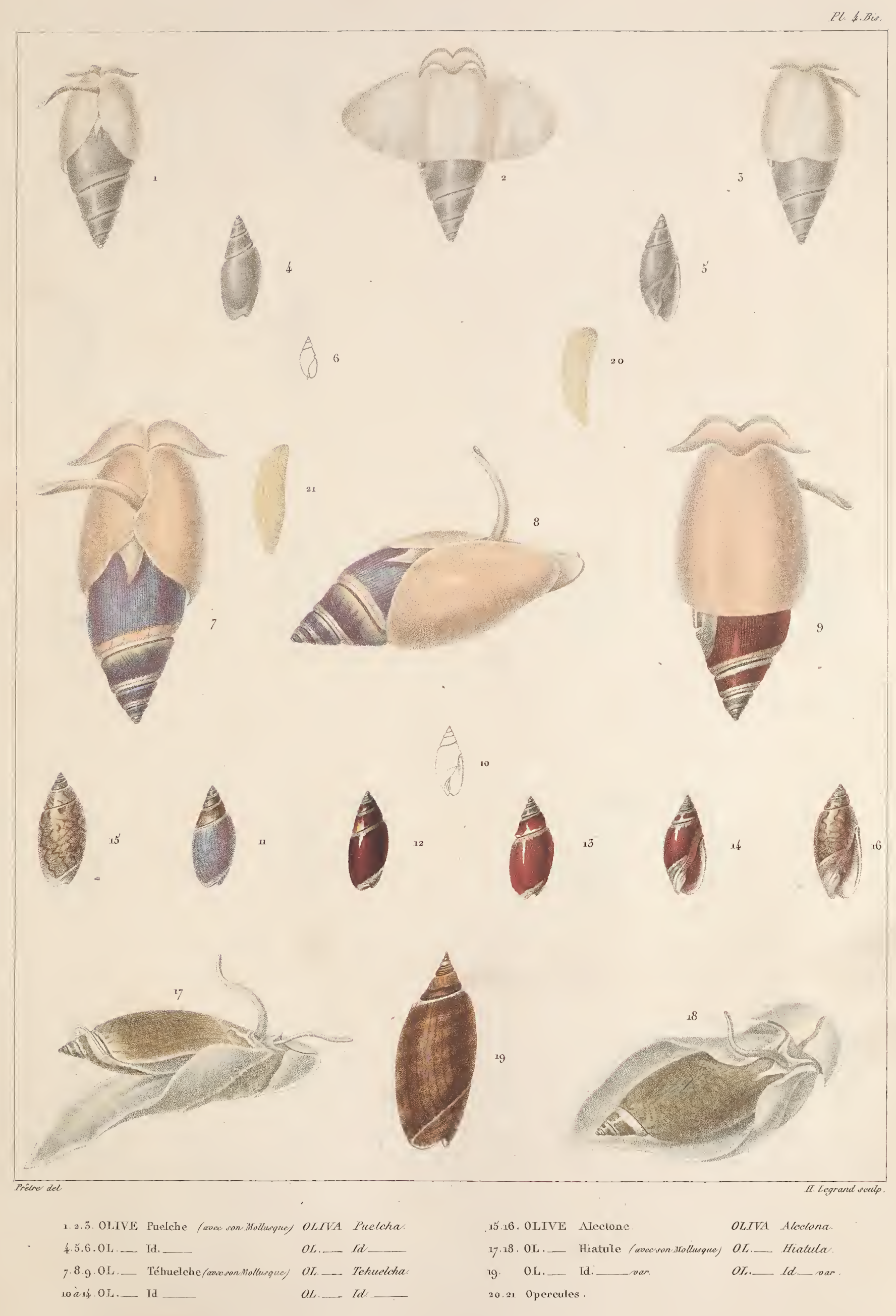





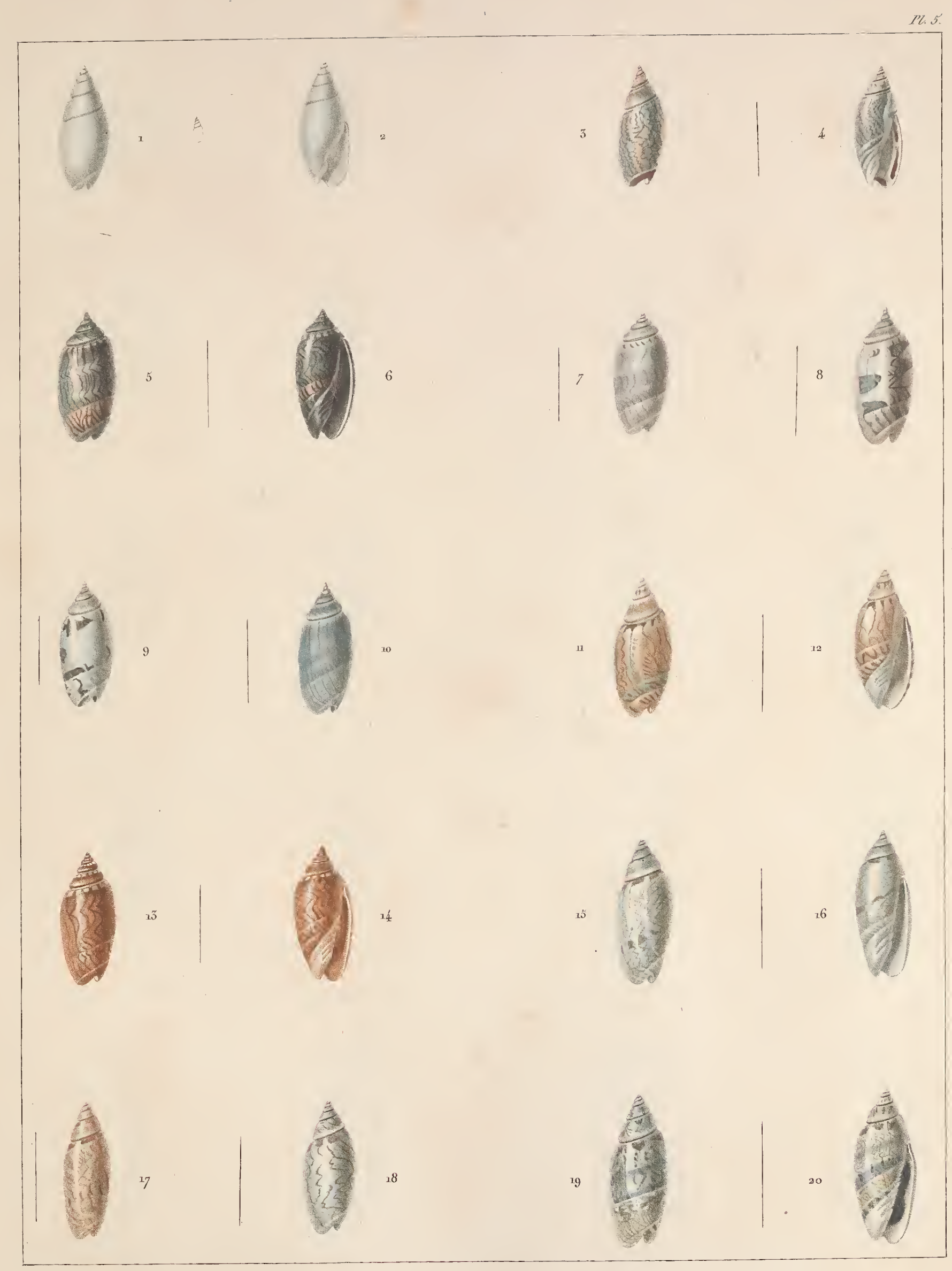
1.2. OLIVE Miriadinc. OLIVA Miriadina.
13.14. OLIVE Néduline. OLIVA Nedulina.
3.4. OL.__ Anazore. OL._ Anarara.
5.6. OL._ Ondatella. OL._ Undatella.
15.16. OL__- Drapéc. Of.___ Panniculata
5.6. OL._ Ondatella. OL.._ Undacella
17. OL._. Id. var OL__ Id_ _oar.
nit.12. OL._ Mignone. OL._. Pulchellar
19.20. OL___._. Oxodone. OL._ Orodona. 



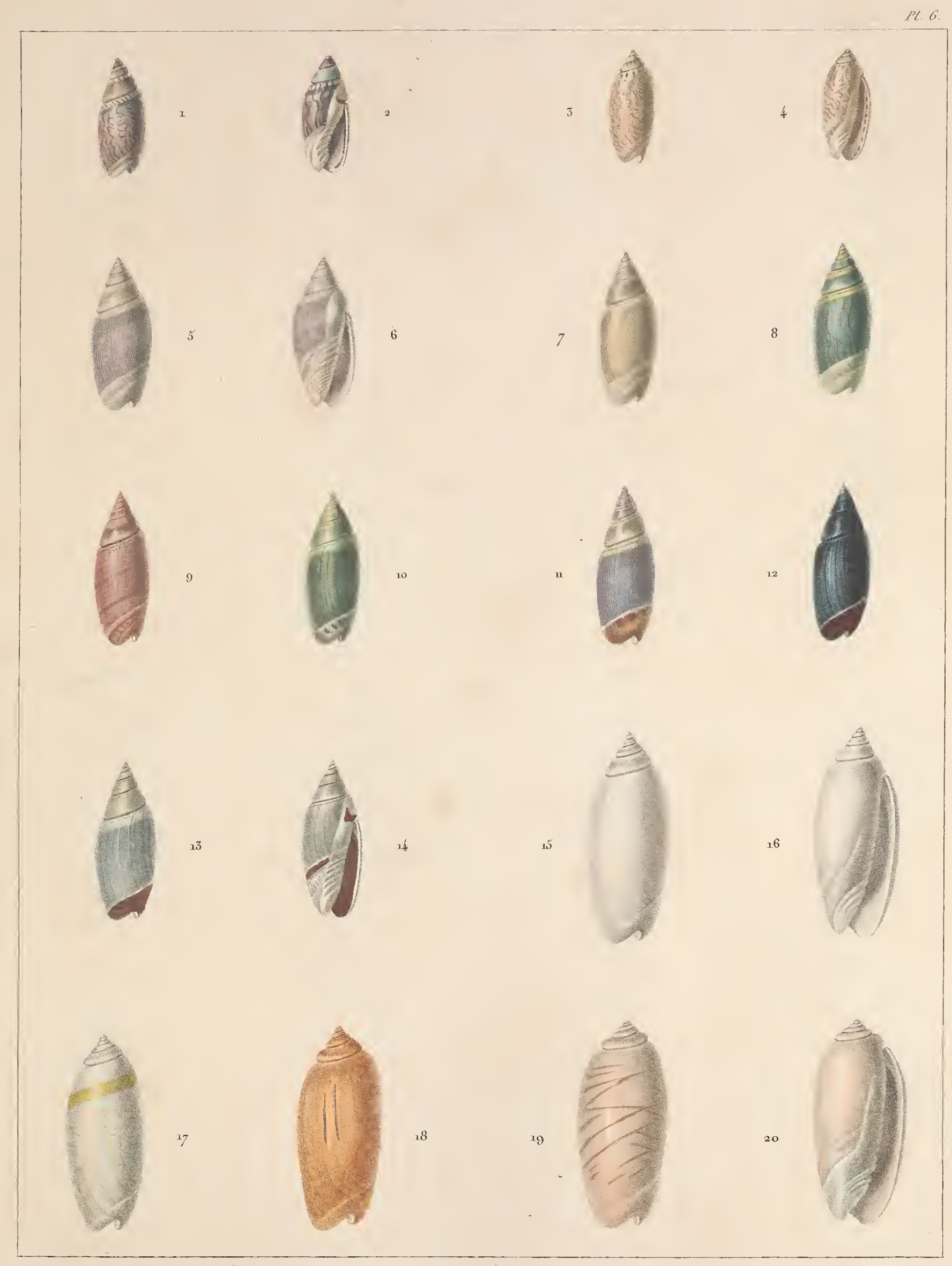
LIVE Tonqune. OLIVA. Tunquina
7-14. OLIVE Volutelle. OLIVA Volutellar.
3.4. OL___ Caldanie OL____ Caldania
15.16. OL.__ Olorinelie. OL.__ Olorinella.
5.6. OL.__ Razamole. OL.__ Ramamola.
17-20. OL. Flaréole, OI - Flareola 



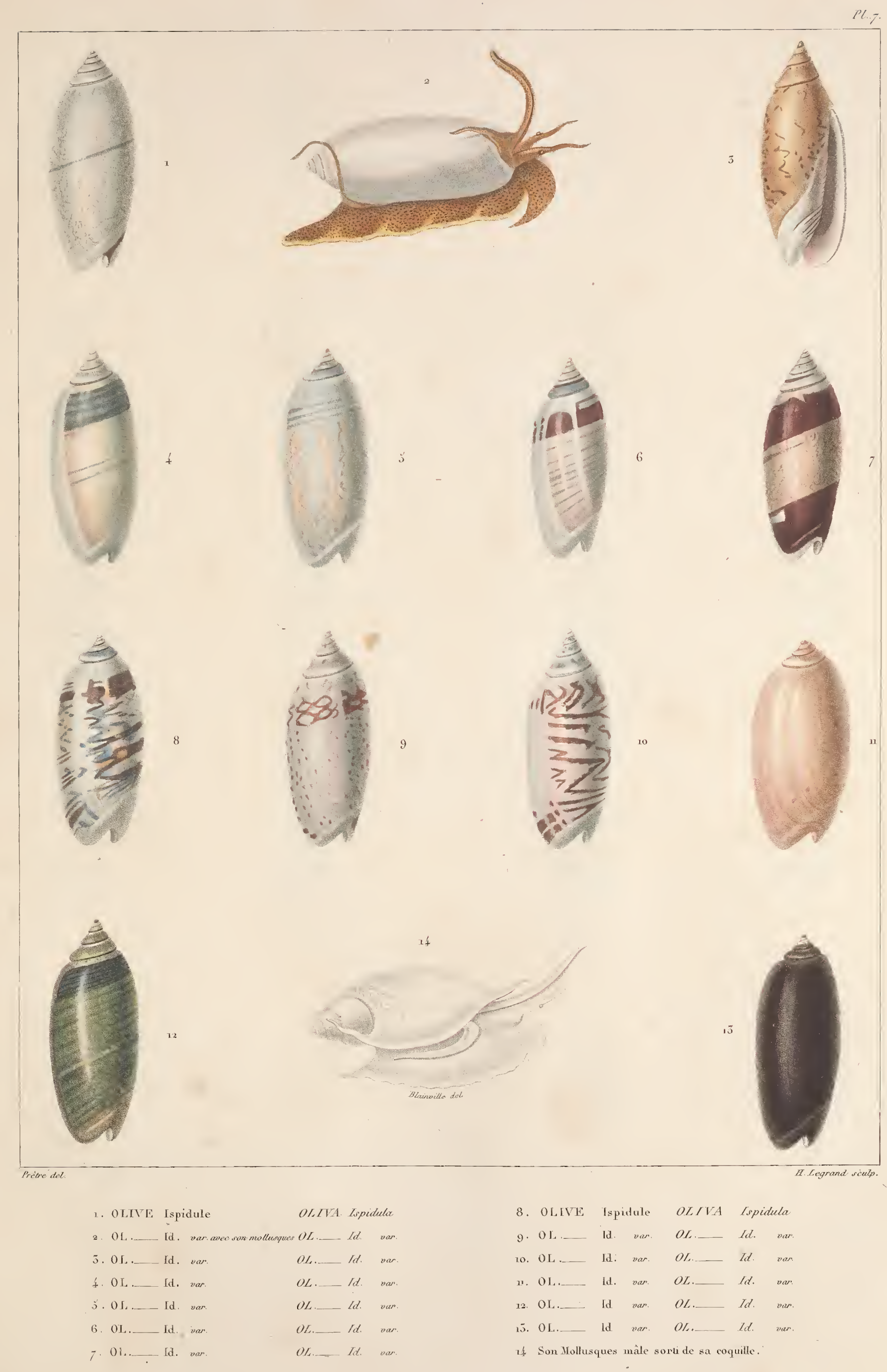





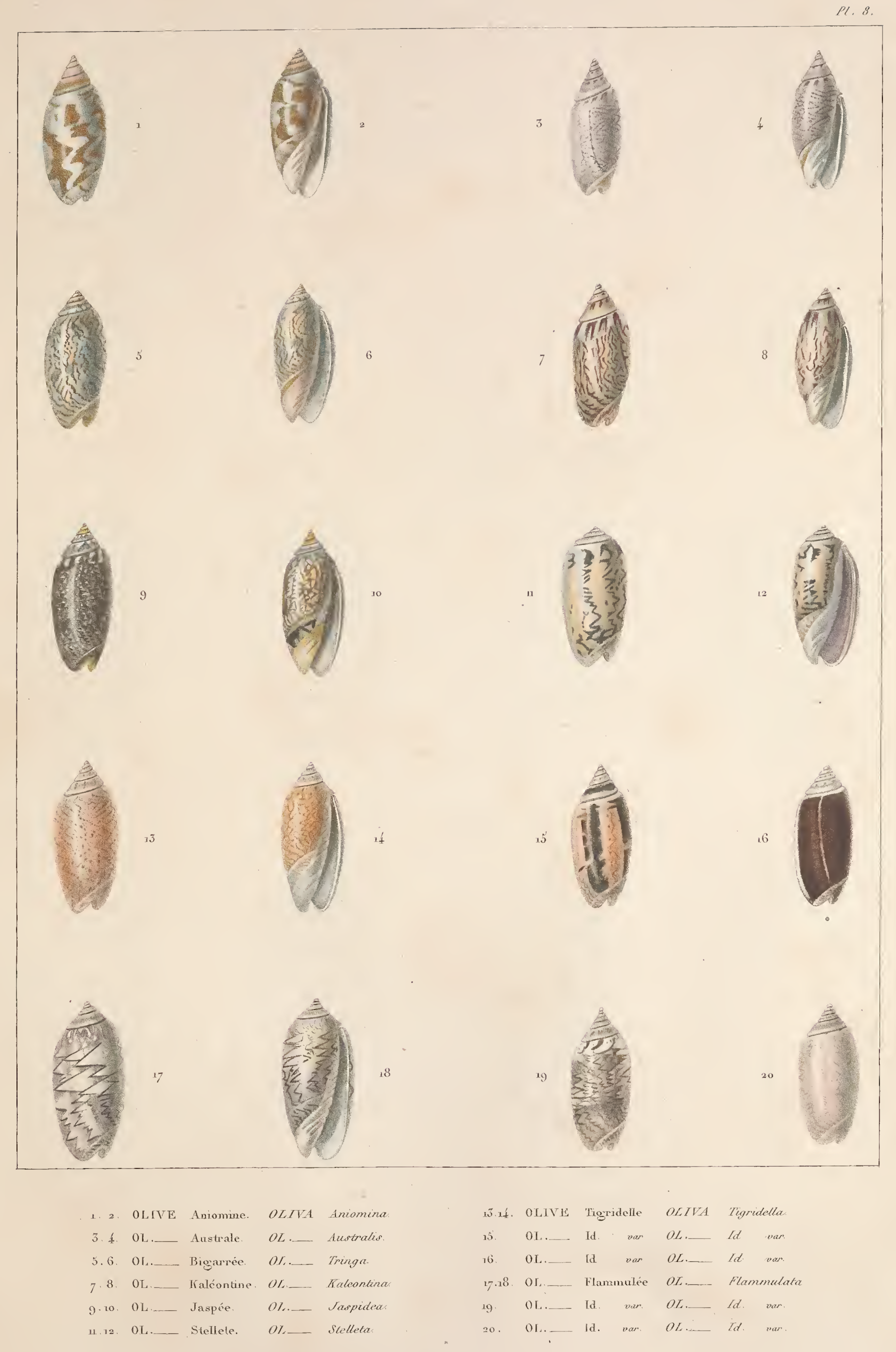





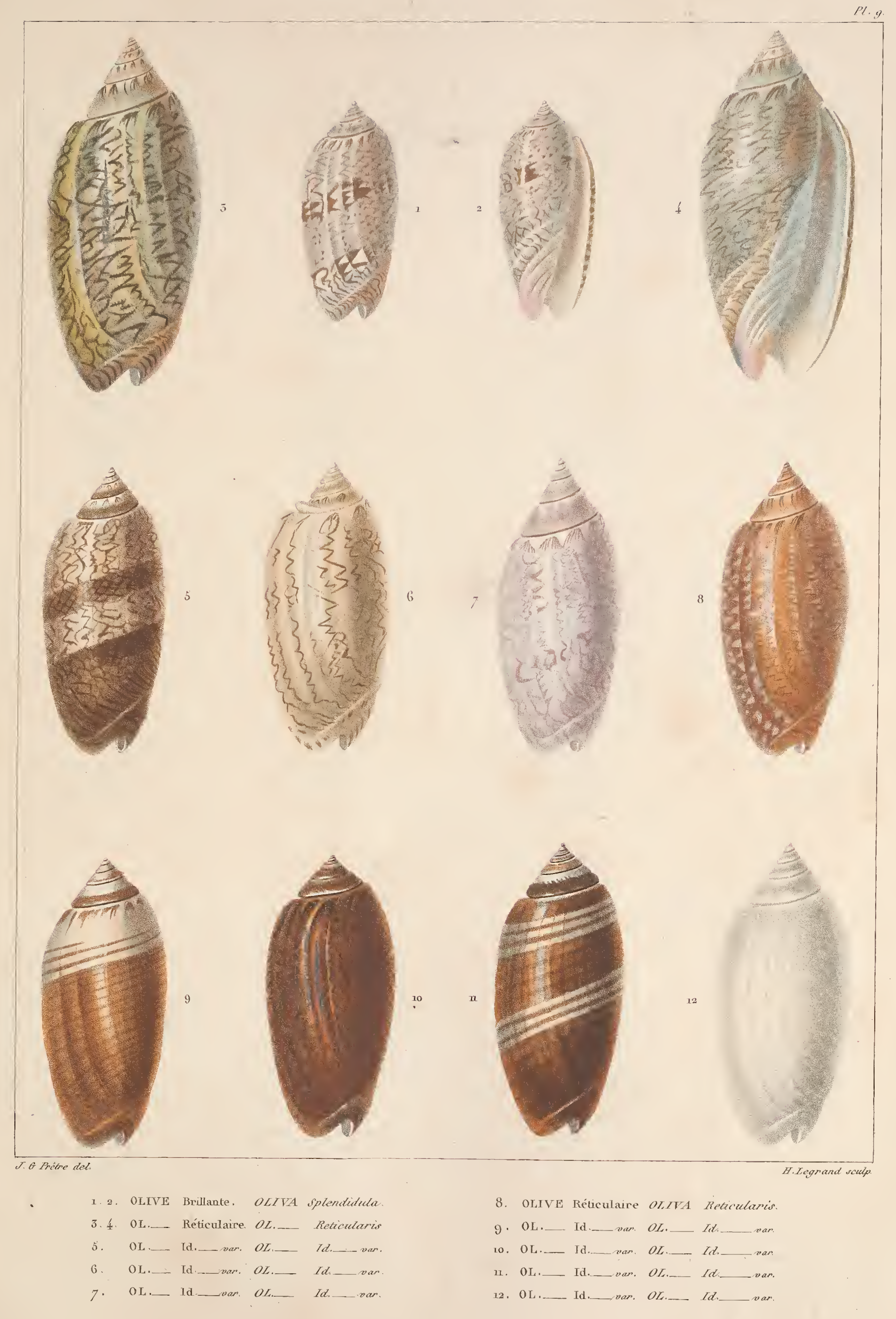





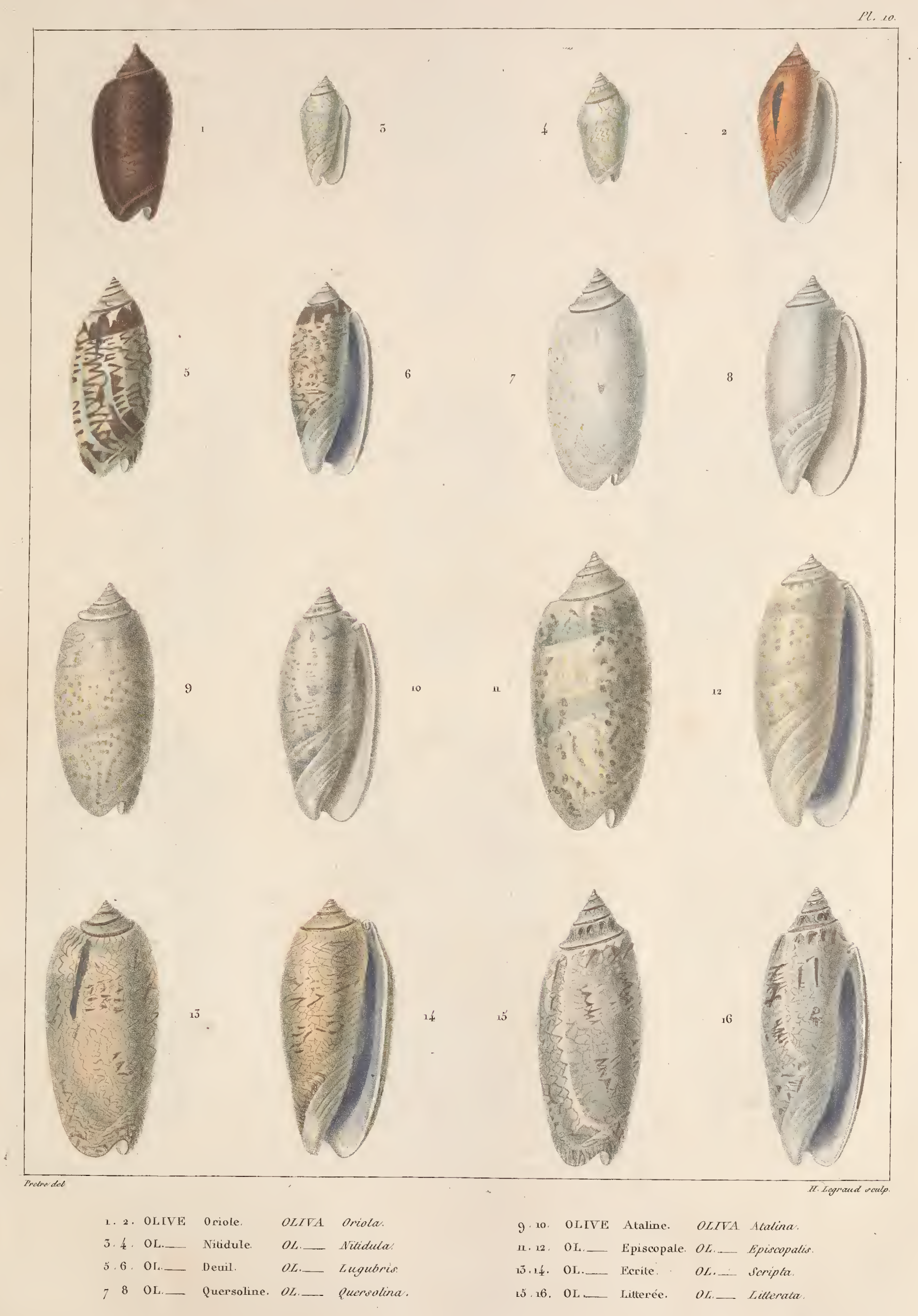





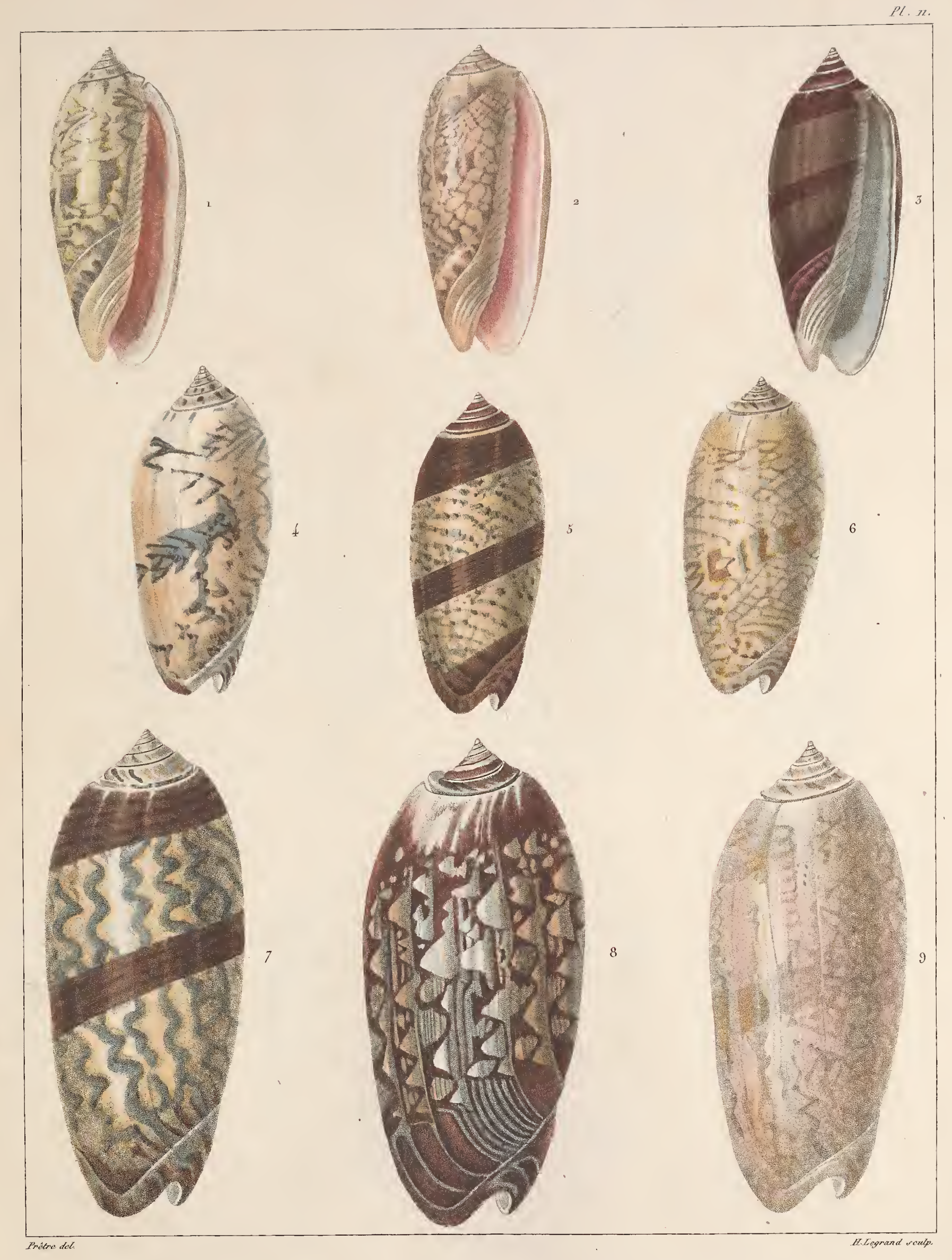
1. Or.TVE Trémuline. OLTTA Tremulina.
5. OLIVE Trémuline. OLIVA Tremulina.

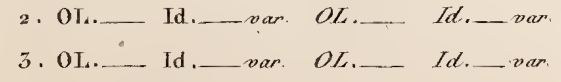

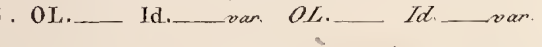
4. OL___ Id._oan. OL.__ Id__ van.

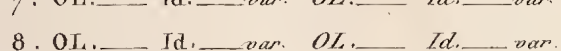





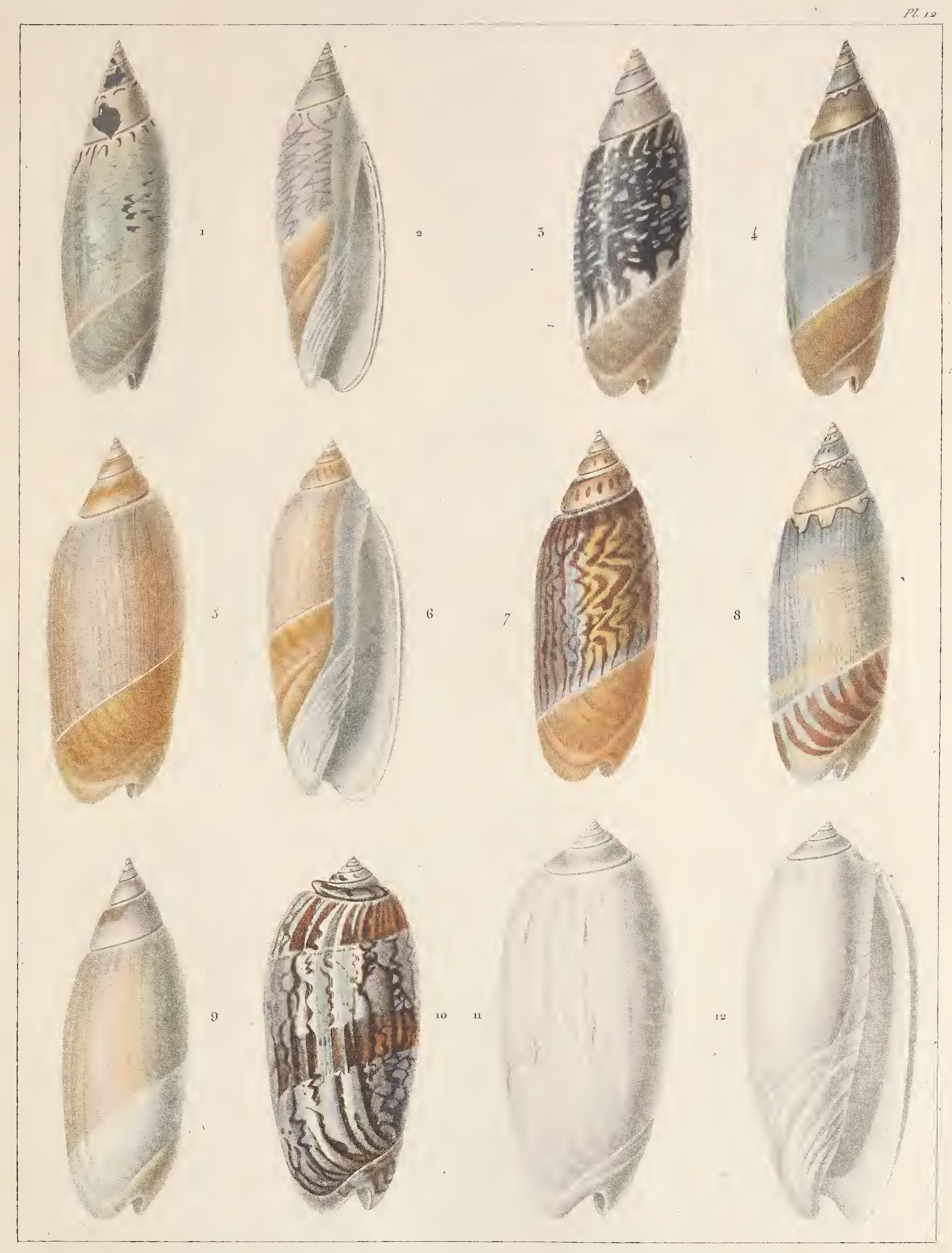

$$
\begin{aligned}
& \text { 1.2. OLIVE Acuminés. OTIVA Acuminata 7. OLIVF Subulée dépouillée OLIVA Subulata. }
\end{aligned}
$$

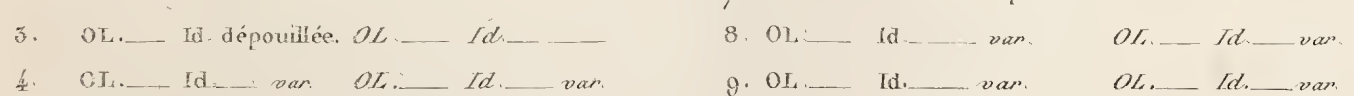

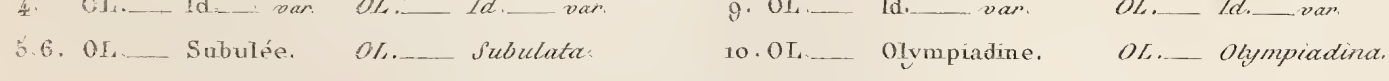





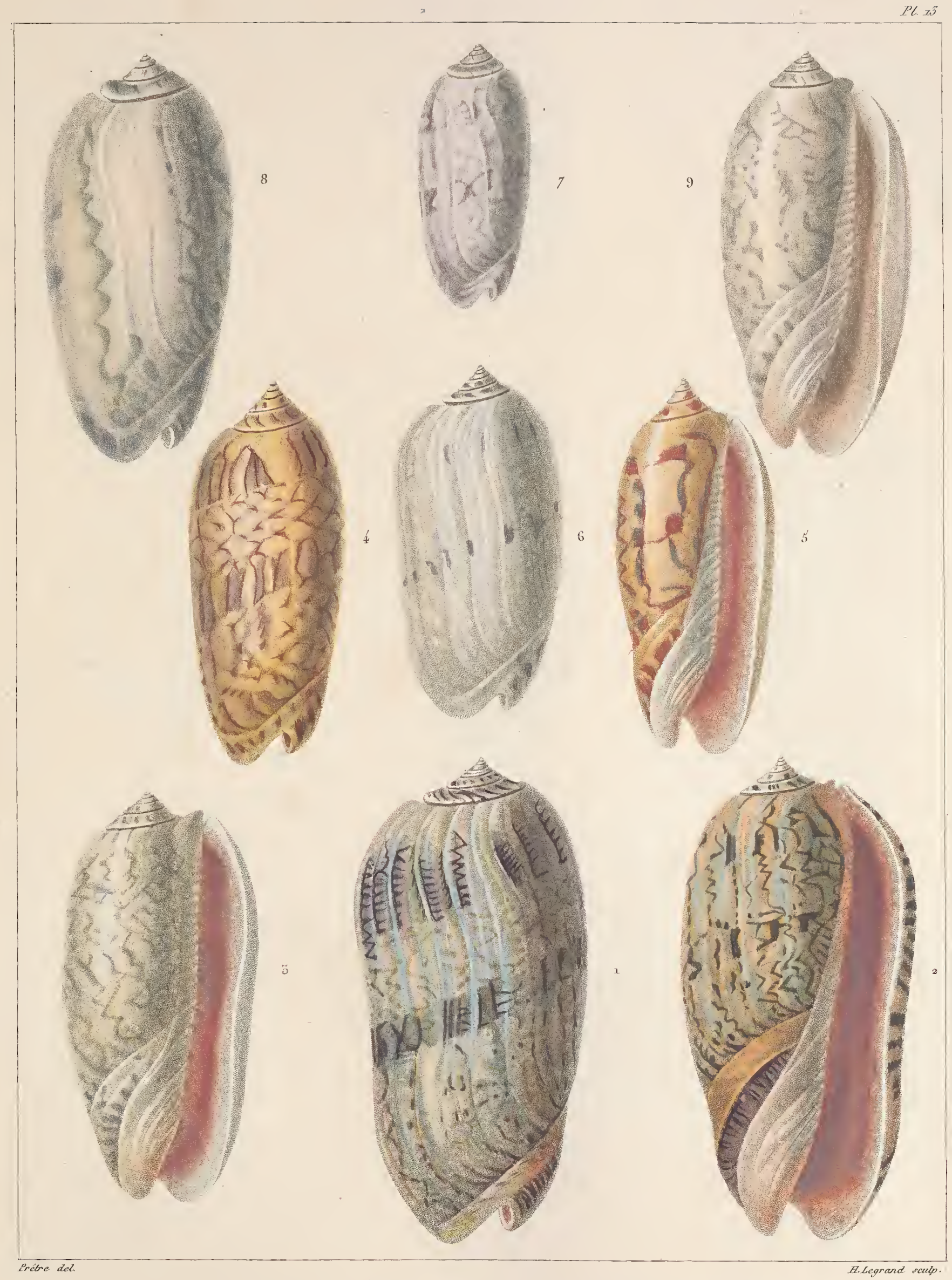

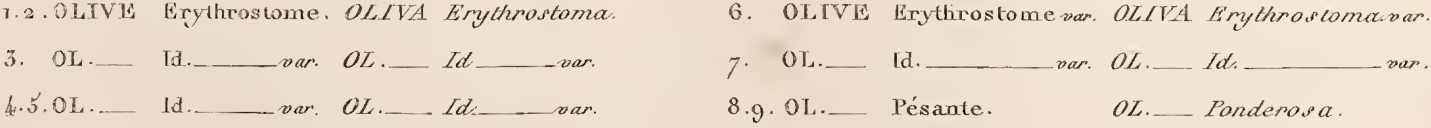





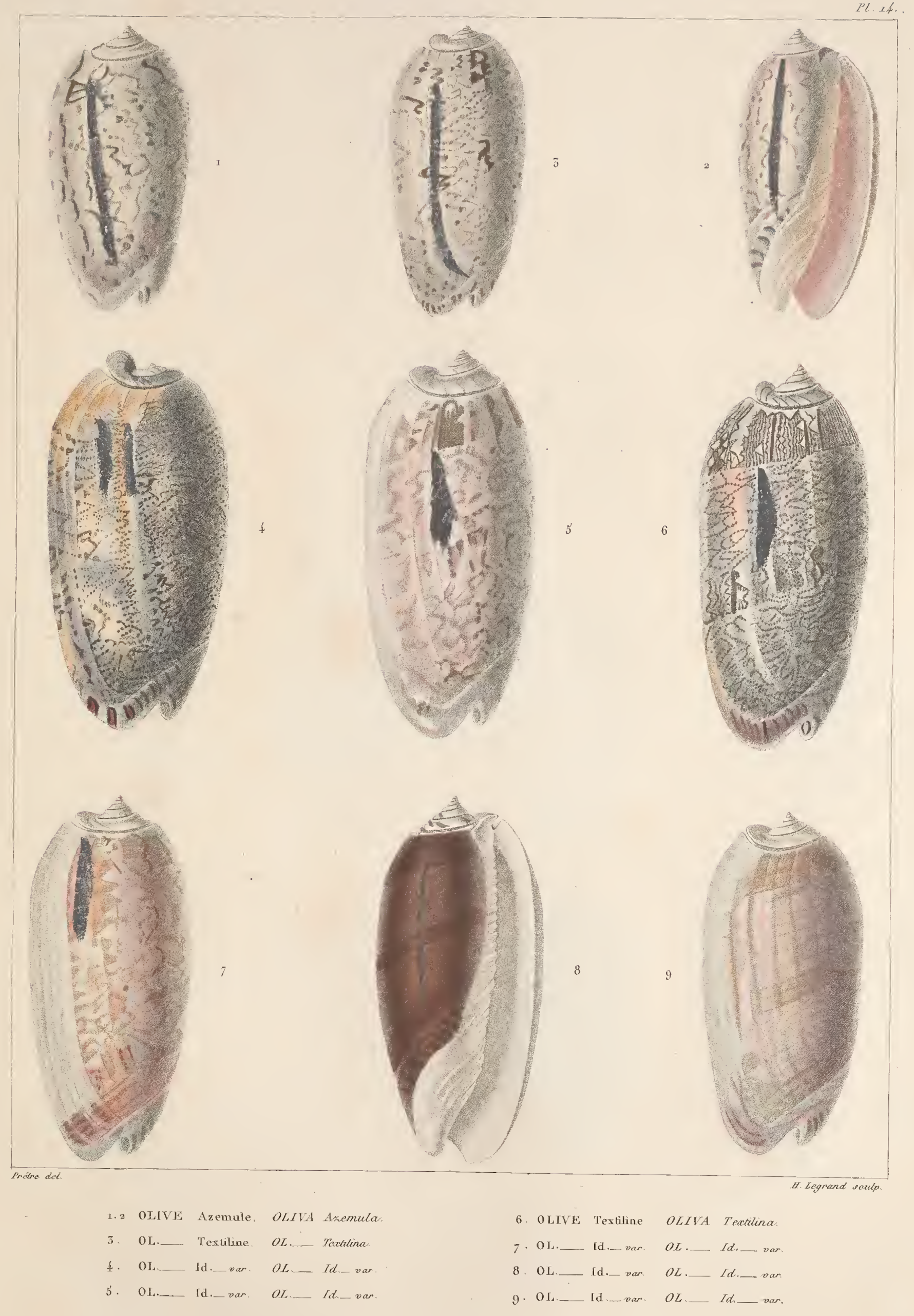





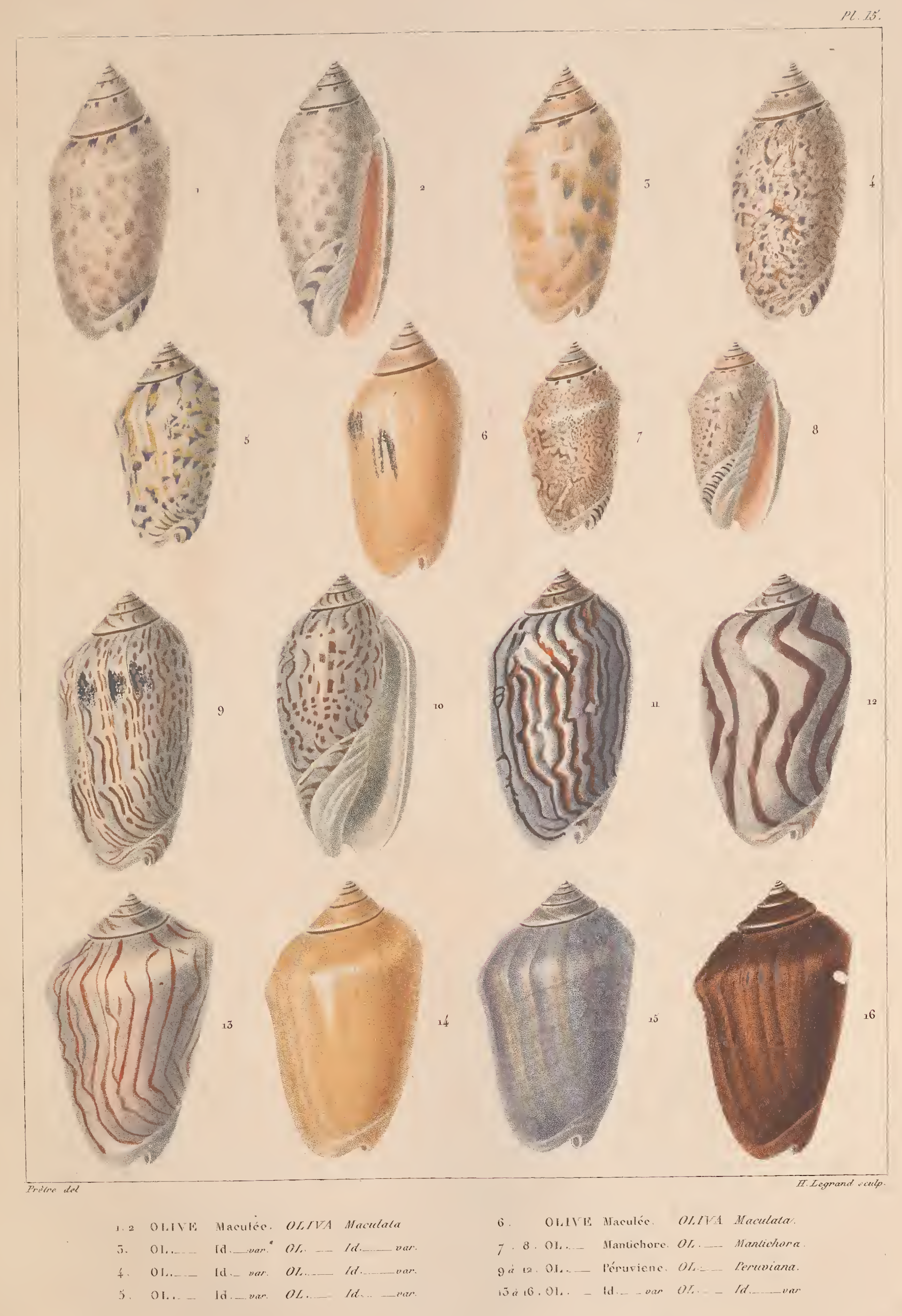





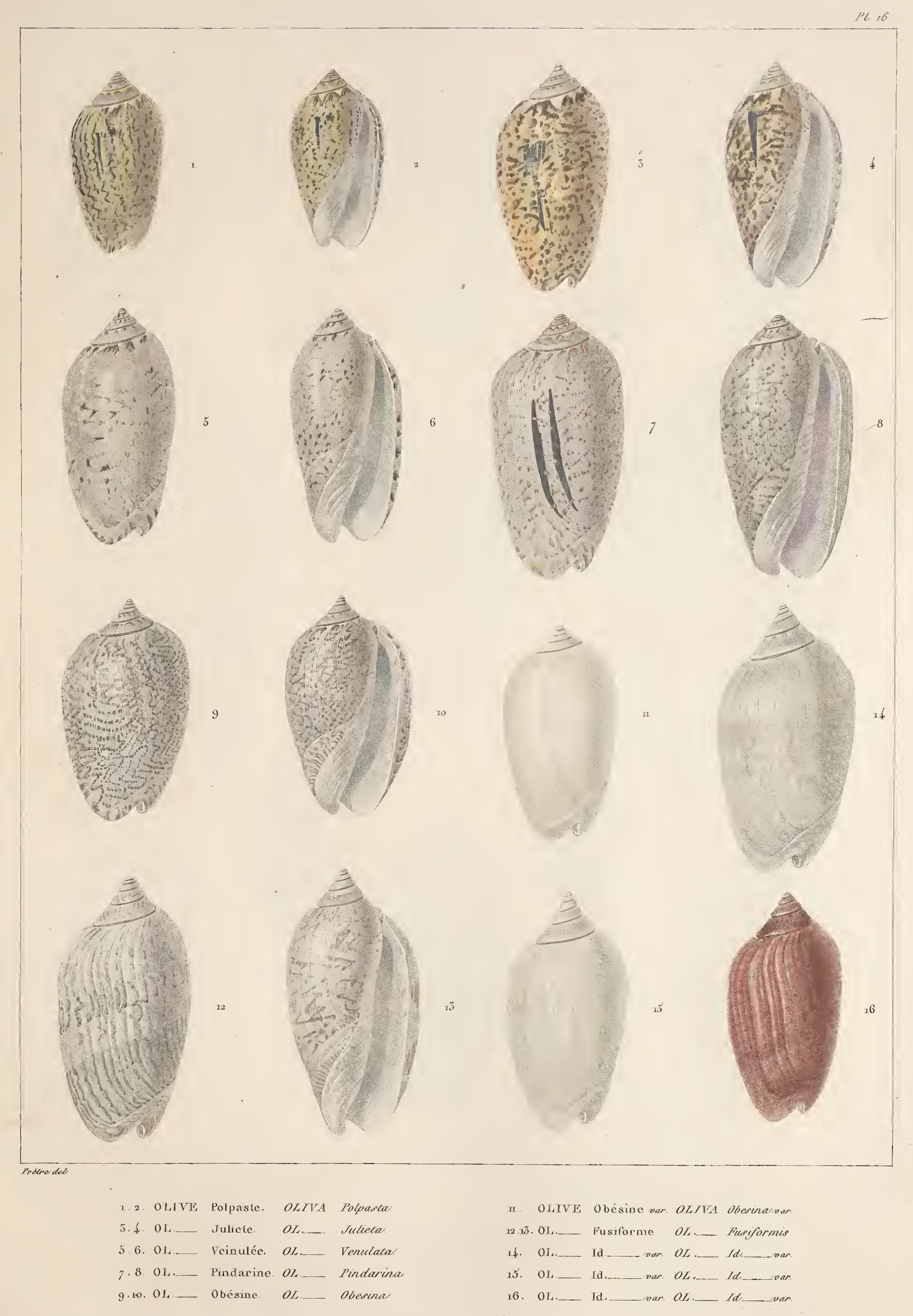





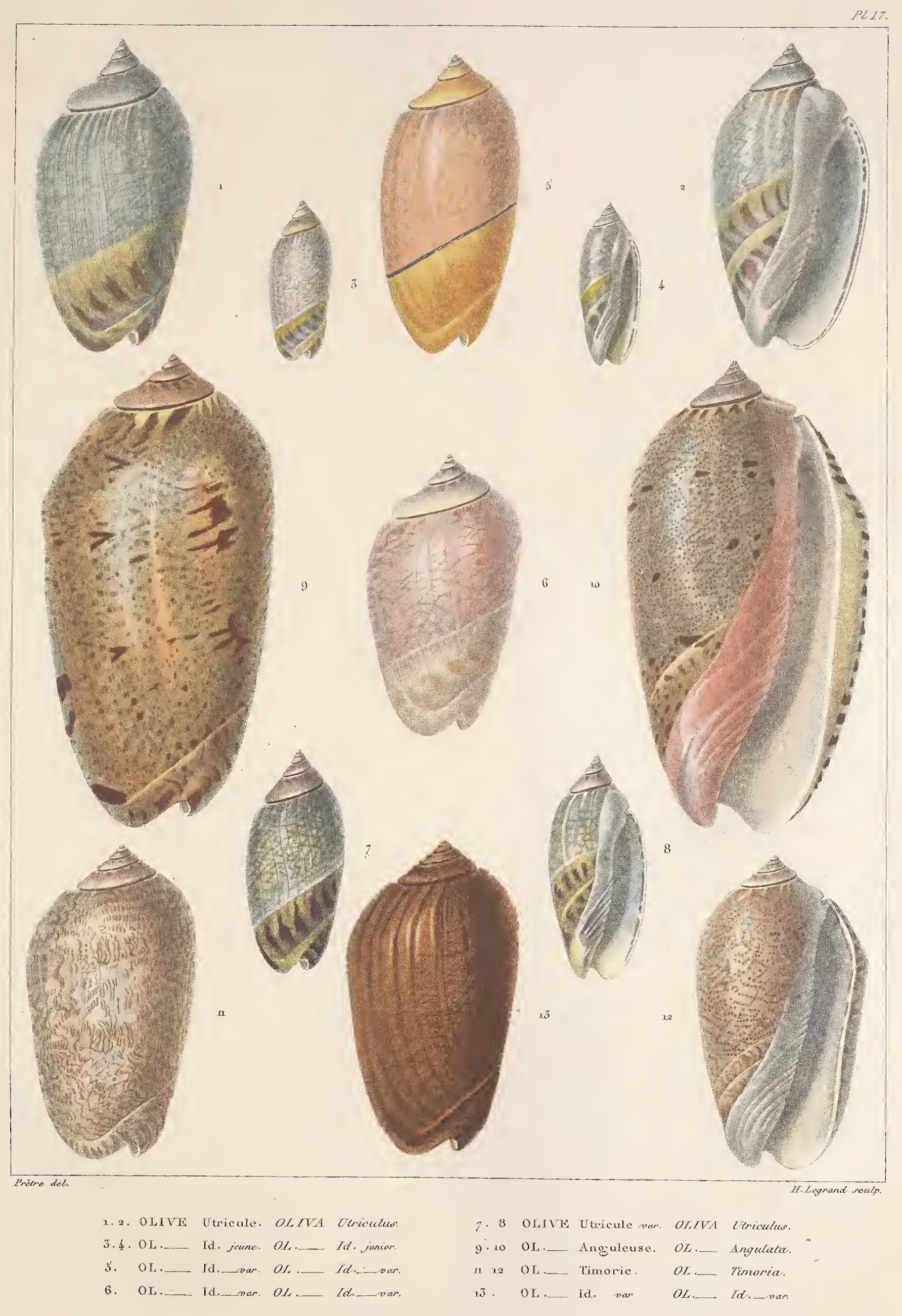




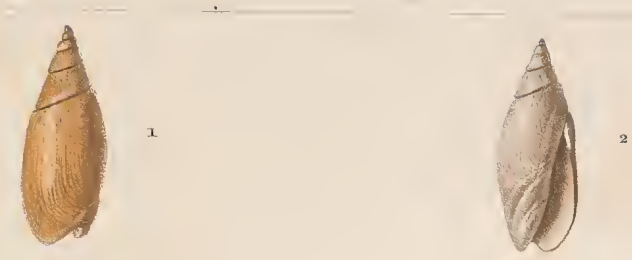

0

1
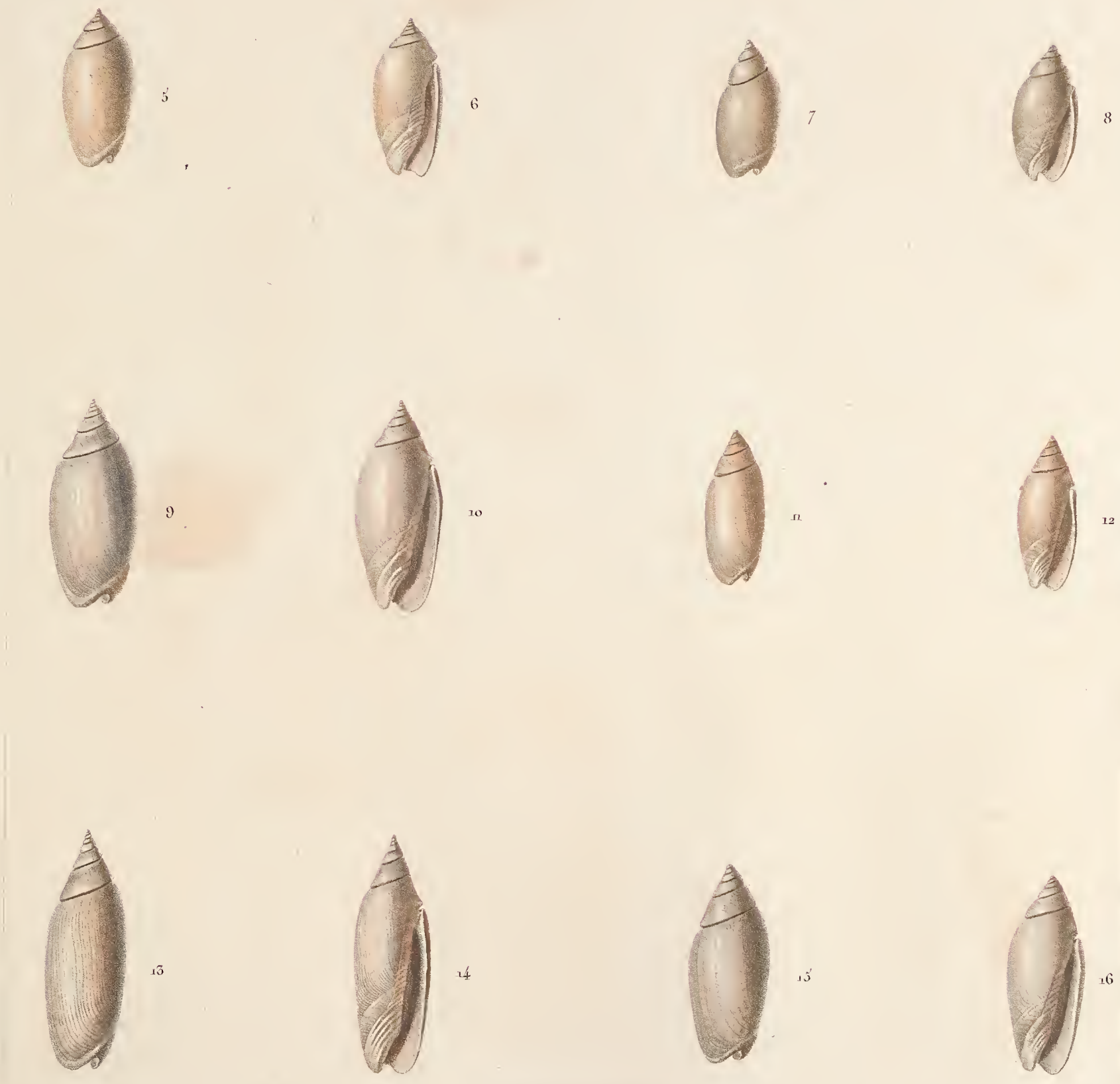

\begin{tabular}{|c|c|c|c|c|c|c|}
\hline 2. OLIVE & Nilotide. & $O L I V A$ & Nilotida & 9.10. OLIVE & Dufresne & OLIVA \\
\hline 4. OI & Phitlips. & $O L \ldots$ & Phillipsit & $11.12 . \mathrm{OI}_{+}$ & Gaysiane. & $O L$. \\
\hline . Or: & Picholine. & $O L$ & Picholina & $13.14 .0 L_{2}$ & Chevillete & $O L$ \\
\hline L.. & Padolide. & $O L$ & Padolida. & 15.16, OL. & erine. & $O L$ \\
\hline
\end{tabular}





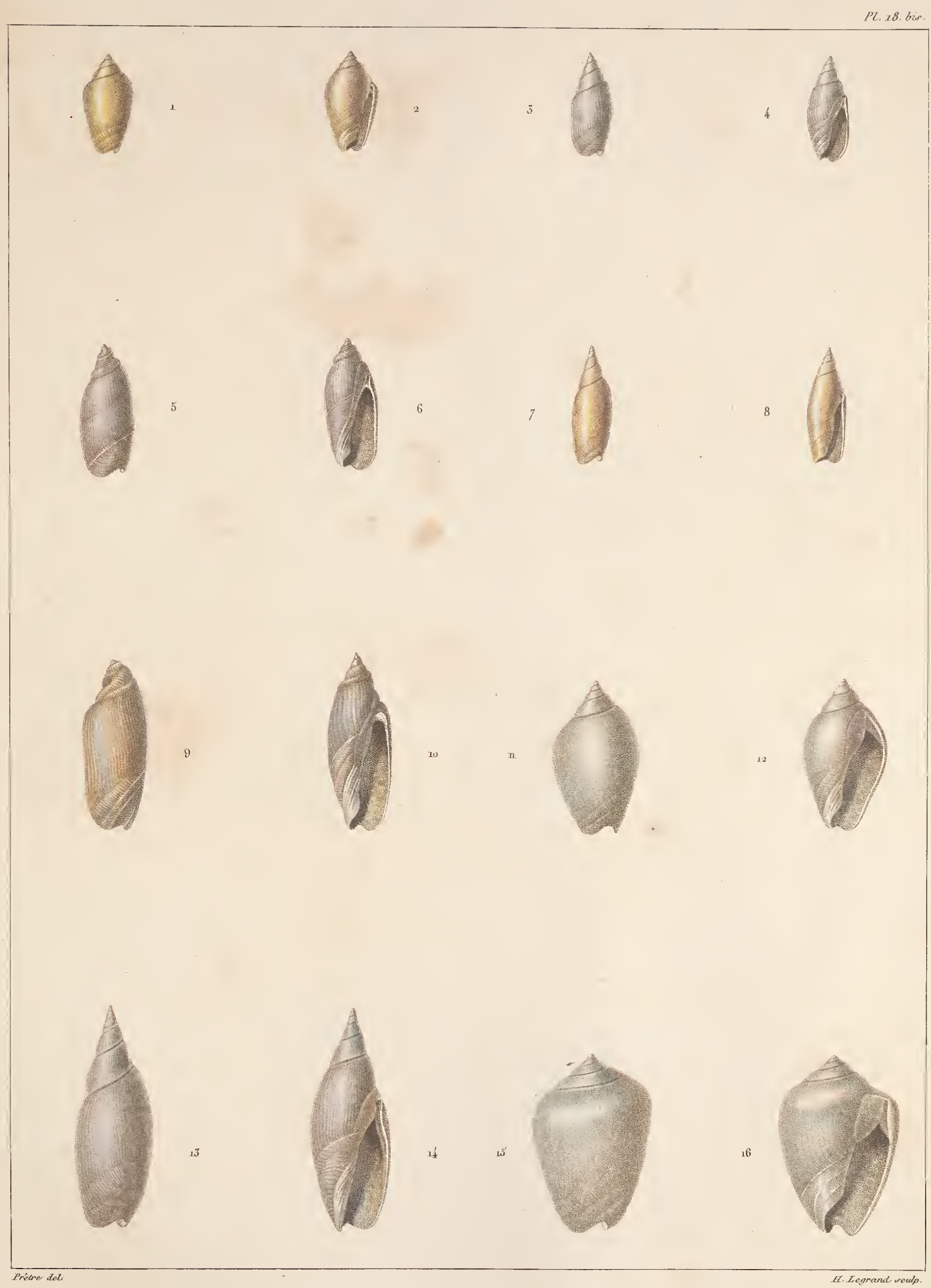

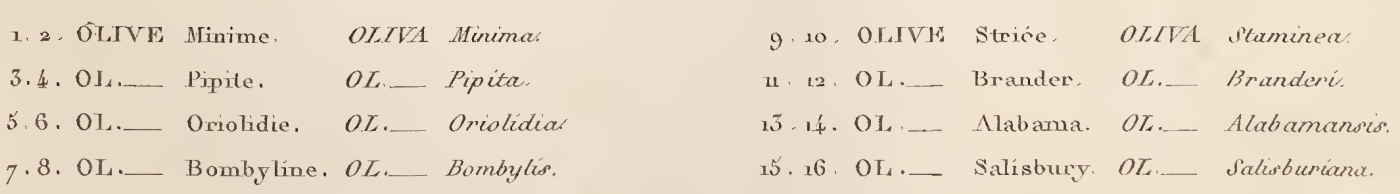





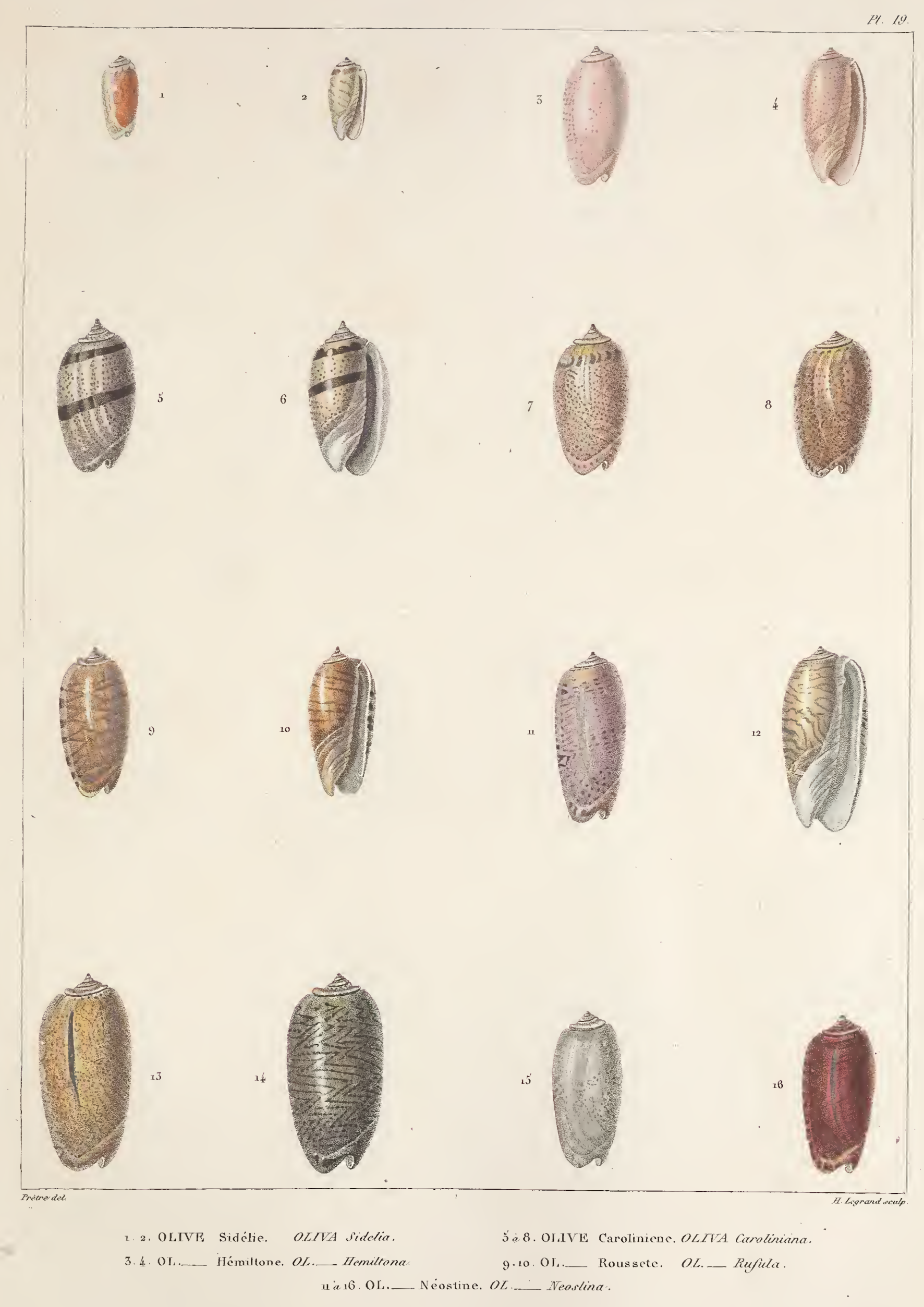





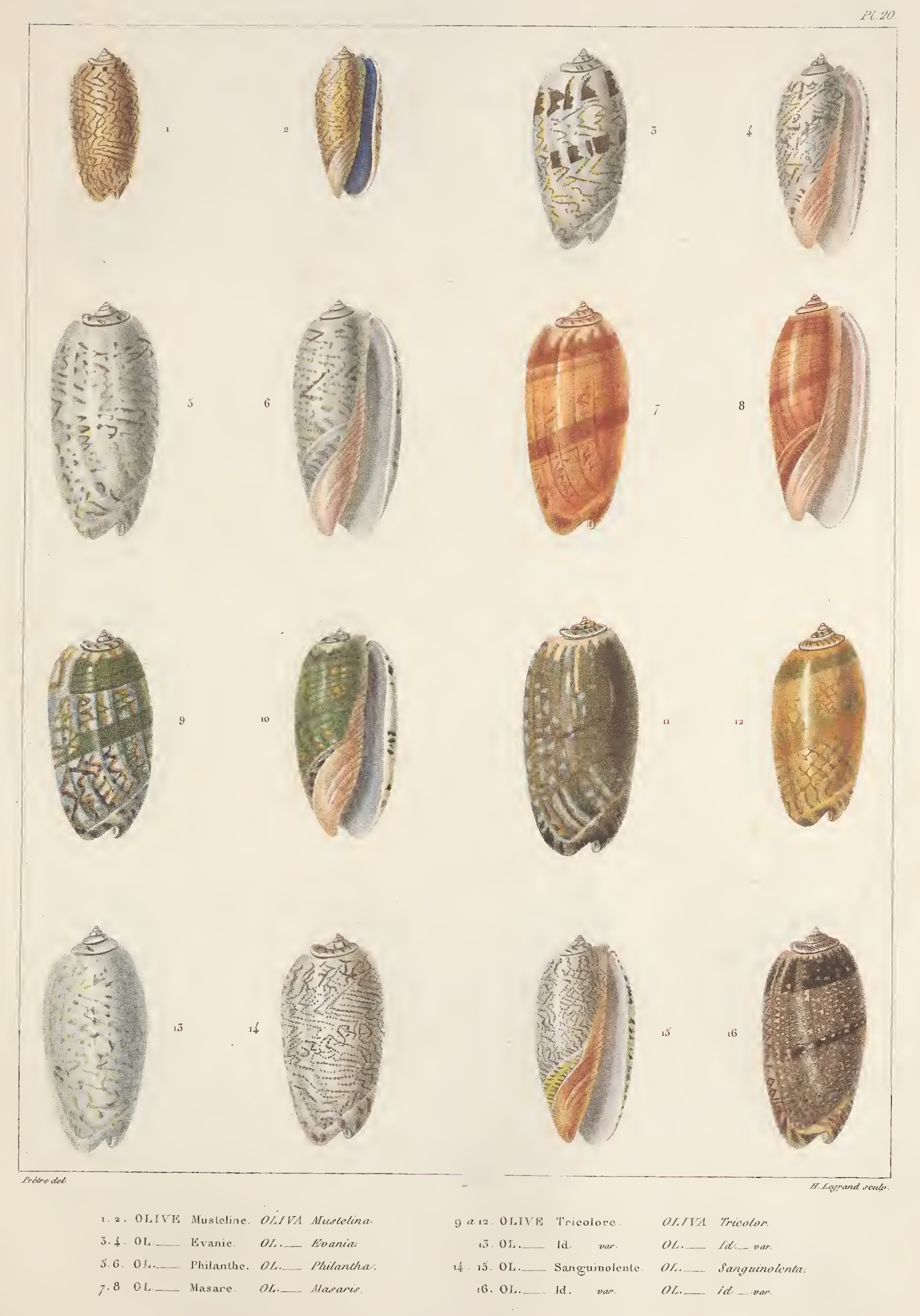





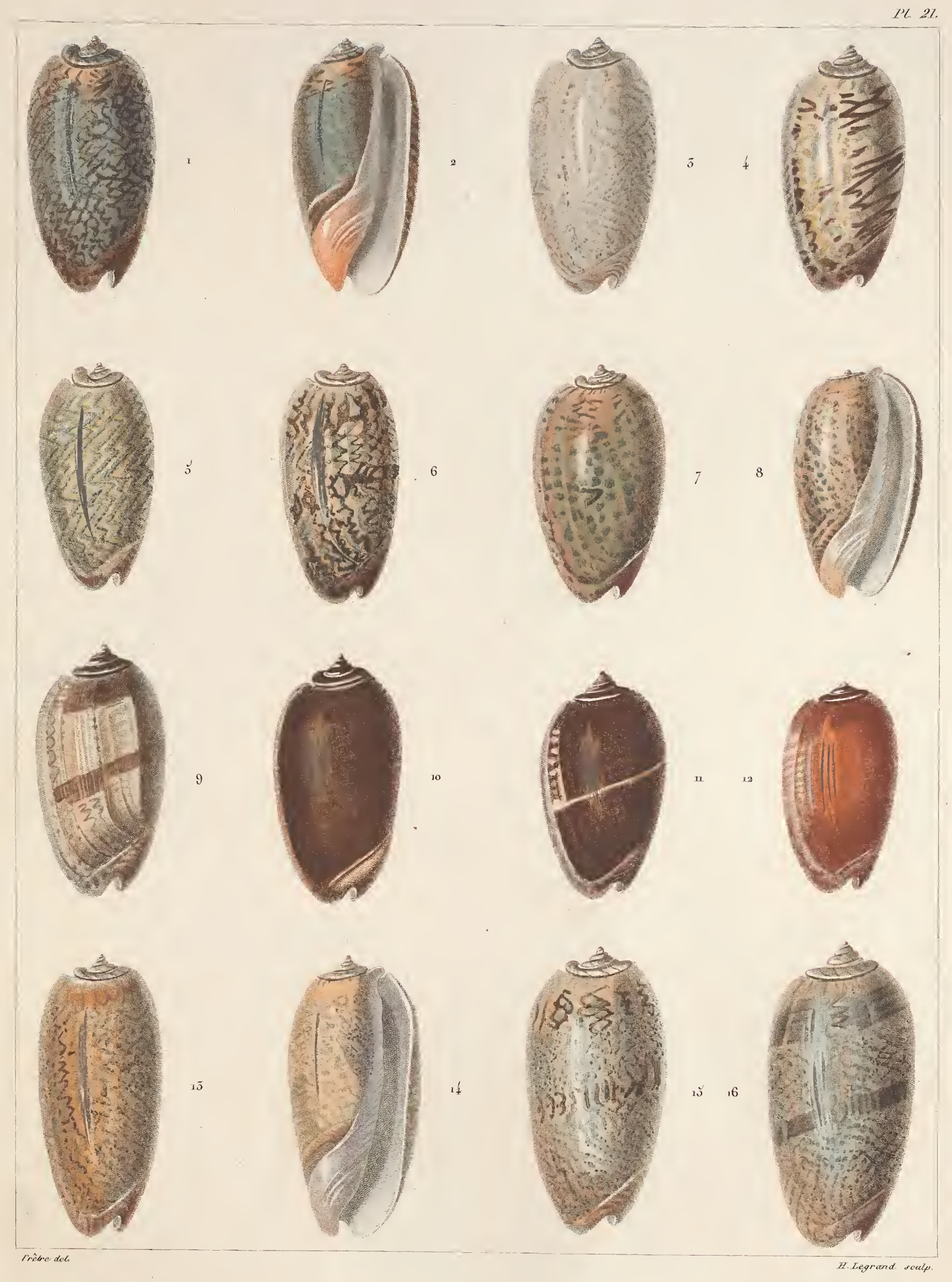
1.2. OLIVE Eléggante. OtIVA E'legano.
$9 \dot{a} 12.0 \mathrm{~J}$ IVE Tigrime van. OLITA Tigrina van.

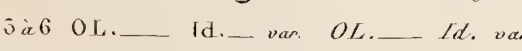
15. if OL._. Macleave. OL.__ Nälecaya.
$7.801 . . \quad$ Ligrine. OL.__ Tigrina
15. 16. OI.___ Id.__ van OL____ Id___ ow 



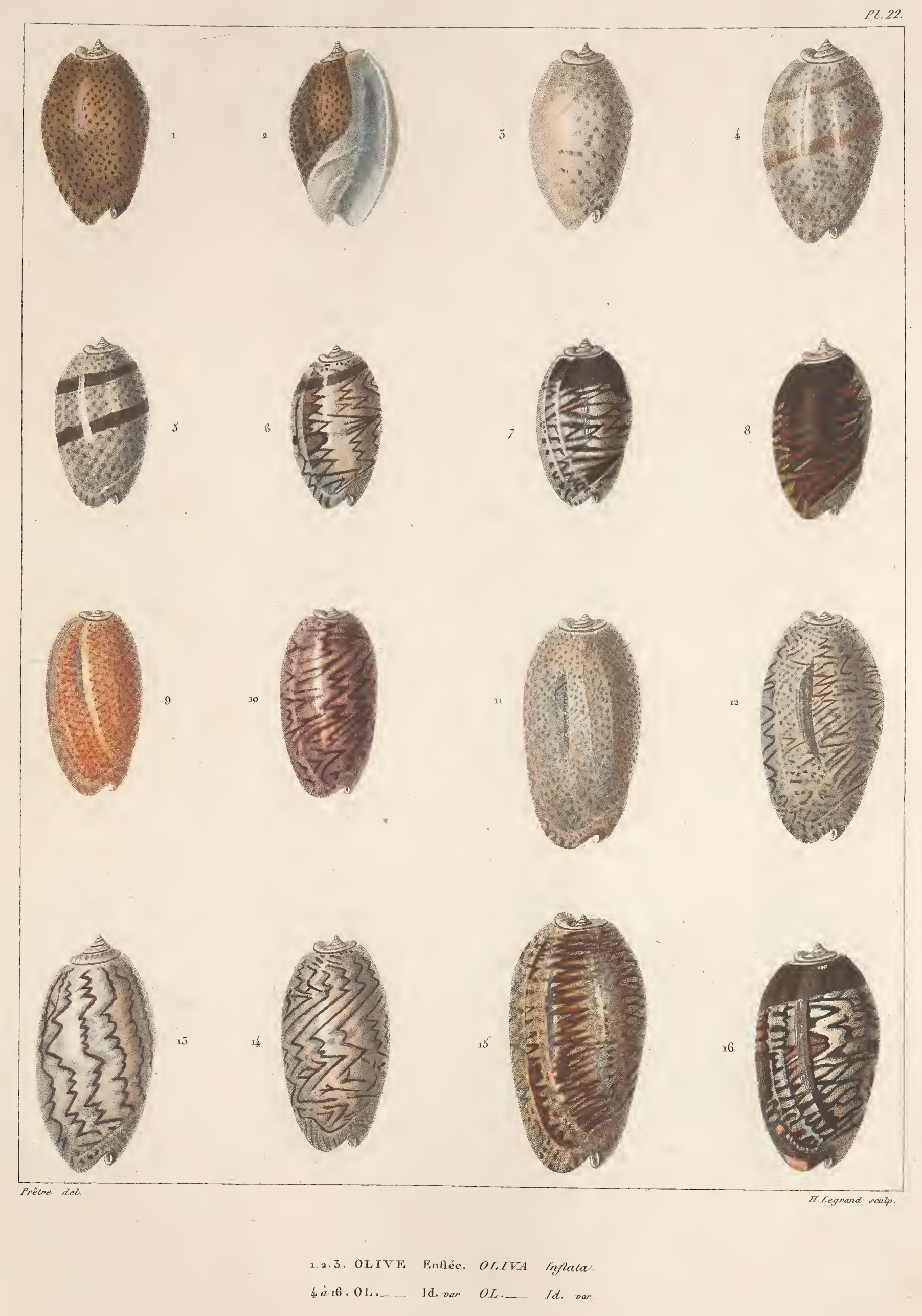





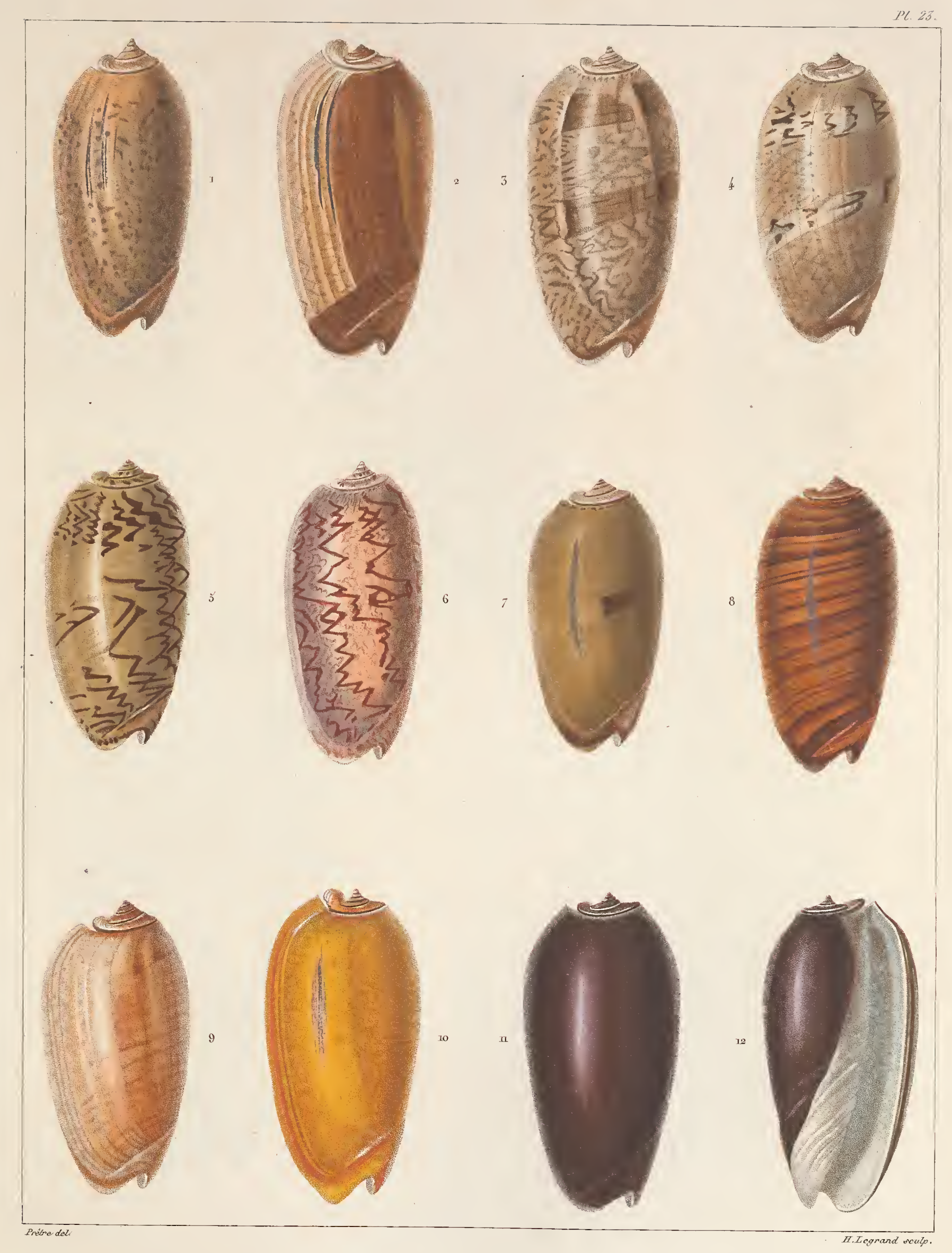

1 a12. OLIVE Maure OLIVA Maura 

PL. 24

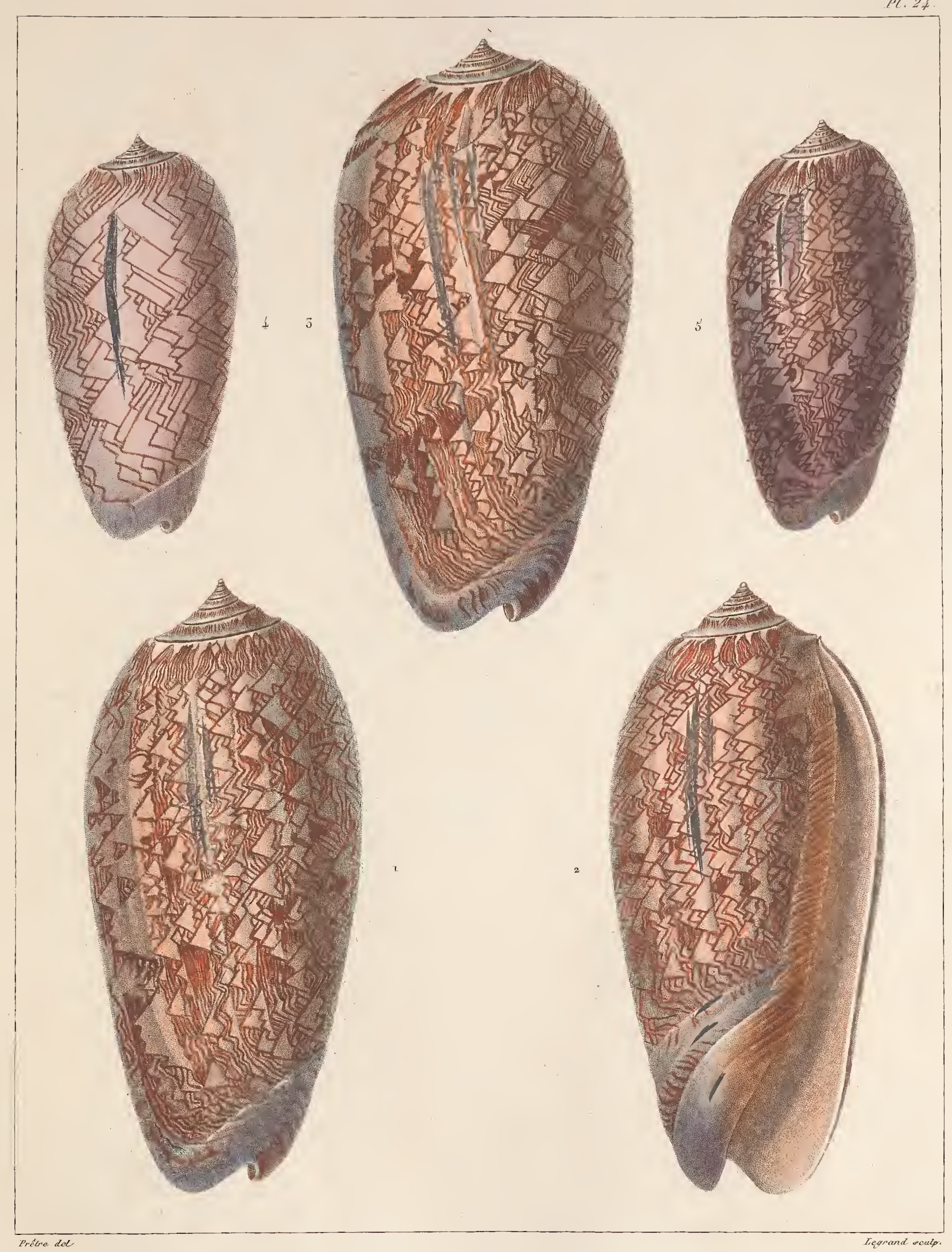

$$
\begin{aligned}
& \text { 1. 2. OLIVE Porphỹe Mâte. OlALA Porphyria. }
\end{aligned}
$$

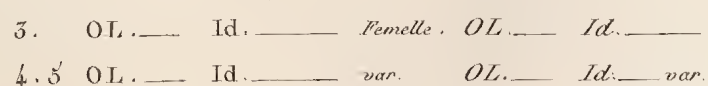





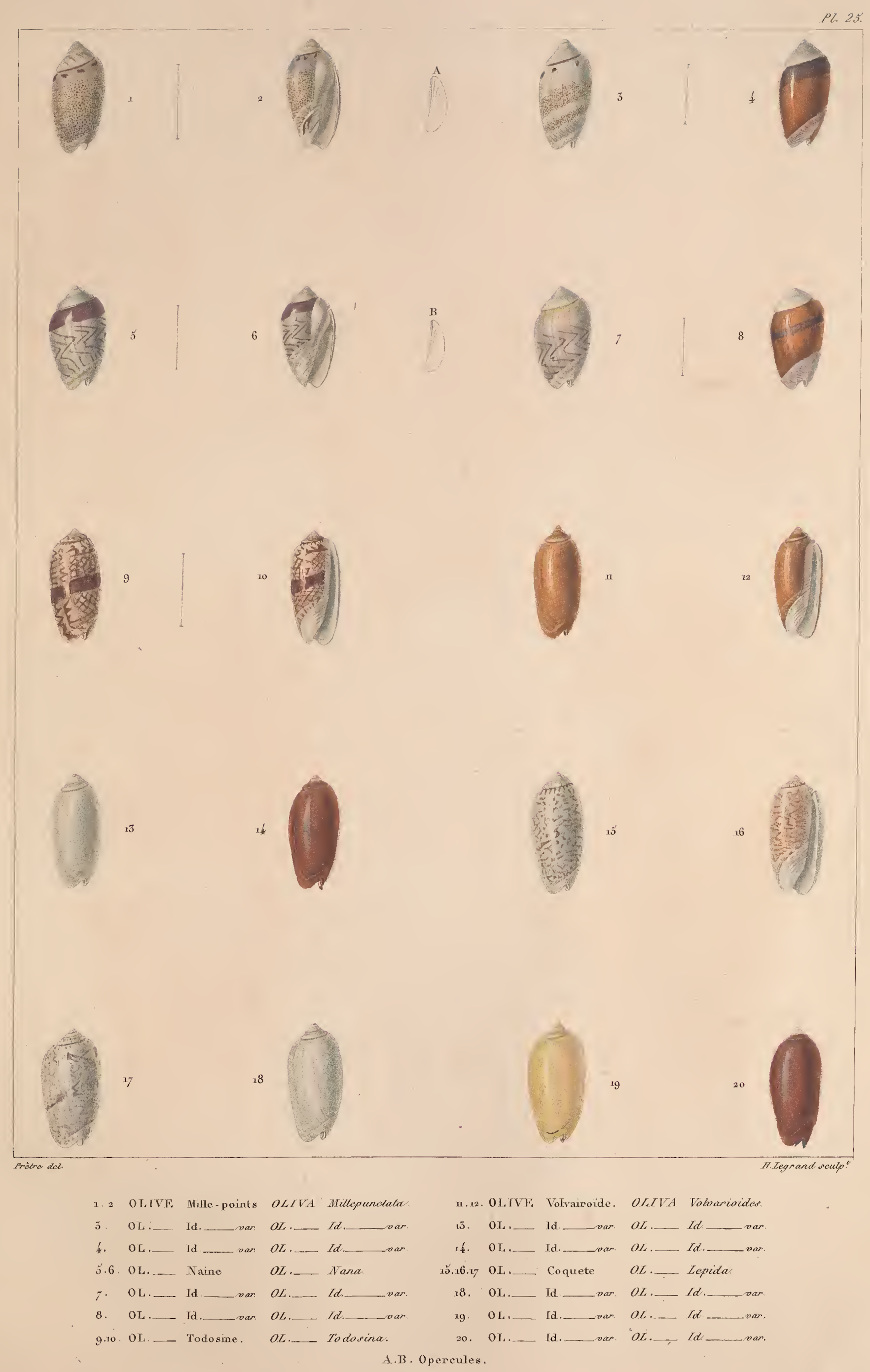





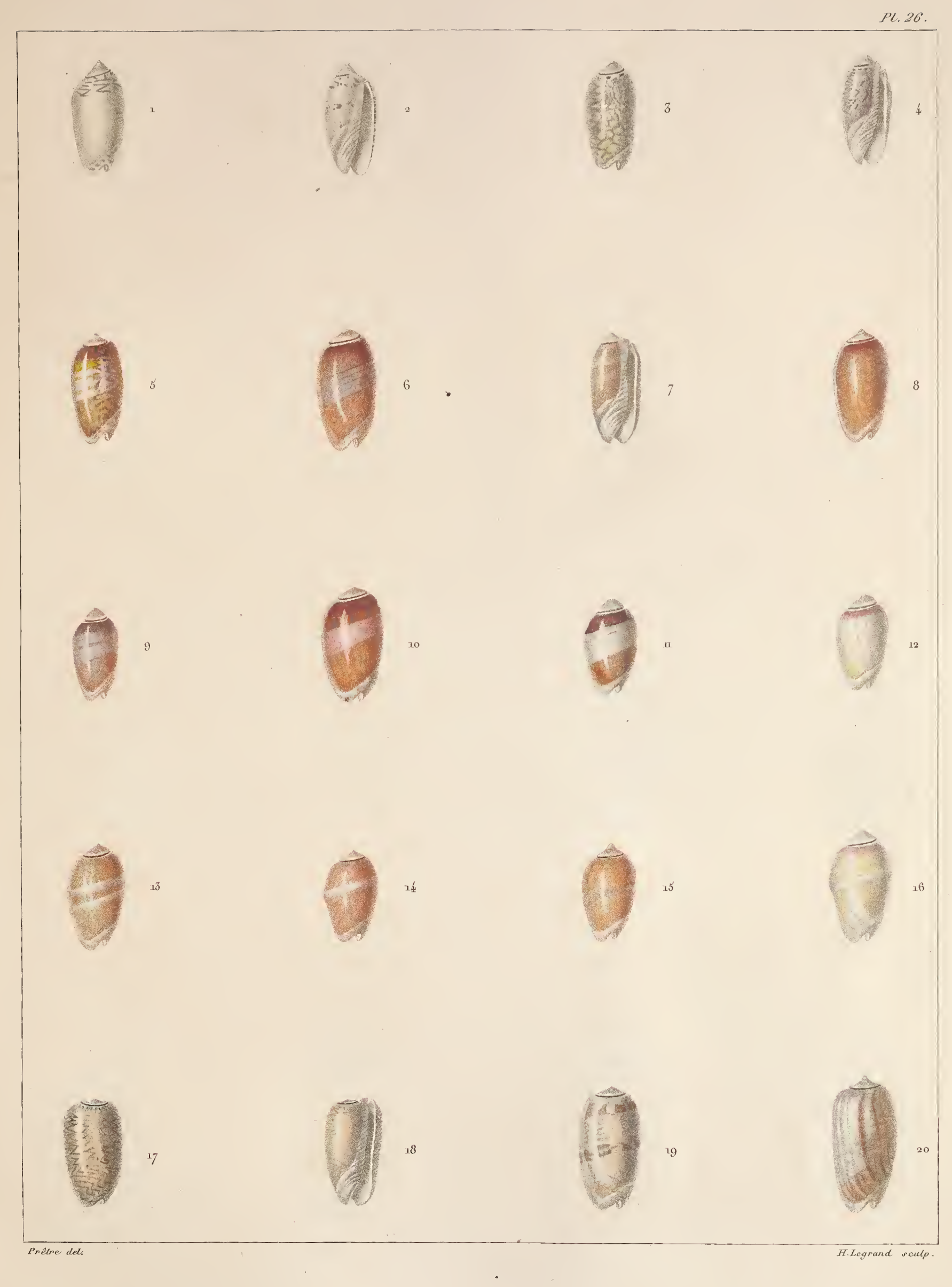

1.2. OLIVE Calôsôme. OLIVA Calosoma.

3-L6. OL._ Carnéole. OL.__ Carneola

17-20. OL._ Ahémie. OL__ Athenia. 



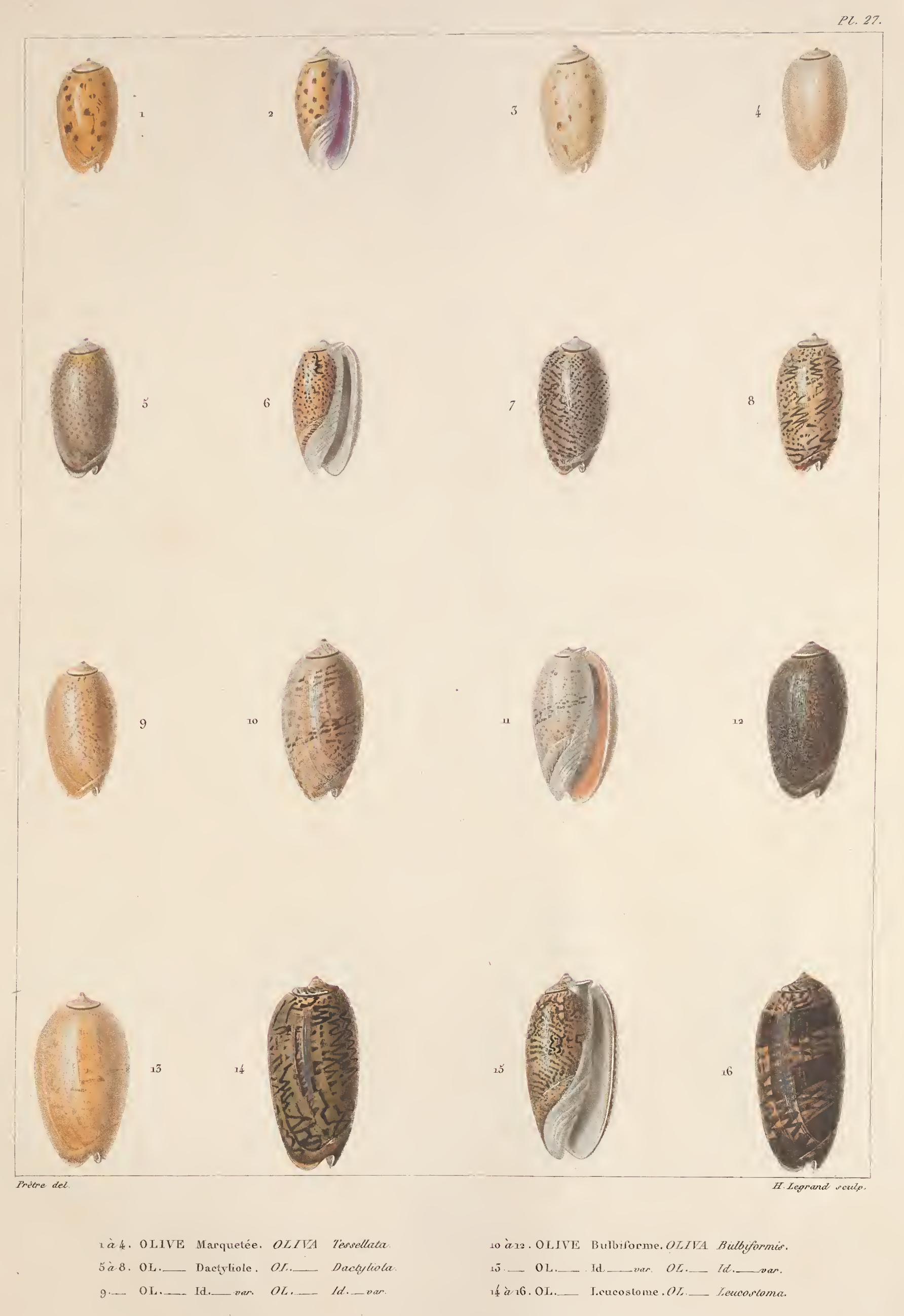





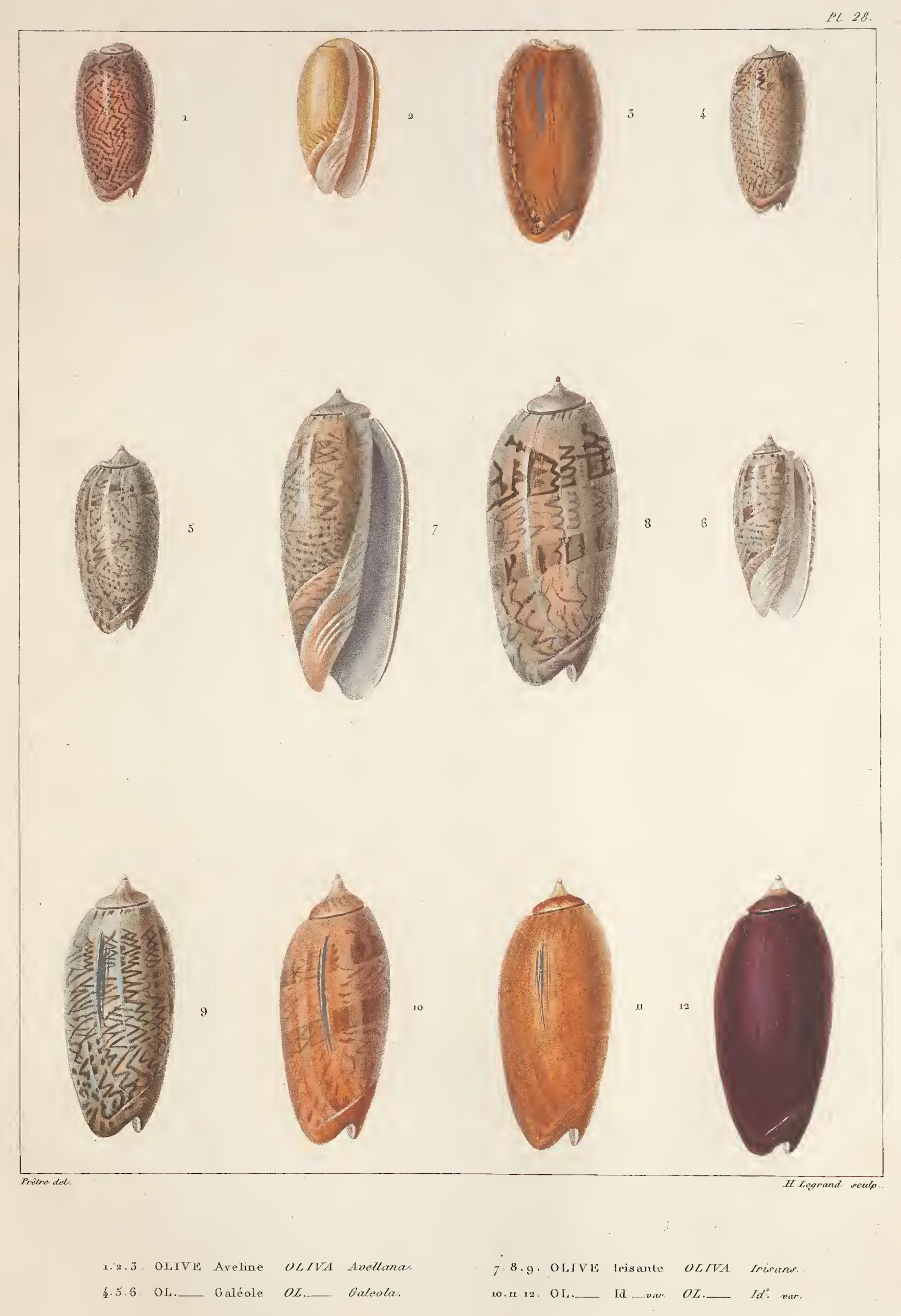





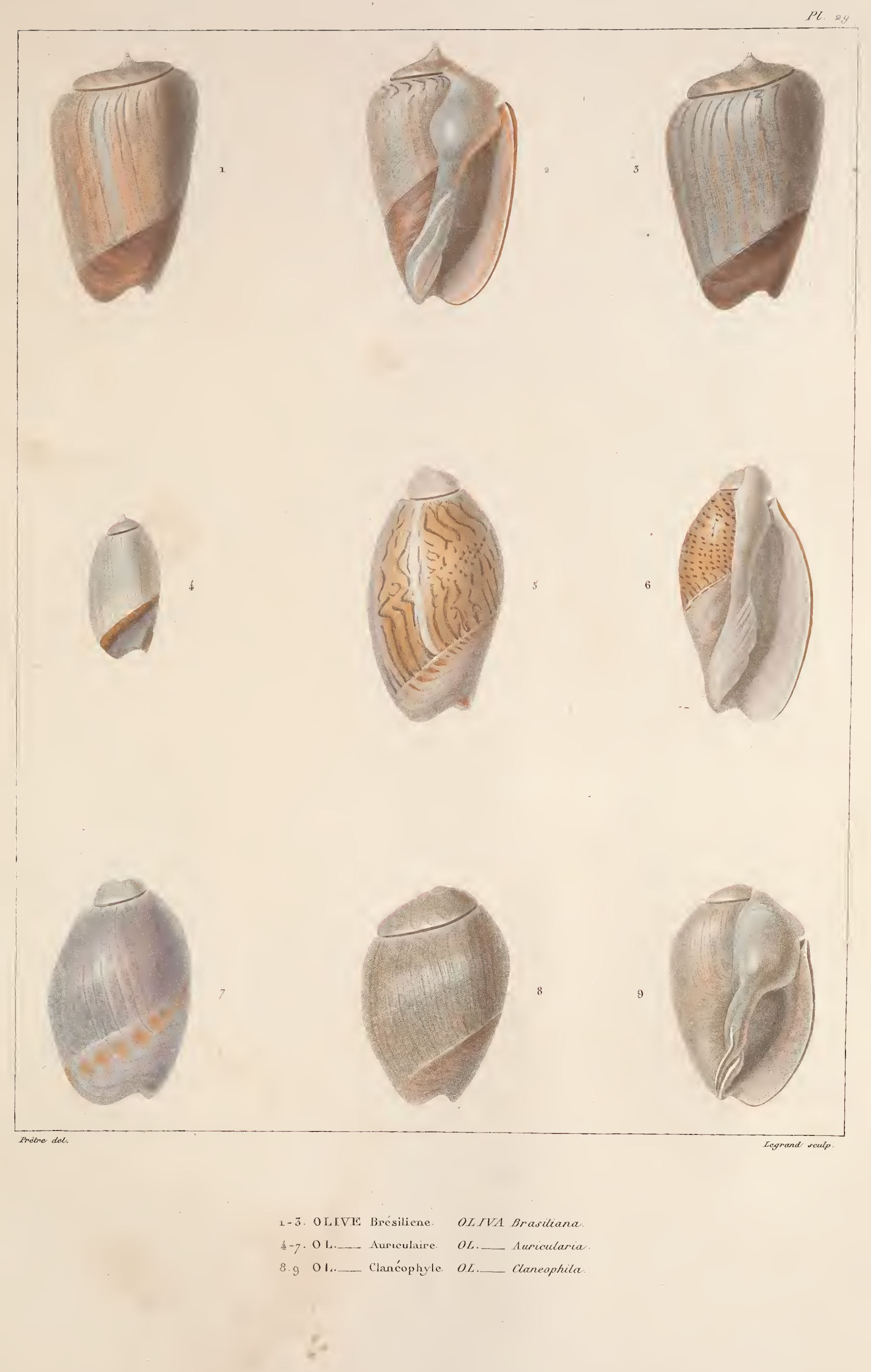





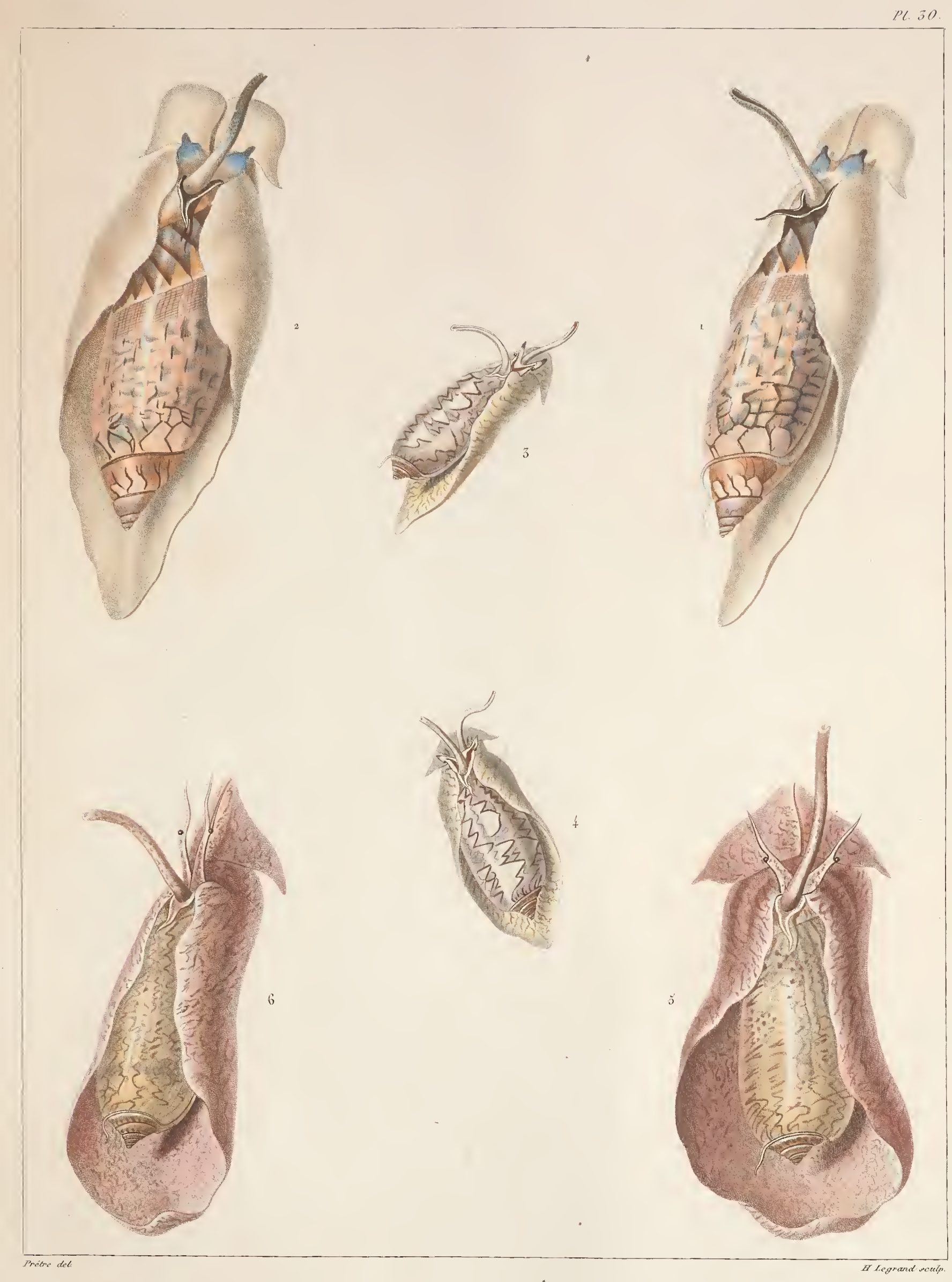

1.2. OLIVE Subulee of son Mollusque OLITA Subulatar

3.4. OL.___ Flammule td.___ OL___ Flammulata.

5.6. OL... Ecrite Id._OL._ Scripla 



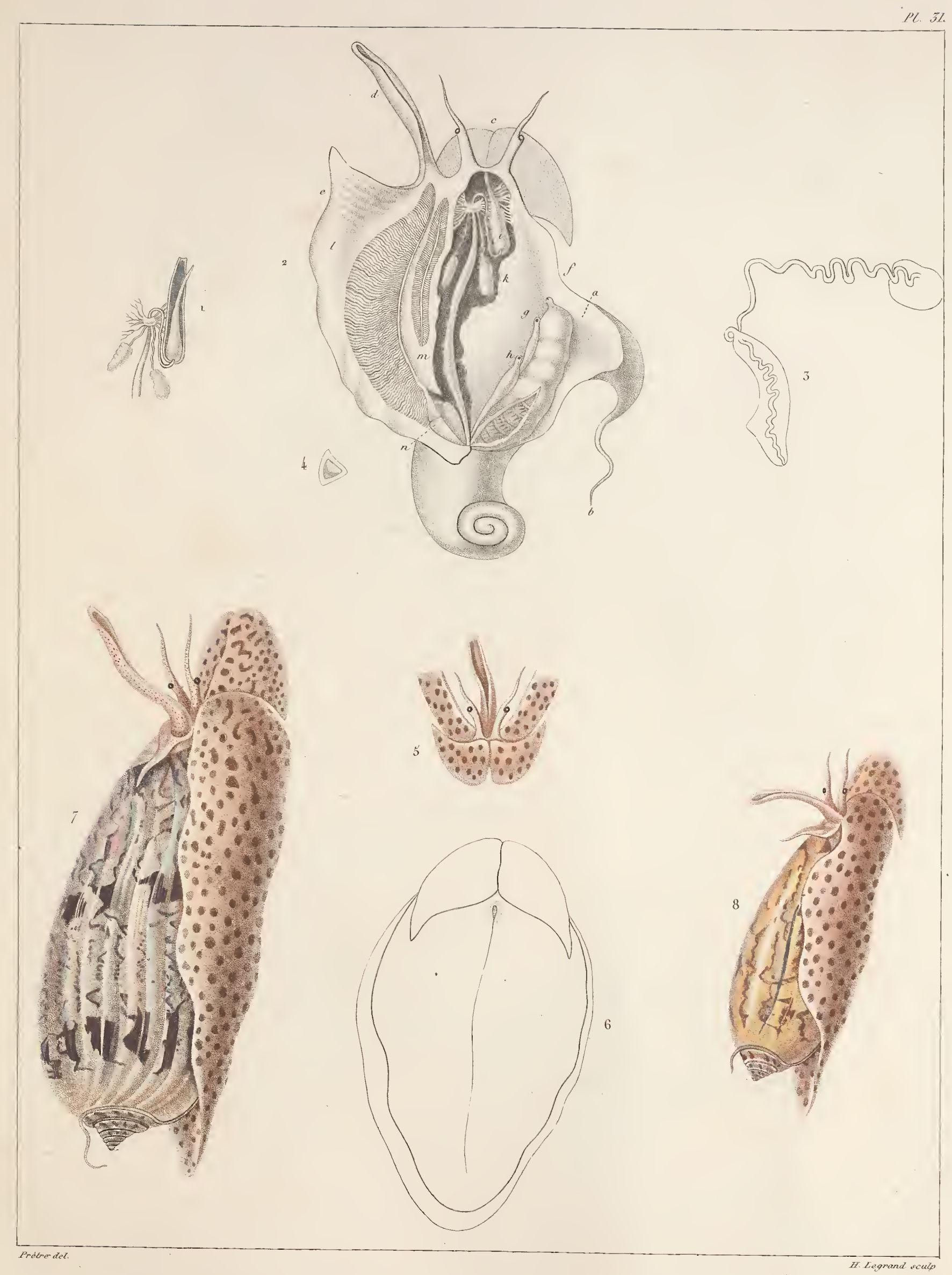

1' 6 . Anatomic du Mollusque de L'OlatVE.

7. OLIVLE Erythrostome. OlIVA Erythrostoma

8. Or. _ Id._- vern Or._- Id 


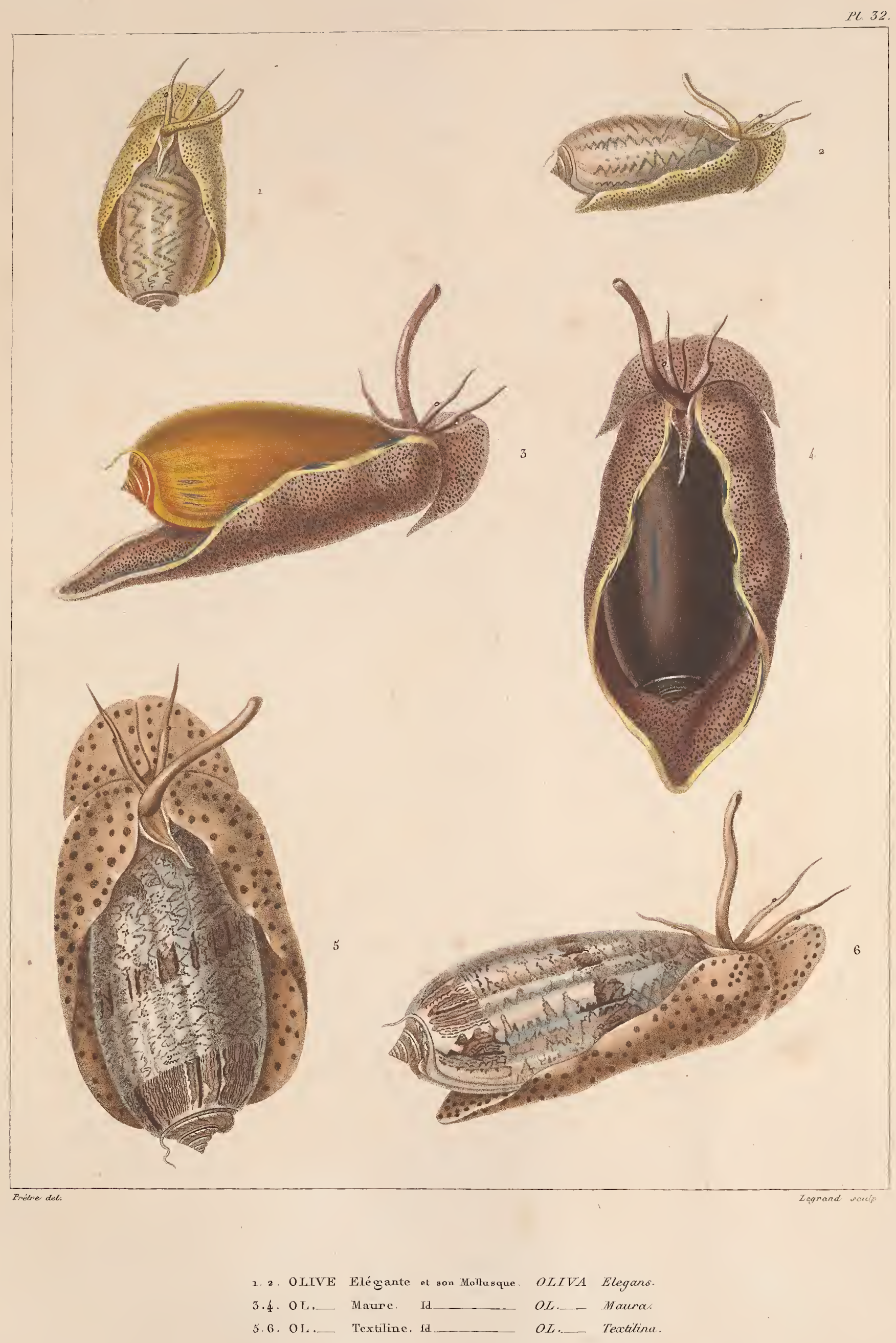



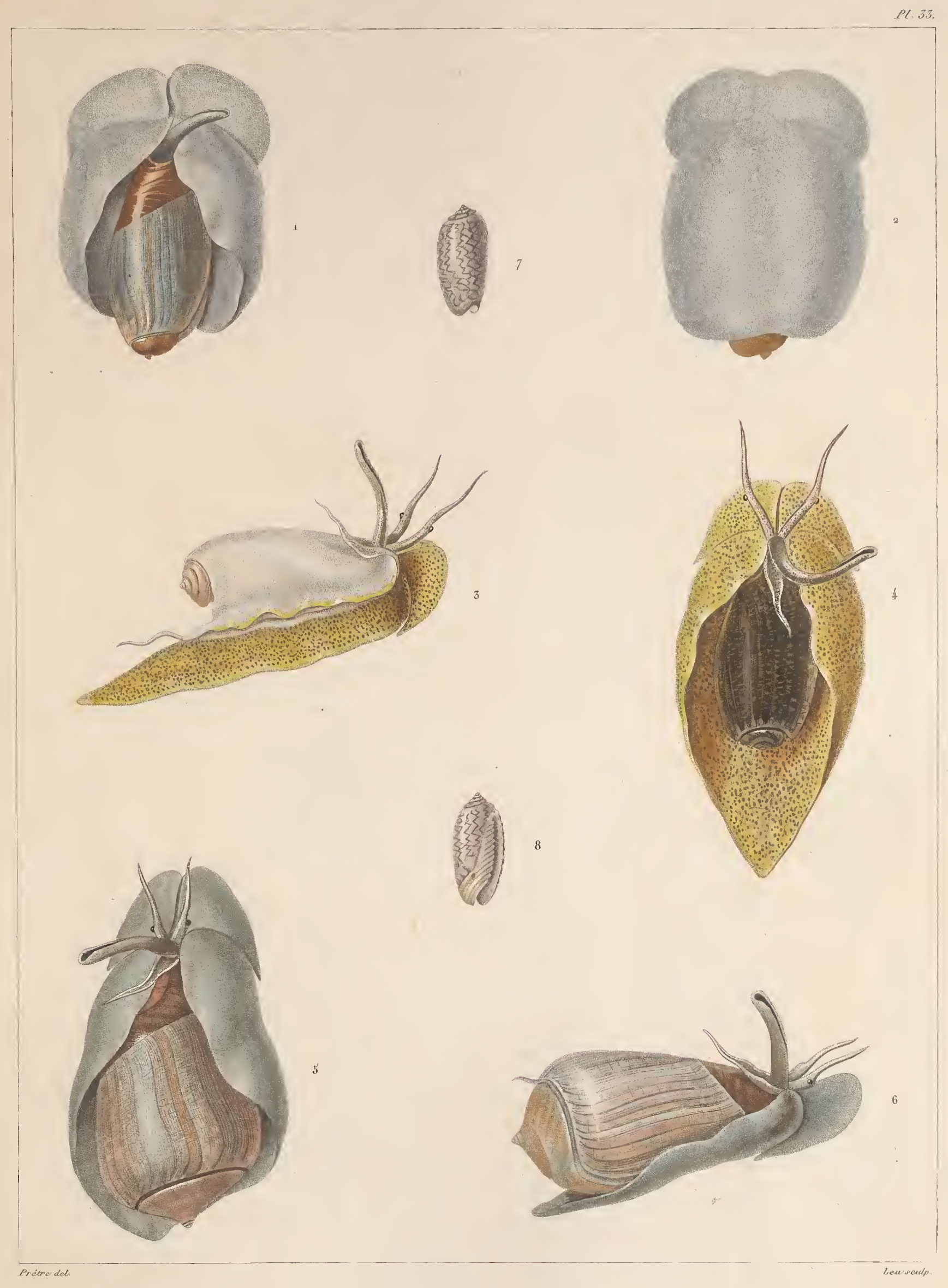

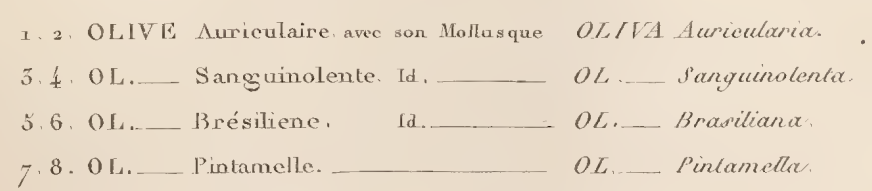




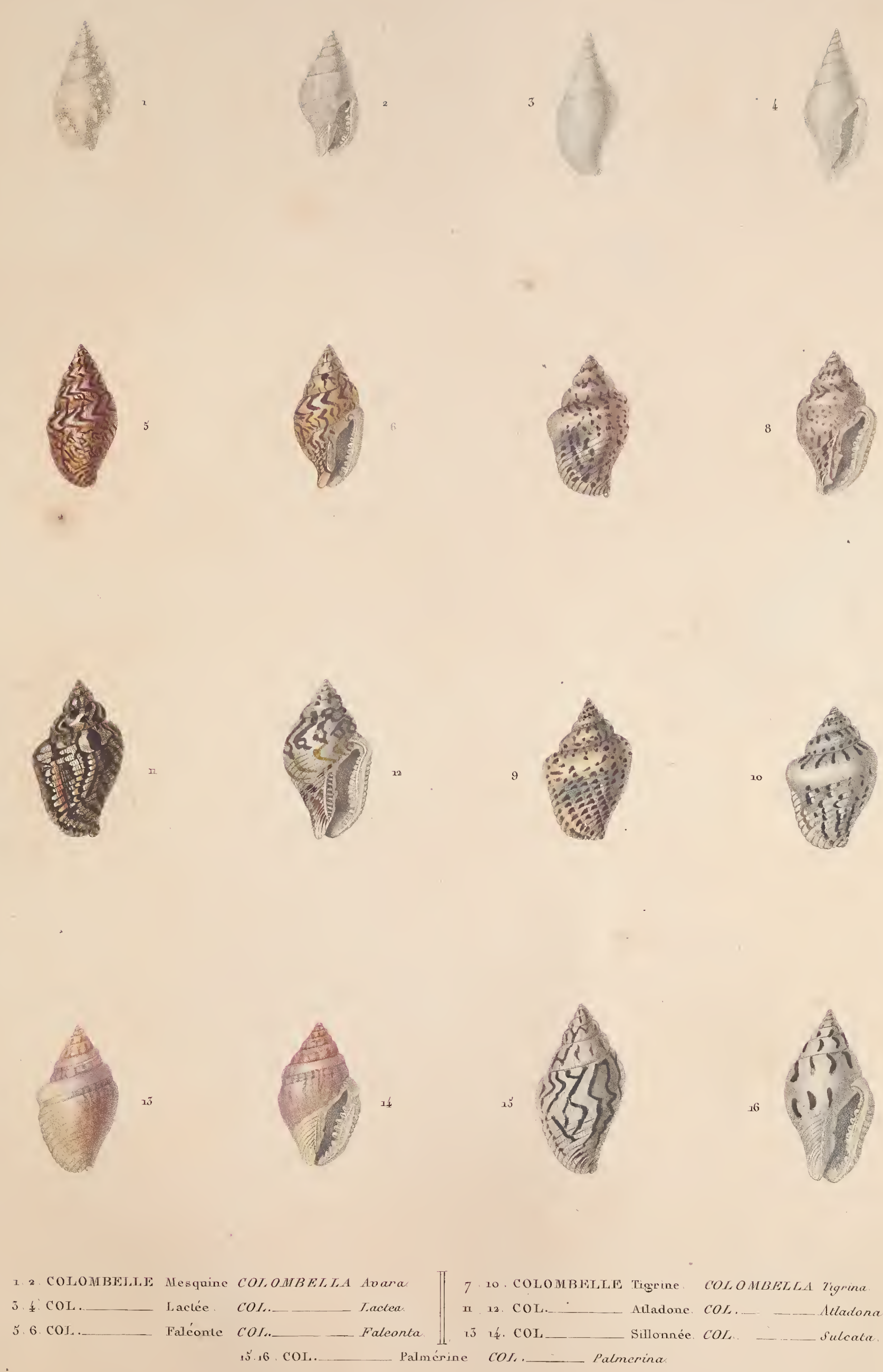


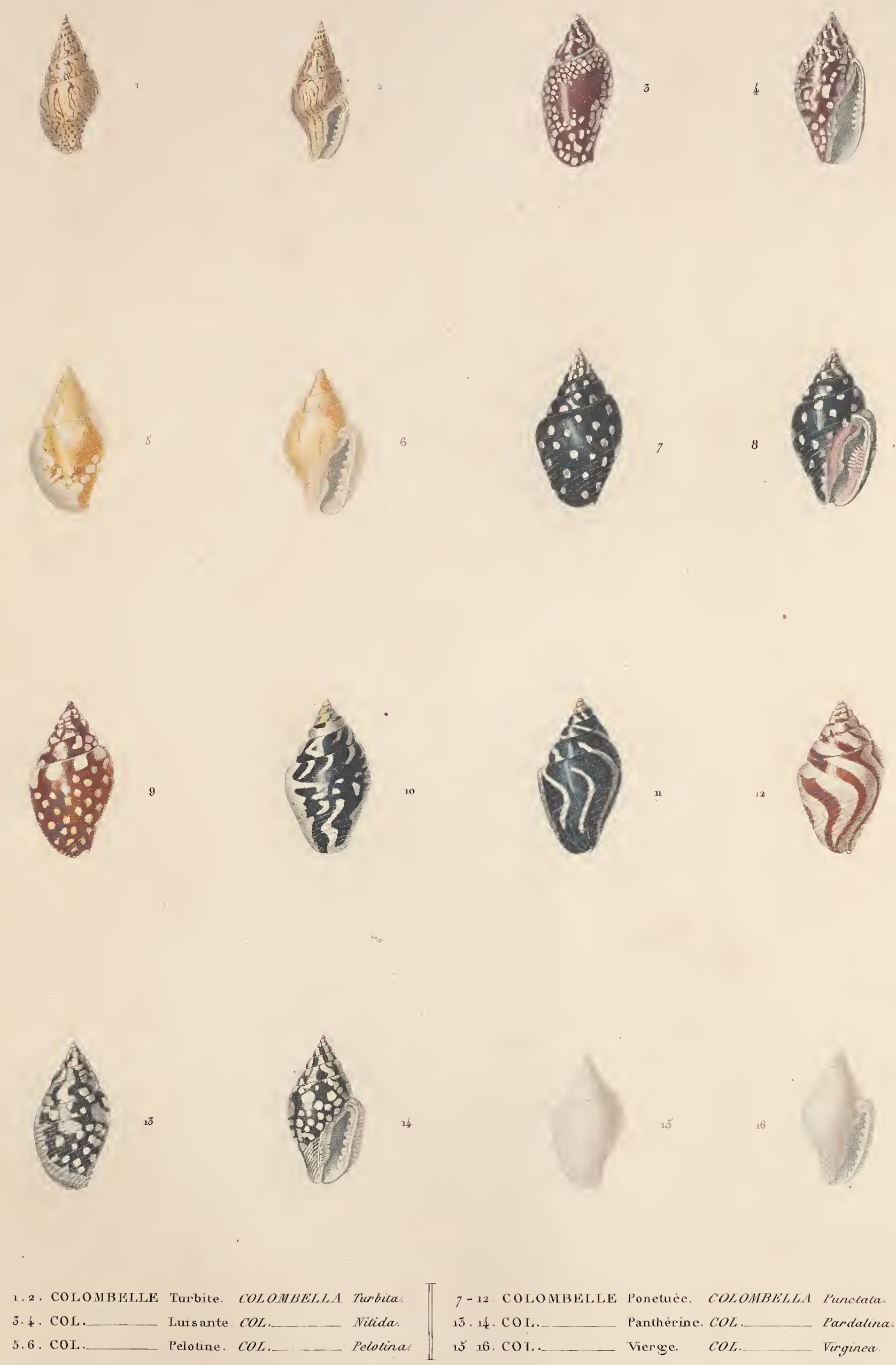


$$
\begin{aligned}
& 0.01 \\
& 0.000 \\
& 0.010
\end{aligned}
$$
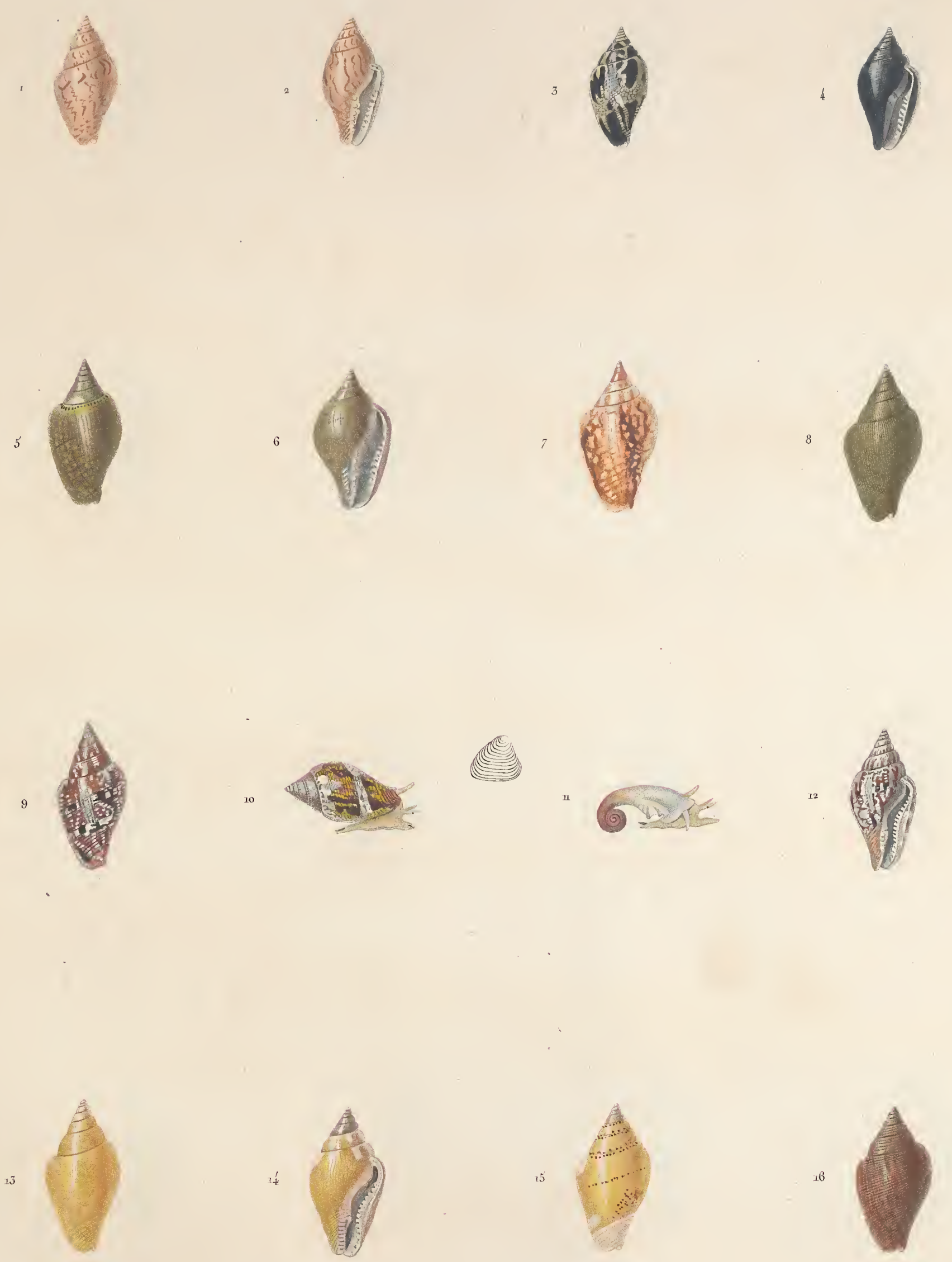

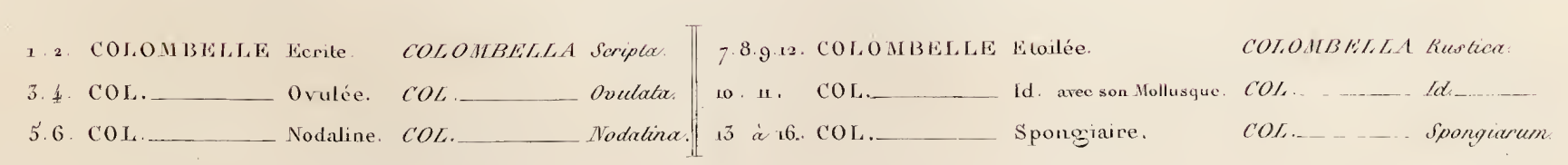




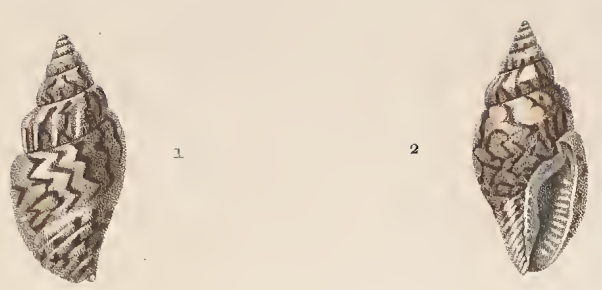

(3)
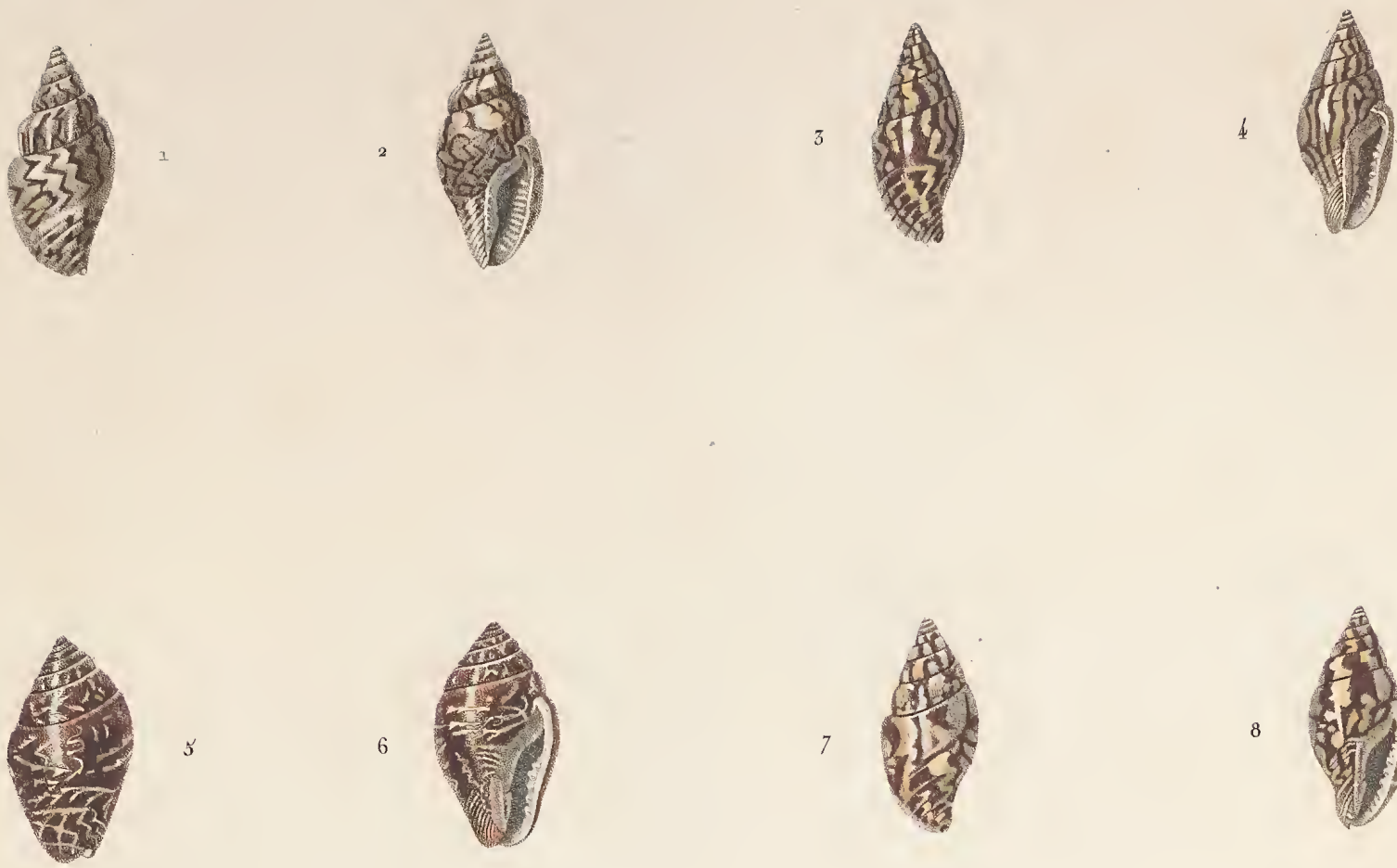

0
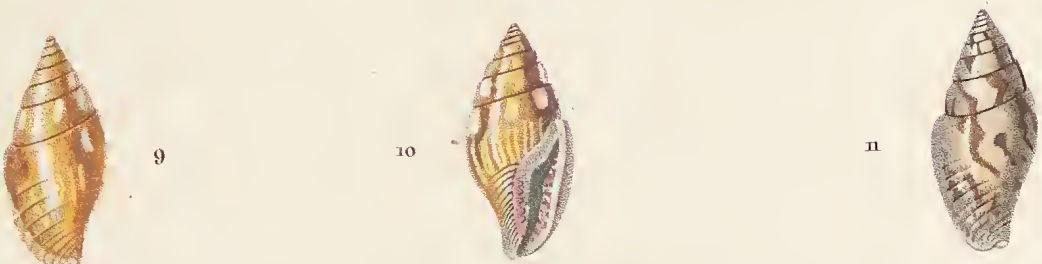

a
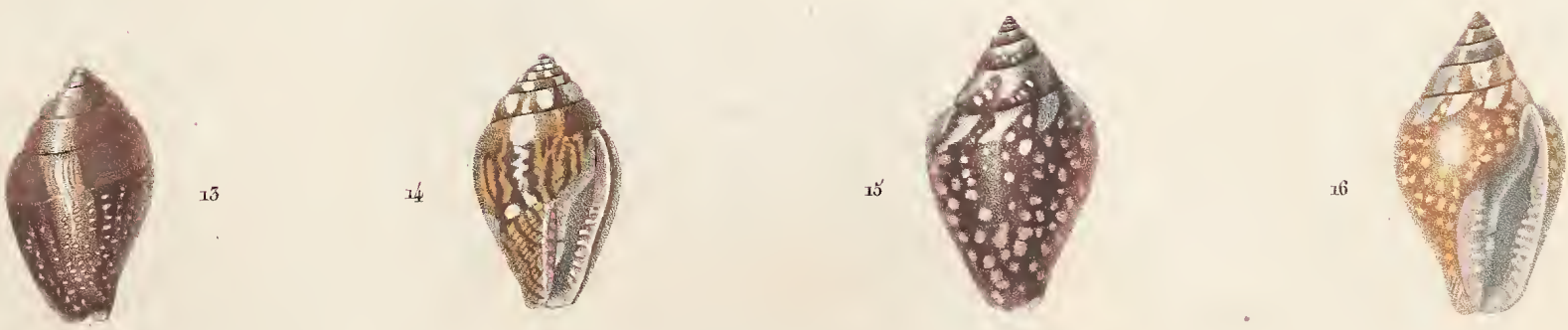

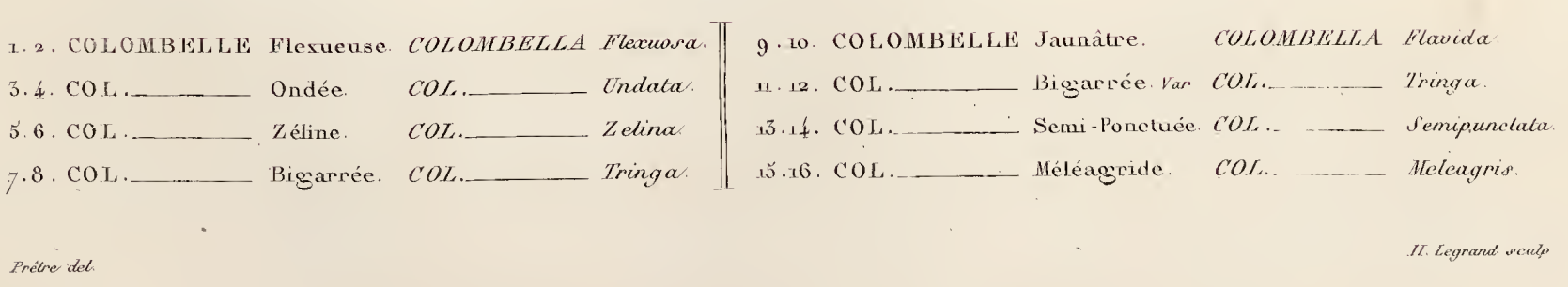




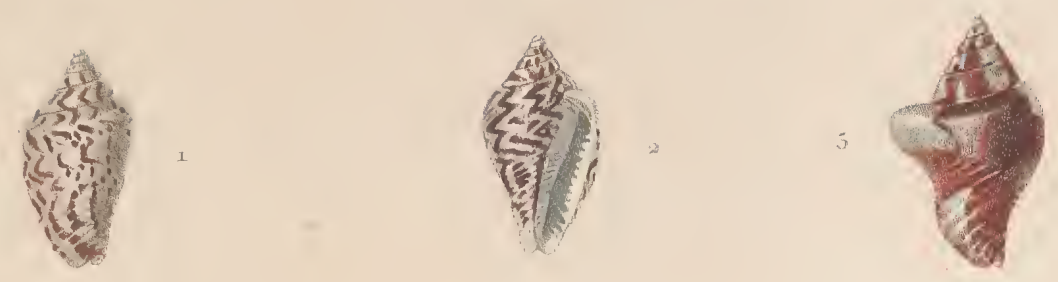

$+\frac{1}{8}$
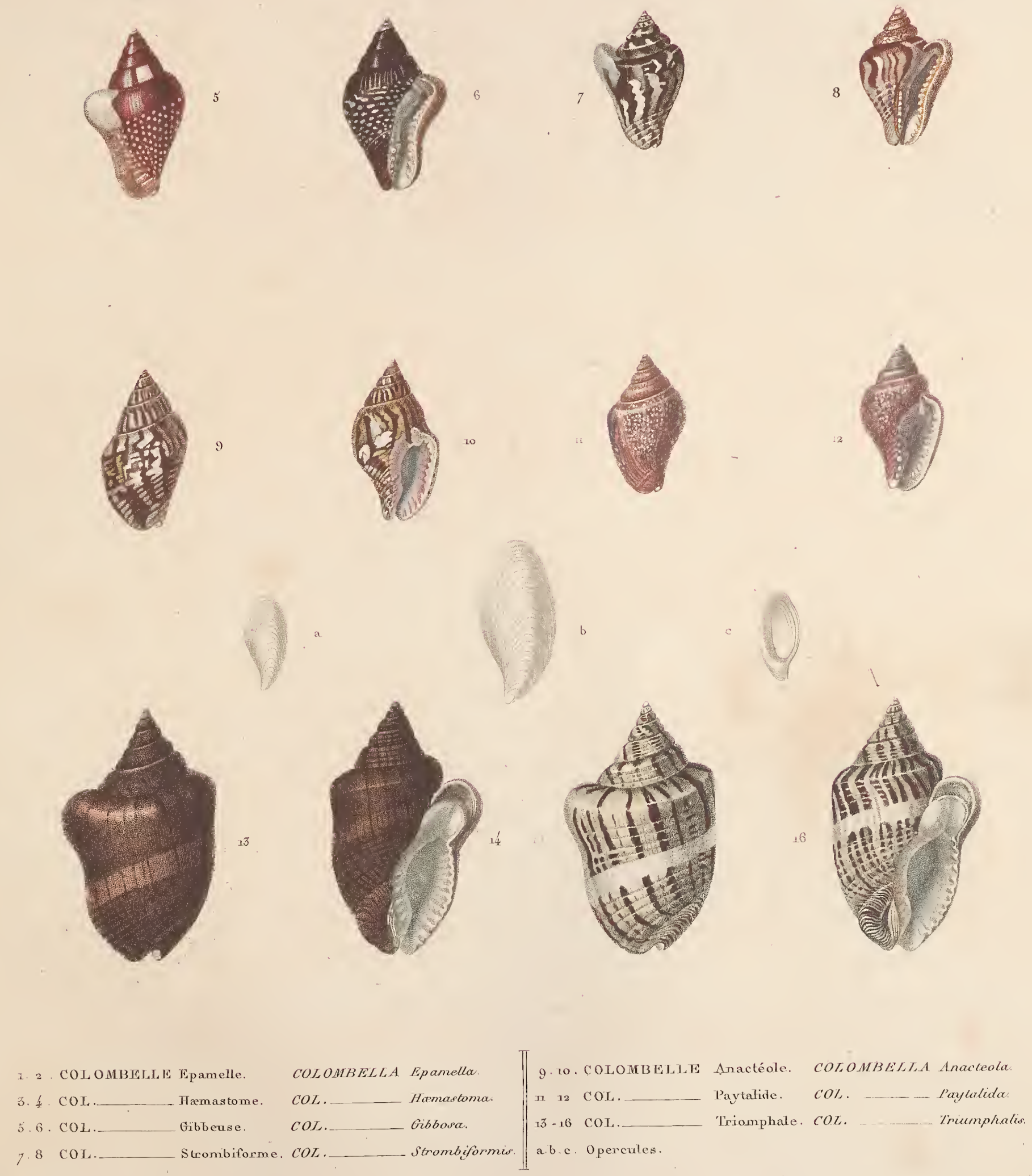


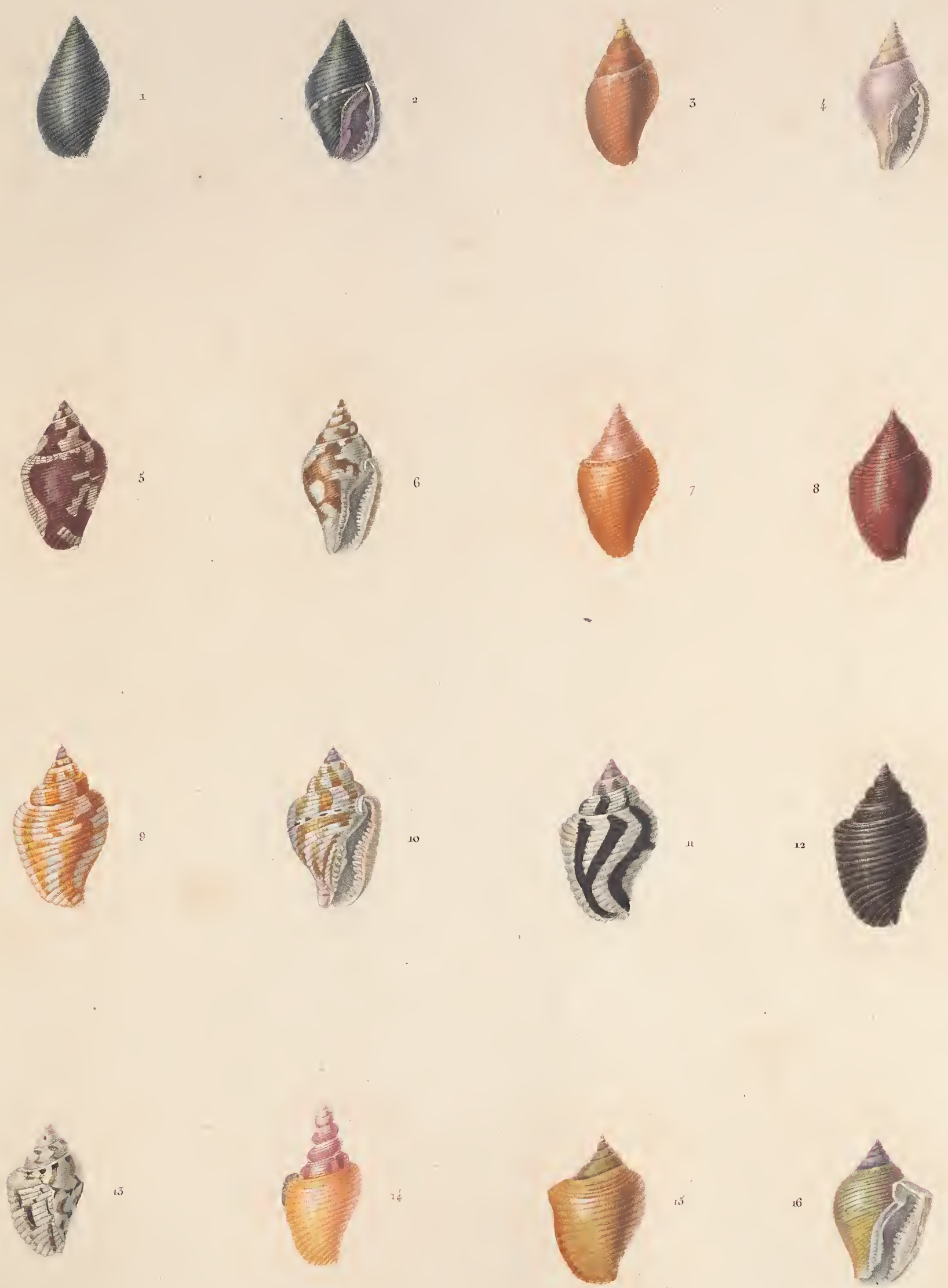

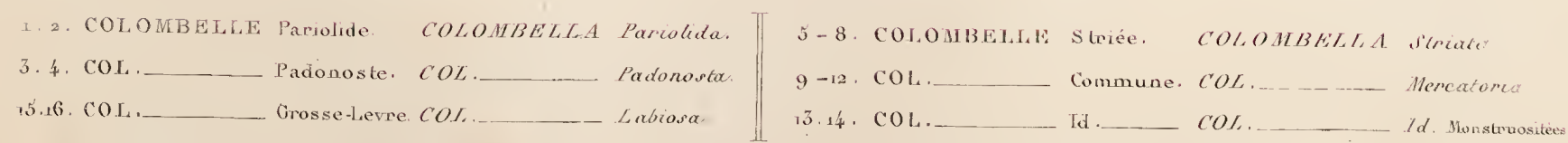




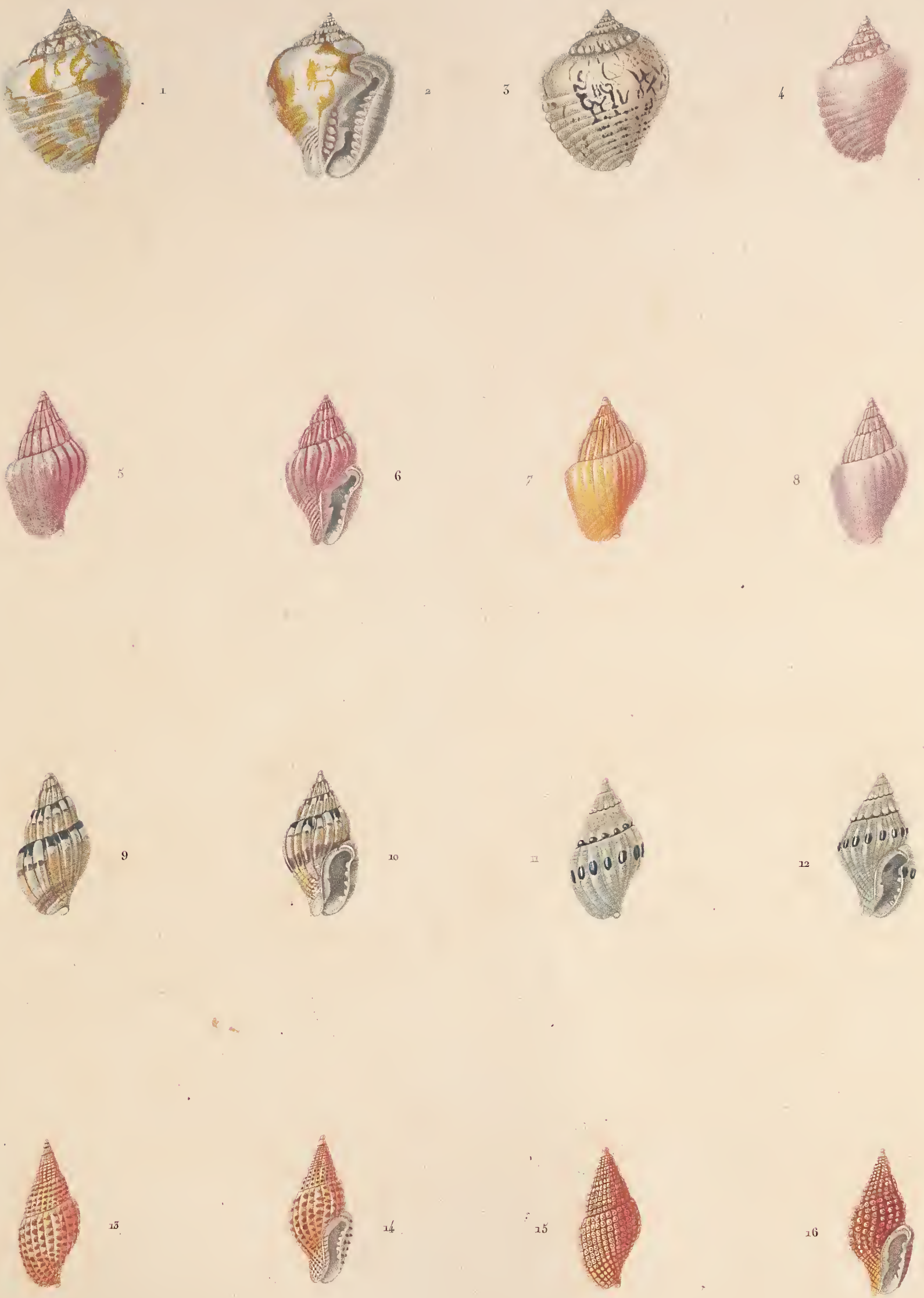

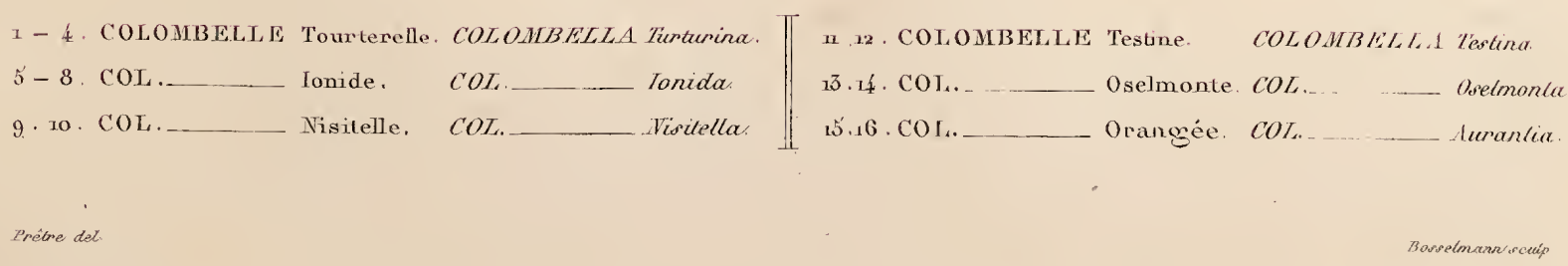




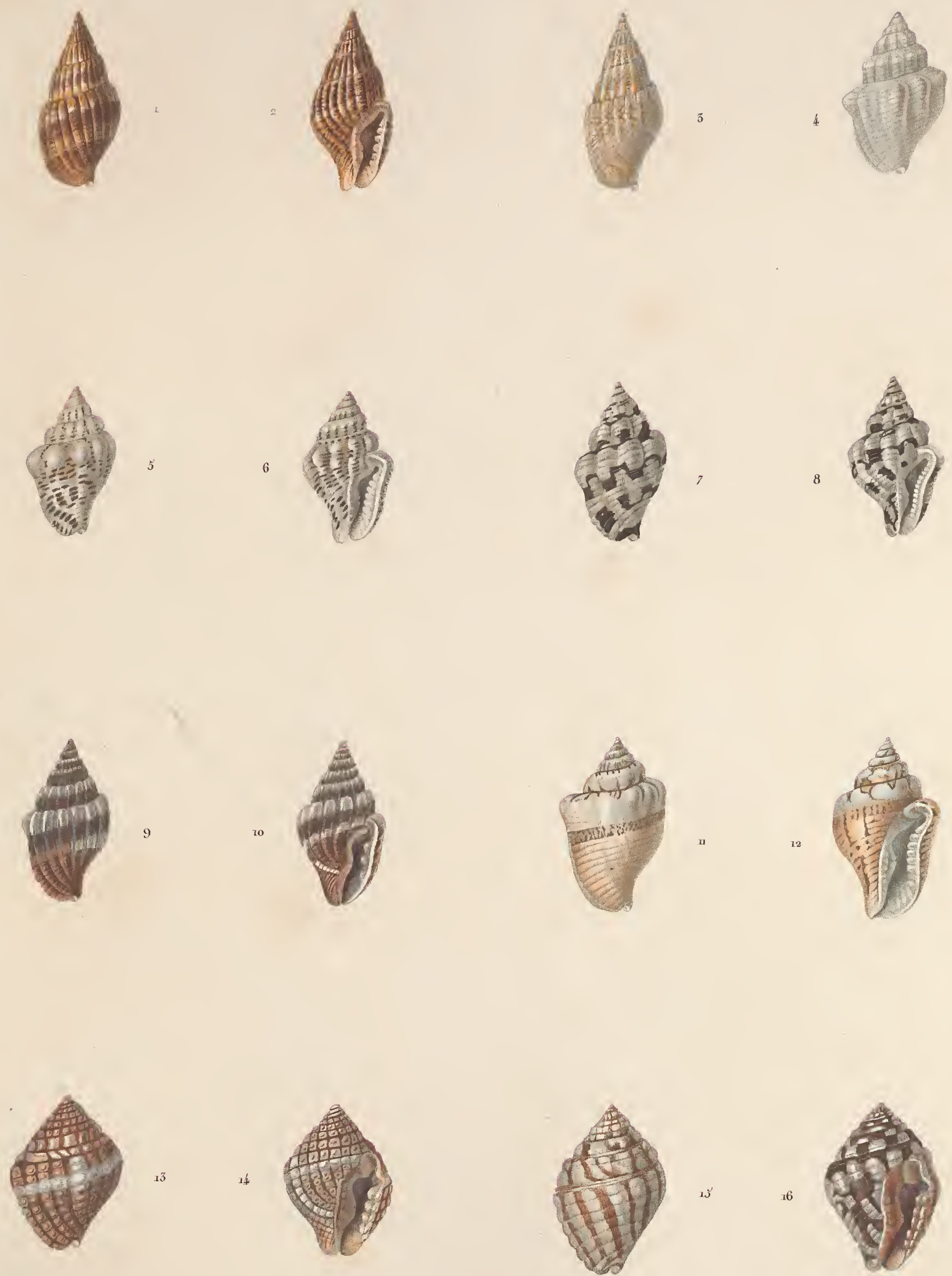

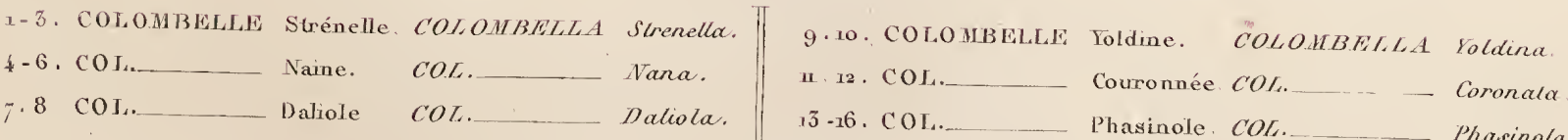




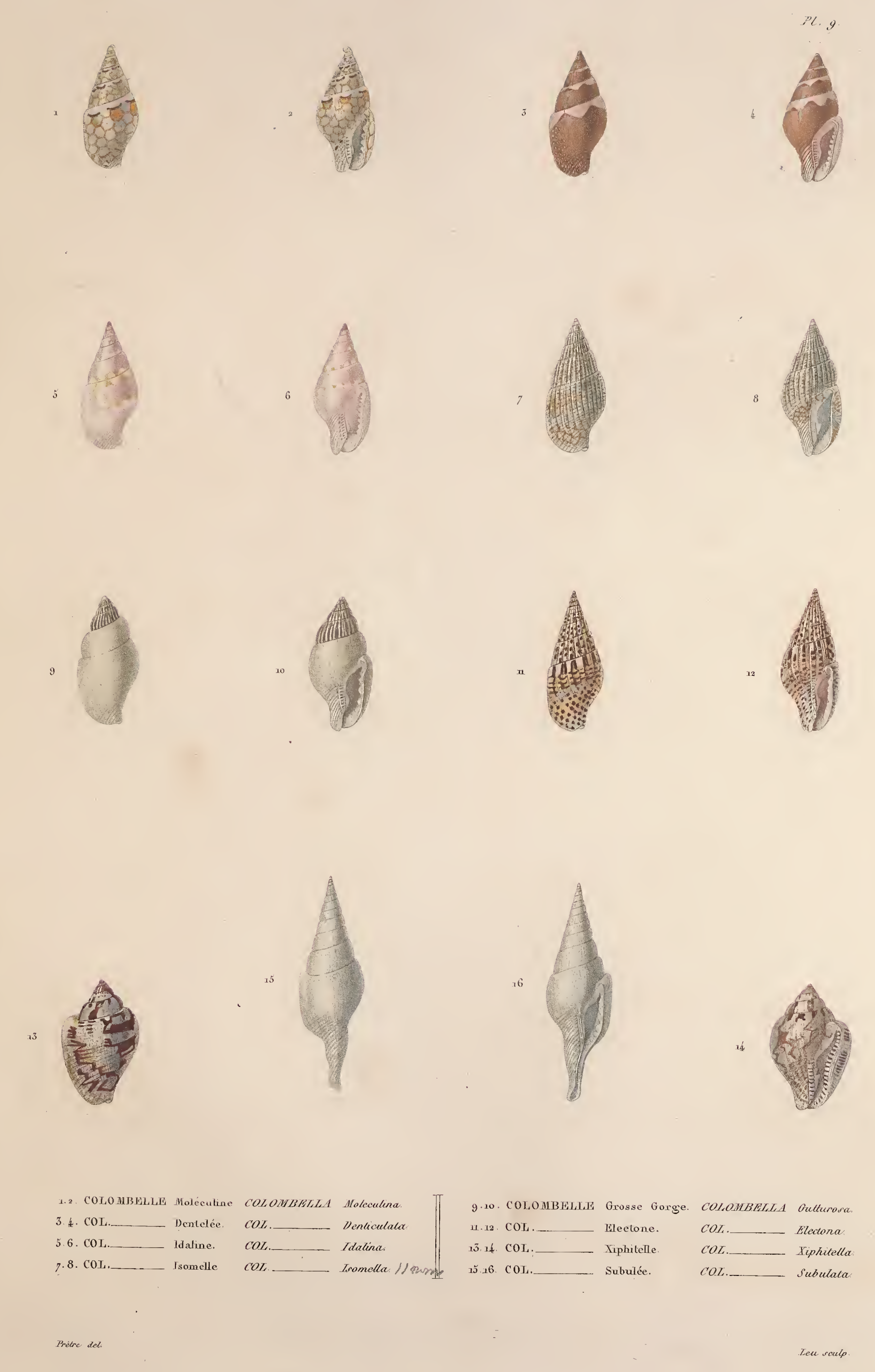




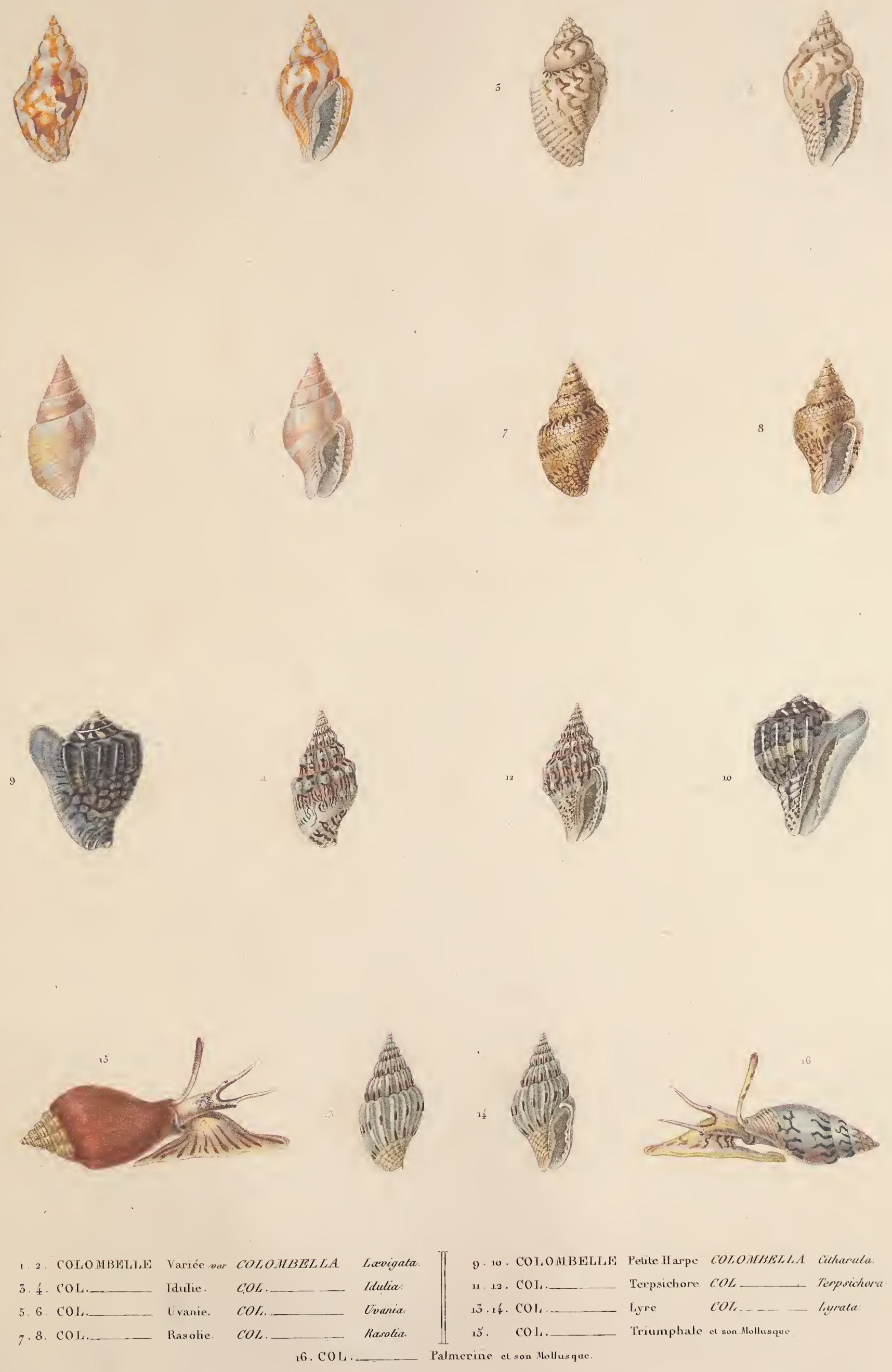


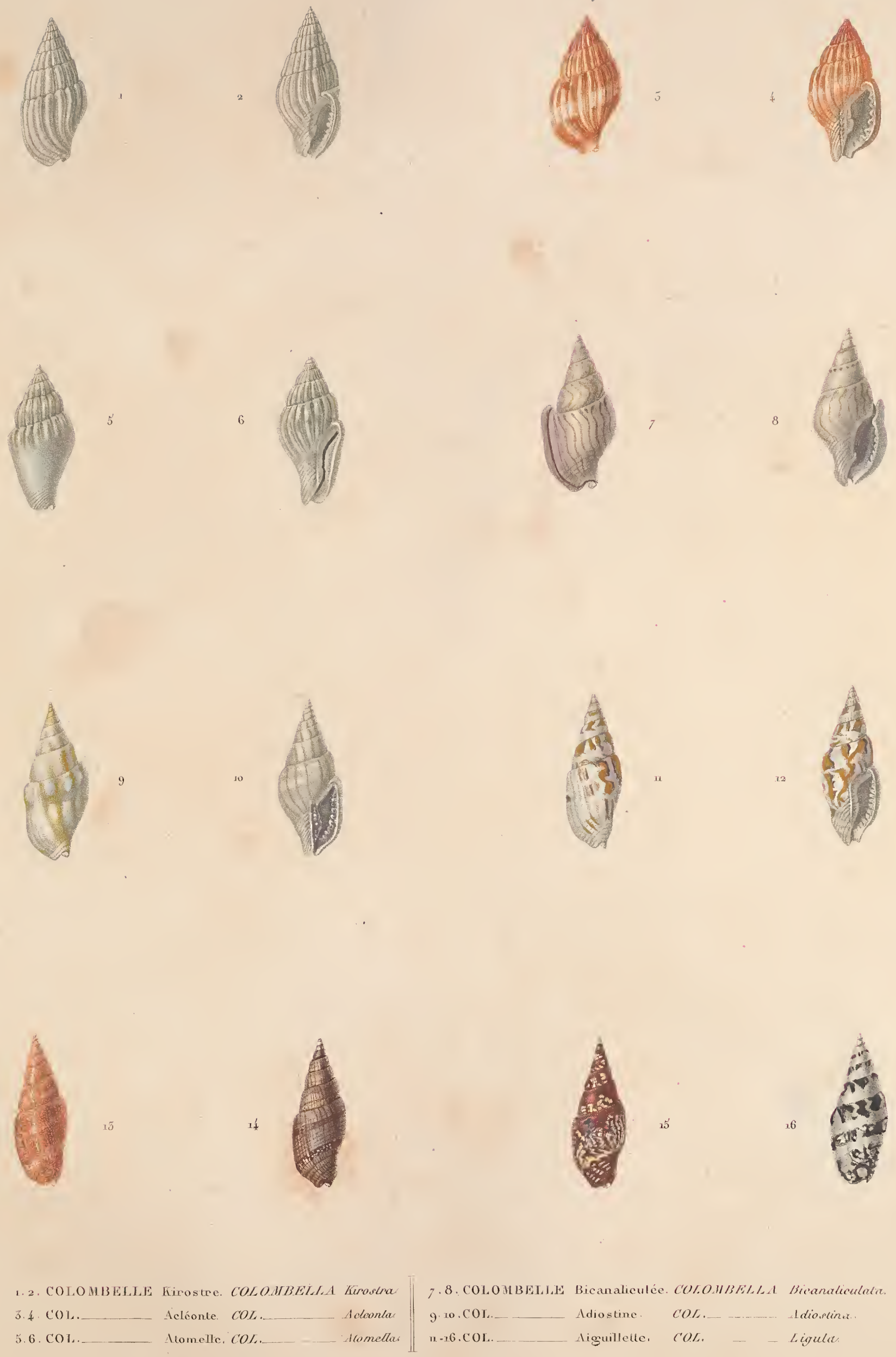


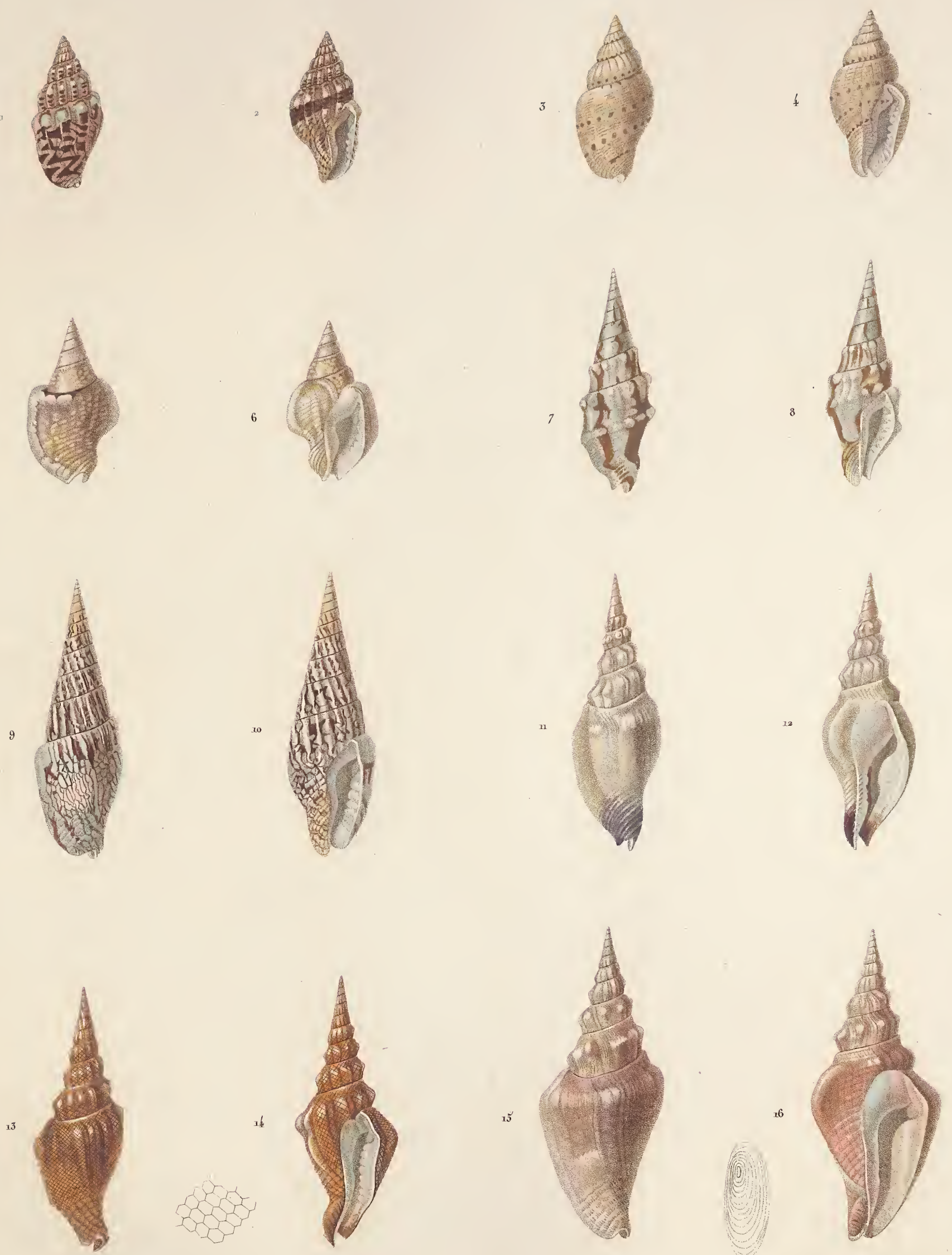

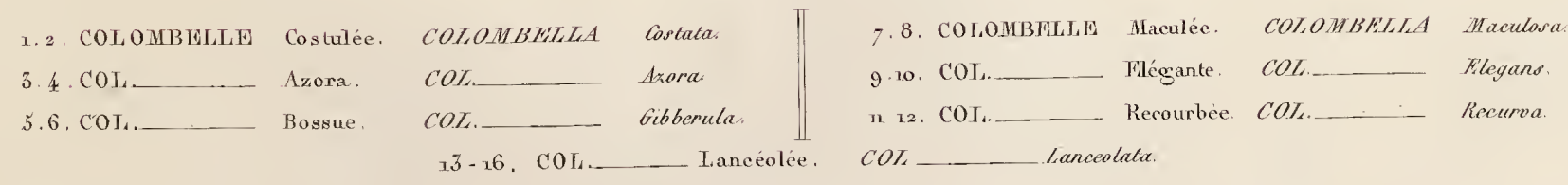




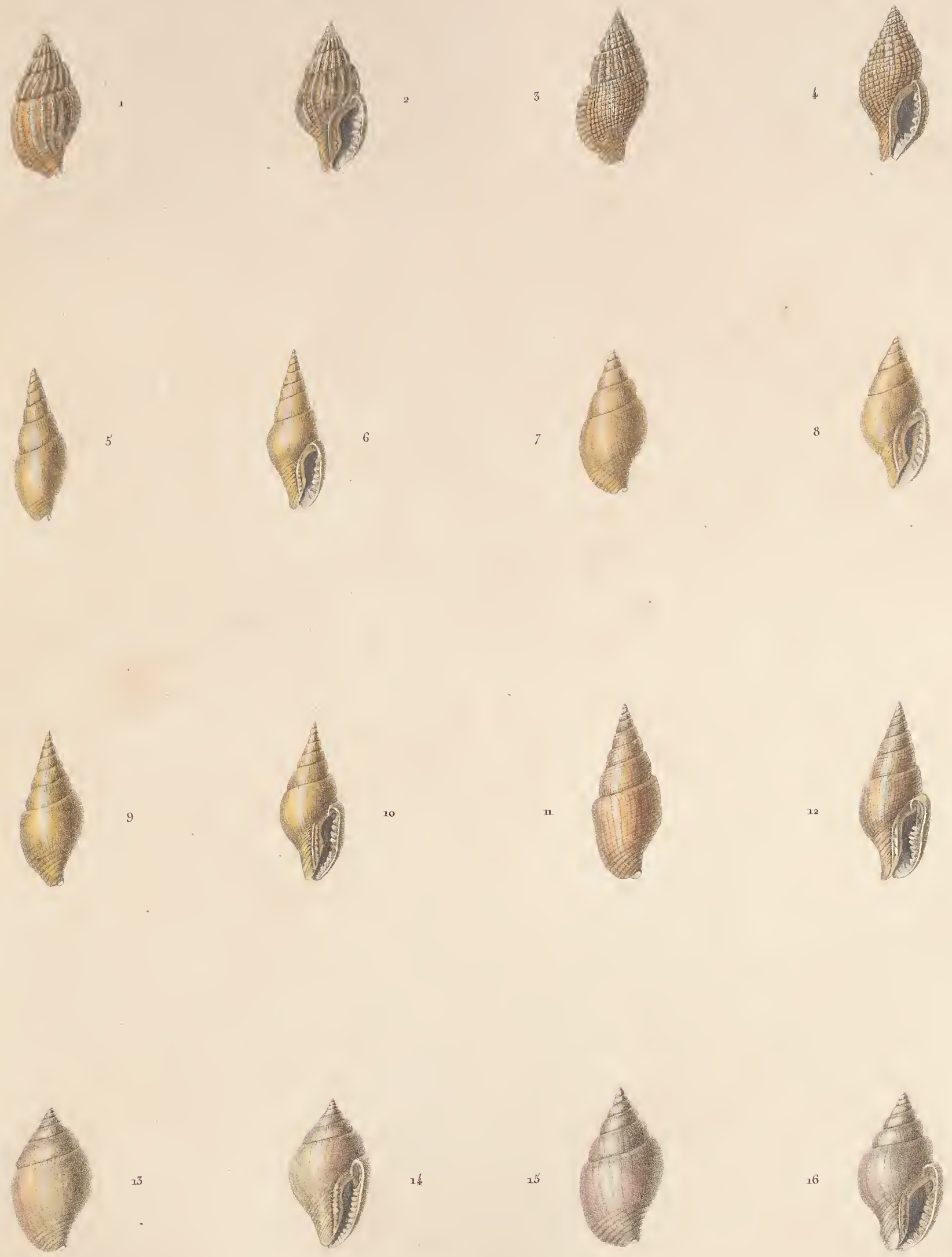

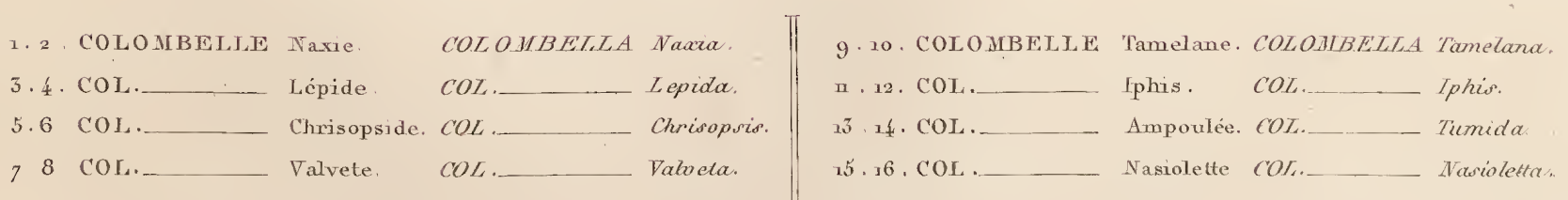





